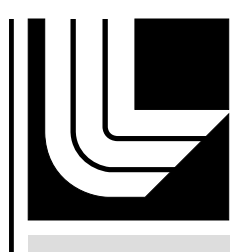

LA W REN CE LIVERMORE N A TION A L LABORATORY

LOW COST, HIGH

EFFICIENCY, ULTRA LOW NOX ARICE SOLUTION USING HCCI COMBUSTION

D. L. Flowers

October 30, 2012 
This document was prepared as an account of work sponsored by an agency of the United States government. Neither the United States government nor Lawrence Livermore National Security, LLC, nor any of their employees makes any warranty, expressed or implied, or assumes any legal liability or responsibility for the accuracy, completeness, or usefulness of any information, apparatus, product, or process disclosed, or represents that its use would not infringe privately owned rights. Reference herein to any specific commercial product, process, or service by trade name, trademark, manufacturer, or otherwise does not necessarily constitute or imply its endorsement, recommendation, or favoring by the United States government or Lawrence Livermore National Security, LLC. The views and opinions of authors expressed herein do not necessarily state or reflect those of the United States government or Lawrence Livermore National Security, LLC, and shall not be used for advertising or product endorsement purposes.

This work performed under the auspices of the U.S. Department of Energy by Lawrence Livermore National Laboratory under Contract DE-AC52-07NA27344. 
LLNL-TR-596952

LOW COST, HIGH EFFICIENCY, ULTRA LOW NOX ARICE SOLUTION USING HCCI COMBUSTION 
Public Interest Energy Research (PIER) Program FINAL PROJECT REPORT

\section{LOW COST, HIGH EFFICIENCY, ULTRA-LOW NOX ARICE SOLUTION USING HCCI COMBUSTION}

Prepared for: California Energy Commission

Prepared by: Lawrence Livermore National Laboratory 
Prepared by:

Primary Author:

Daniel L. Flowers

Lawrence Livermore National Laboratory

Livermore, CA, 94551

Contract Number: $500-02-003$

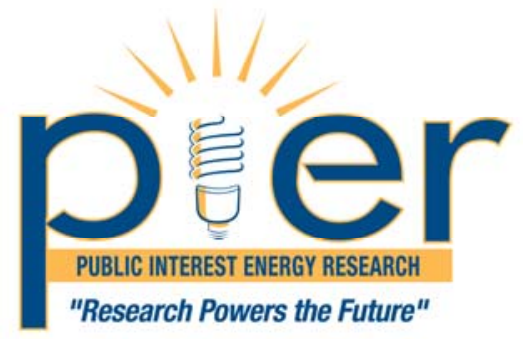

Prepared for:

California Energy Commission

Avtar Bining, Ph.D.

Project Manager

Mike Gravely

Office Manager

Energy Systems Research Office

Laurie ten Hope

Deputy Director

RESEARCH AND DEVELOPMENT DIVISION

Robert P. Oglesby

Executive Director

\section{DISCLAIMER}

This report was prepared as the result of work sponsored by the California Energy Commission. It does not necessarily represent the views of the Energy Commission, its employees or the State of California. The Energy Commission, the State of California, its employees, contractors and subcontractors make no warrant, express or implied, and assume no legal liability for the information in this report; nor does any party represent that the uses of this information will not infringe upon privately owned rights. This report has not been approved or disapproved by the California Energy Commission nor has the California Energy Commission passed upon the accuracy or adequacy of the information in this report. 


\section{Legal Notice}

This document was prepared as an account of work sponsored by an agency of the United States Government. Neither the United States Government nor the University of California nor any of their employees, makes any warranty, express or implied, or assumes any legal liability or responsibility for the accuracy, completeness, or usefulness of any information, apparatus, product, or process disclosed, or represents that its use would not infringe privately owned rights. Reference herein to any specific commercial

product, process, or service by trade name, trademark, manufacturer, or otherwise, does not necessarily constitute or imply its endorsement, recommendation, or favoring by the United States Government or the University of California. The views and opinions of authors expressed herein do not necessarily state or reflect those of the United States Government or the University of California, and shall not be used for advertising or product endorsement purposes.

This work was performed under the auspices of the U. S. Department of Energy by the University of California, Lawrence Livermore National Laboratory under Contract No. W-7405-Eng-48. 



\section{Acknowledgements}

Many individuals have supported this research and development effort:

- Drs. Scott Fiveland, Martin Willi, and Rey Agama of Caterpillar Engine Company graciously worked to provide the hardware platform (an Engine-Generator set) upon which to conduct this research and development work, as well as a great deal of technical guidance.

- Dr. Joel D. Hiltner provided technical guidance and support on selection and design of many components of this engine system.

- Professor Robert Dibble of University of California, Berkeley and his students provided extensive collaborative input and support on many aspects of this research program.

- Professor Mraslov Kristic of University of California, San Diego and his Ph.D. student, Nick Killingsworth, provided their unique control expertise to this project.

- David Fisher of Continental Controls Corporation of San Diego, CA, provided specialized fuel control hardware and support for the automatic fuel system control valve.

- Rob Anderson of Vortech Engineering provided customized supercharger hardware and support for the implementation of the supercharging system.

- The enthusiastic encouragement of Dr. Avtar Bining, of the California Energy Commission's Public Interest Energy Research (PIER) program, is gratefully acknowledged.

- Salvador Aceves, Cindy Atkins-Duffins, Francisco Espinosa, Julie Fone, Joel Martinez, Helen Magann, Don Podesta, Tim Ross, Doug Rotman, Ray Smith, and Dick Spears of Lawrence Livermore National Laboratory are also acknowledged for their many contributions to this project.

Please cite this report as follows:

Lawrence Livermore National Laboratory. 2010. Low Cost, High Efficiency, Ultra-low NOx ARICE Solution using HCCI Combustion. California Energy Commission, CEC-500-2012074 


\section{Preface}

The Public Interest Energy Research (PIER) Program supports public interest energy research and development that will help improve the quality of life in California by bringing environmentally safe, affordable, and reliable energy services and products to the marketplace.

The PIER Program, managed by the California Energy Commission (Energy Commission) conducts public interest research, development, and demonstration (RD\&D) projects to benefit the electricity and natural gas ratepayers in California. The Energy Commission awards up to $\$ 62$ million annually in electricity-related RD\&D, and up to $\$ 24$ million annually for natural gas RD\&D.

The PIER program strives to conduct the most promising public interest energy research by partnering with RD\&D organizations, including individuals, businesses, utilities, and public or private research institutions.

PIER funding efforts are focused on the following RD\&D program areas:

- Buildings End-Use Energy Efficiency

- Energy Innovations Small Grants

- Energy-Related Environmental Research

- Energy Systems Integration

- Environmentally Preferred Advanced Generation

- Industrial/Agricultural/Water End-Use Energy Efficiency

- Renewable Energy Technologies

- Transportation

Low Cost, High Efficiency, Ultra-low NOx ARICE Solution using HCCI Combustion is the final report for the Low Cost, High Efficiency,Ultra-low NOx ARICE Solution using HCCI Combustion Project (contract number 500-02-003) conducted by Lawrence Livermore National Laboratory. The information from this project contributes to PIER's Environmentally Preferred Advanced Generation (EPAG) Advance Reciprocating Internal Combustion Engine (ARICE) program area.

For more information on the PIER Program, please visit the Energy Commission's Web site at www.energy.ca.gov/pier or contact the Energy Commission at (916) 654-5164. 


\section{Table of Contents}

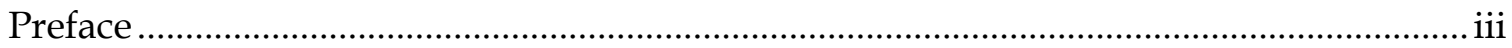

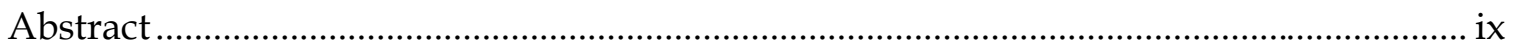

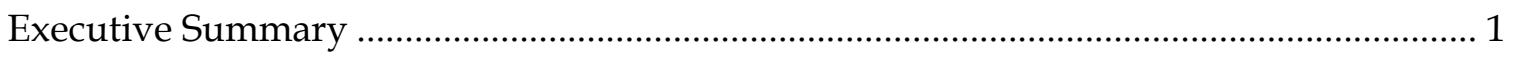

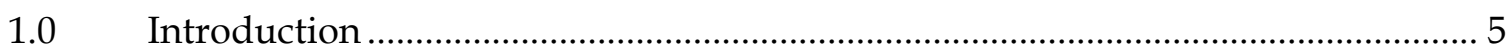

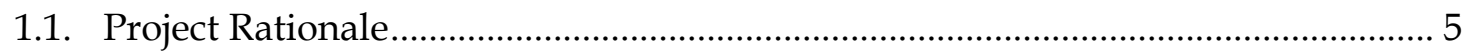

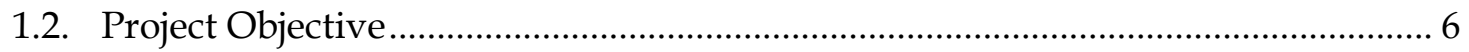

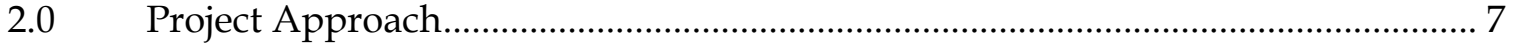

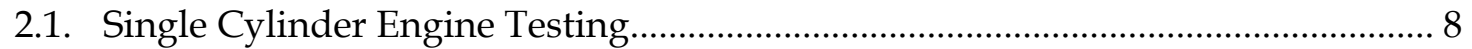

2.2. Breathing Design for Multi-cylinder Engine ........................................................ 9

2.3. Multi-cylinder Engine Set-point Optimization ..................................................... 9

2.4. Siting and Installation of Multi-cylinder Engine ................................................... 9

2.5. Install ETV on Multi-cylinder engine and Initial HCCI Operation ....................... 9

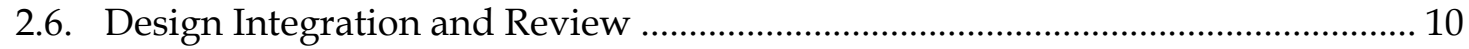

2.7. Implement ARICE Design on Multi-cylinder HCCI Engine ................................. 10

2.8. 1000 Hours Operation of HCCI ARICE Multi-cylinder Engine ........................... 10

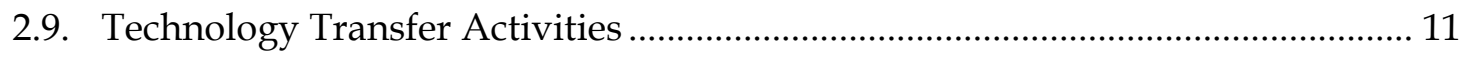

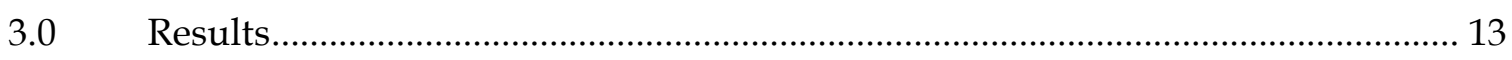

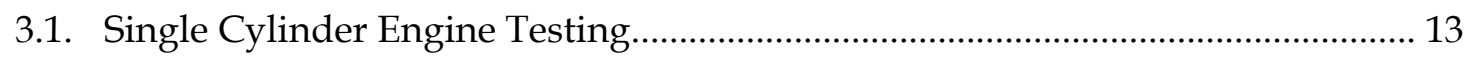

3.2. Breathing Design for Multi-Cylinder Engine....................................................... 21

3.3. Multi-Cylinder Engine Set-Point Optimization..................................................... 30

3.4. Siting and Installation of Multi-cylinder Engine .................................................... 41

3.5. Install ETV on Multi-cylinder engine and Initial HCCI Operation ...................... 48

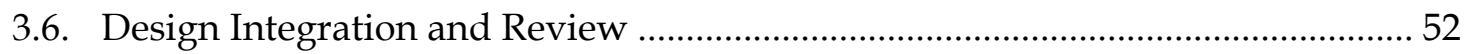

3.7. Implement ARICE Design on Multi-cylinder HCCI Engine ............................... 54

3.8. 1000 Hours Operation of HCCI ARICE Multi-cylinder Engine ............................ 65

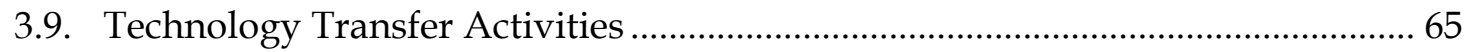

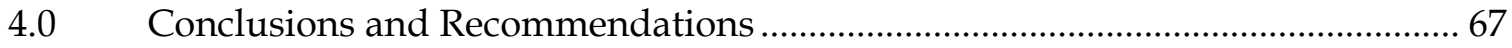

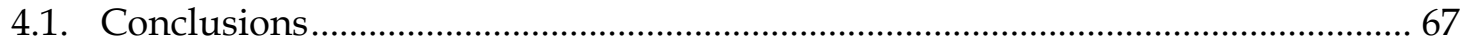

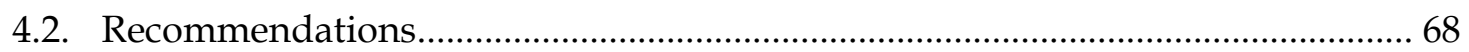

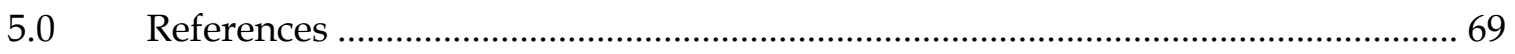

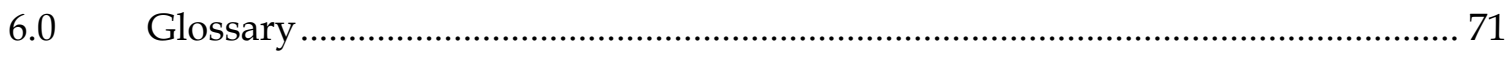


Appendix A: WAVE Analysis of CAT 3406 HCCI Engine for ARICE 1

Appendix B: HCCI-ARICE Natural Gas Engine Development for Stationary Power Applications in California .

Appendix C: Thermal Management for 6-Cylinder HCCI Engine: Low Cost, High Efficiency, Ultra-Low NOx power Generation................................................................. 1

Appendix D: Development and Testing of a 6-Cylinder HCCI Engine and for Distributed Generation... 1

Appendix E: Analysis of Homogeneous Charge Compression Ignition (HCCI) Engines for Cogeneration Applications .... 1

\section{List of Figures}

Figure 1: Picture and schematic of modified exhaust throttle

Figure 2: These seven sequential pressure traces are from a transient experiment when exhaust throttle was given a step input signal: fully closed to fully open

Figure 3: Variation of the steady-state pressure trace with varied exhaust throttle positions19

Figure 4: Closed loop control response of HCCI engine to transient intake temperature by

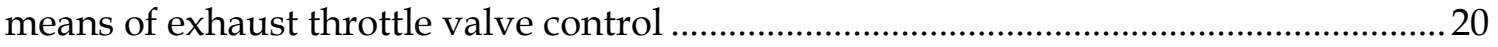

Figure 5: Closed loop control response to change in operational set-point .............................2 21

Figure 6: Schematic of the system considered for HCCI engine turbo charging .................... 22

Figure 7: Schematic of the system considered for HCCI engine supercharging .....................23

Figure 8: Color contours of engine brake power in $\mathrm{kW}$, as a function of turbine pressure ratio and compressor pressure ratio, with dotted lines showing brake thermal efficiency and dashed lines peak cylinder pressure.

Figure 9: Color contours (and solid lines) of engine brake power in $\mathrm{kW}$, as a function of supercharger aerodynamic efficiency and boost pressure, with dotted lines showing brake thermal efficiency and dashed lines peak cylinder pressure 26

Figure 10: Schematic of the thermal control system for the HCCI engine 31

Figure 11: Optimum heater and intercooler effectiveness as a function of brake power for $1800 \mathrm{rpm}$, where solid line shows the heater effectiveness and the dotted line shows the intercooler effectiveness 37

Figure 12: Equivalence ratio as a function of brake power for optimum operating conditions for the engine, at $1800 \mathrm{rpm}$.

Figure 13: Optimum intake cylinder pressure and intake cylinder temperature as a function of brake power, for $1800 \mathrm{rpm}$, where dotted line shows the intake cylinder pressure and solid line shows intake cylinder temperature

Figure 14: NOx emissions in parts per million ( $\mathrm{ppm}$, solid line) and peak cylinder pressure in bar (dotted line) as a function of brake power, for the optimum operating conditions for the engine, at $1800 \mathrm{rpm}$ 40 
Figure 15: Optimum brake thermal efficiency as a function of brake power, for $1800 \mathrm{rpm}$, where the solid line shows HCCI engine efficiency of the operating with the heater and the dotted line shows the efficiency of the HCCI engine with the intercooler 41

Figure 16:Caterpillar 3406 Genset before delivery to LLNL …............................................... 44

Figure 17:Design system breakdown for the HCCI conversion of the 3406 Engine ................ 45

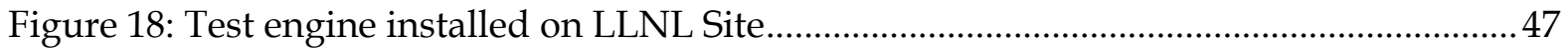

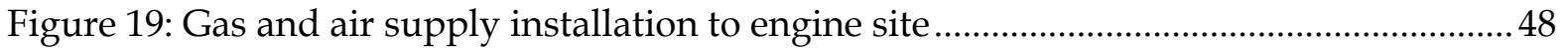

Figure 20:Engine picture showing the fueling system components. ....................................... 50

Figure 21: Dual manifold intake system allows for controlling intake temperature on a

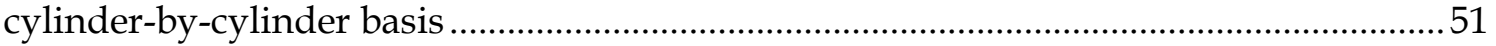

Figure 22: Pressure versus crank angle for each cylinder during initial HCCI operation with new intake manifold, but no attempt to compensate for cylinder-by-cylinder variations.

Figure 23: ARICE HCCI Engine schematic showing implementation of the thermal

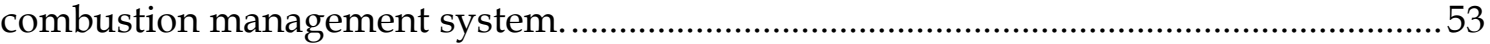

Figure 24: The natural gas carburetor (rugged and low cost) maintains ultra-lean

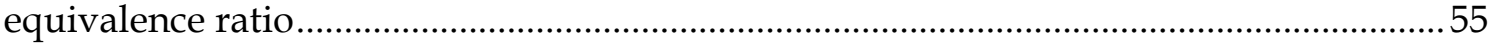

Figure 25: The Supercharger Drive transmission was designed, fabricated, and installed on

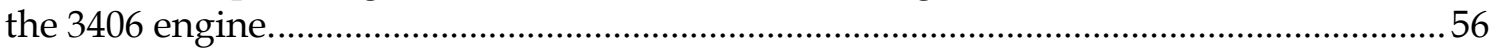

Figure 26: Intake gasses are preheated by exchanging heat with exhaust gasses................... 57

Figure 27: Independent jacket water circulation system allows for preheating jacket water, engine block, and assists HCCI startup ..........................................................................59

Figure 28: Flexible Data acquisition and control hardware and software system ..................61

Figure 29:Engine speed versus time for HCCI mode startup ................................................. 62

Figure 30: Pressure versus crank angle for each cylinder during initial HCCI operation with

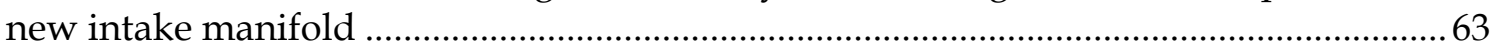

Figure 31: Combustion timing controlled by adjusting the balance of hot and cold flow on an individual cylinder

Figure 32: Pressure traces for steady state operation of the generator set at $40 \mathrm{~kW}$ and 1800 RPM naturally aspirated. 


\section{List of Tables}

Table 1: Performance Targets for ARICE HCCI Engine System .............................................. 6

Table 2: Summary of the Results Obtained from WAVE for the HCCI Turbocharger............ 25

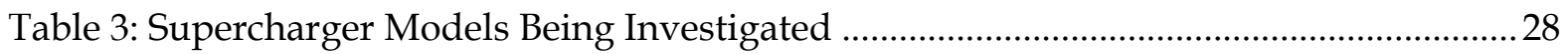

Table 4: Summary of the Options Evaluated for Turbocharging and Supercharging of the HCCI Engine.

Table 5: Main Characteristics of the Caterpillar 3406 6-Cylinder Engine Used for the HCCI Experiments and Composition of the Natural Gas Fuel......................................... 32

Table 6 :Summary of Important Performance Specifications for Base Engine, a Natural Gas 3406 Generator Set Operating on Natural Gas ....................................................... 42 


\section{Abstract}

This report documents the development of a Homogeneous Charge Compression Ignition engine for the Advanced Reciprocating Internal Combustion Engine Program of the California Energy Commission. The goal of this research project was to develop and demonstrate a homogeneous charge compression ignition internal combustion engine for stationary power generation applications meeting the advanced reciprocating internal combustion engine program efficiency and emissions goals, primarily the development of a 200 kilowatt engine operating at 45 percent efficiency with 0.015 grams/brake horse power hour nitrogen oxide emissions. While this project did not attain this goal, innovative solutions were developed to many of the technical barriers that prevent homogeneous charge compression ignition from being a practical combustion system for the stationary power generation marketplace. The project focused on converting a Caterpillar 6-cylinder engine model 3406 natural gas generator set to operate in natural gas homogeneous charge compression ignition mode. A key challenge of homogeneous charge compression ignition is control of combustion. A novel system for control of the engine was developed based on thermal management, where recovered heat from the engine exhaust was used to control intake air temperature. Controlling intake air temperature allows control of the timing of the homogeneous charge compression ignition combustion process, and a specially designed dual intake manifold system allowed for control of the engine on a cylinderby-cylinder basis. Control of fuel-air ratio is another significant technical issue in homogeneous charge compression ignition combustion, and is especially difficult with natural gas fuelled engines. A novel approach to fuel-air ratio control was developed by modifying a conventional natural gas carburetor and coupling it with an electronic pressure regulator, allowing for precise control of fuel air ratio. Startup is challenging for homogeneous charge compression ignition engines, most strategies proposed involve starting the engine in conventional operation (i.e., spark-ignition), then transition to homogeneous charge compression ignition once the engine is started. The transition approach invites hazards, because the spark-ignition operating regime (fuelair ratio) is not compatible with homogeneous charge compression ignition operating regime. An approach has been developed to start the engine directly in homogeneous charge compression ignition mode, avoiding operation in regimes that could be potentially hazardous. The technical accomplishments of this project lay the groundwork for future development of practical homogeneous charge compression ignition engines.

Keywords: HCCI power generation ARICE combustion 


\section{Executive Summary}

\section{Introduction}

Homogeneous charge compression ignition engines have been often considered as an alternative prime mover for transportation and stationary applications. Automobile and engine manufacturers are interested in homogeneous charge compression ignition engines due to their potential for high efficiency and low emissions. Homogeneous charge compression ignition combustion is fundamentally different than combustion in spark-ignited engines and diesel engines. Homogeneous charge compression ignition combustion is a thermal auto ignition of a premixed fuel-air mixture, with no flame propagation. The combustion temperature is low enough that the engine produces extremely low nitrogen oxide (NOx) emissions (a few parts per million) with no need for after treatment. Also, lean, premixed combustion results in near zero particulate matter emissions. Finally, homogeneous charge compression ignition engines do not require spark plugs or a three-way catalyst, and are therefore expected to have lower maintenance costs than spark-ignited engines. In summary, homogeneous charge compression ignition engines have a combination of potential characteristics that makes them desirable for power generation, including high brake thermal efficiency, low $\mathrm{NOx}$ emissions and low maintenance requirements.

\section{Objective}

The objective of this research and development project was to meet the 2007 performance targets laid out in the advanced reciprocating internal combustion engine program. The performance targets were 45 percent efficient engines achieving with 0.015 grams/brake horse power hour $\mathrm{NO}_{x}$ and 0.02 grams/brake horse power hour carbon monoxide (CO), at less-than or equal to $\$ 700$ per kilowatt $(\mathrm{kW})$ cost and greater than or equal to 10,000 hours B10 durability (greater than or equal to 45,000 hours between major overhauls). This specific project objective focused primarily on research and development towards meeting the performance and emissions targets of the Energy Commission advanced reciprocating internal combustion engine program, with 1000 hours of testing to demonstrate a level of durability.

\section{Project Approach}

This project focused on applying the technological knowledge about homogeneous charge compression ignition to developing and demonstrating stationary operation of a multi-cylinder natural gas homogeneous charge compression ignition engine that meets the advanced reciprocating internal combustion engine program performance targets. Many tasks were involved in the development of the homogeneous charge compression ignition engine for this advanced reciprocating internal combustion engine project:

- $\quad$ Single Cylinder Engine Testing 
- Breathing Design for Multi-cylinder Engine

- Multi-cylinder Engine Set-point Optimization

- Siting and Installation of Multi-cylinder Engine

- Install ETV on Multi-cylinder engine and Initial homogeneous charge compression ignition engines Operation

- Design Integration and Review

- Implement advanced reciprocating internal combustion engine Design on multicylinder homogeneous charge compression ignition Engine

- 1000 Hours Operation of homogeneous charge compression ignition advanced reciprocating internal combustion engine multi-cylinder engine

- Technology Transfer Activities

\section{Project Outcomes}

The technical approach was to develop and operate a Caterpillar 6-cylinder engine model 3406 natural gas engine converted from a spark ignited engine into a homogeneous charge compression ignition engine. The goal of achieving the advanced reciprocating internal combustion engine performance targets, primarily a $200 \mathrm{~kW}$ engine with 45 percent brake thermal efficiency and 0.015 grams/brake horse power hour $\mathrm{NO}_{x}$, has not yet been realized. However progress towards development of practical homogeneous charge compression ignition engine system for stationary power generation was made. All major engine systems were modified with a view to obtain a stationary homogeneous charge compression ignition engine-generator system. The following outcomes and observations were made:

- A thermal management system was designed and built based on analysis. The system consists of a preheater and an intercooler connected in parallel. Fresh charge is circulated through either heat exchanger and then blended to obtain appropriate combustion. This system also allows for cylinder by cylinder control of intake temperature.

- The engine is started in homogeneous charge compression ignition mode by running a natural gas fueled combustor that heats the preheater. The intake gases are then circulated through the hot preheater, reaching a high enough temperature for homogeneous charge compression ignition to occur. Once combustion starts, it is self-sustaining, and therefore the burner can be turned off quickly after ignition.

- The fueling system was modified by replacing the stock natural gas carburetor by a carburetor designed for liquid petroleum gas. This change adjusts the equivalence ratio to the value desired for homogeneous charge compression ignition combustion $(\phi \sim 0.4)$, and eliminates the risk of over fueling that may damage the engine. 
- Selection of a turbocharger caused problems, as the low temperature exhaust in homogeneous charge compression ignition engines makes commercially available turbochargers inappropriate for homogeneous charge compression ignition operation. Instead, a supercharger was selected, at the expense of reduced power output and efficiency.

- A real-time operational control system was implemented and allowed the development of control algorithms for homogeneous charge compression ignition engine control. The control system activated blending valves between hot and cold intake streams to obtain the appropriate charge temperature for optimum ignition timing in all cylinders.

- The engine was run in homogeneous charge compression ignition mode. Good and consistent combustion timing was obtained in all cylinders. High power operation had not been possible because only limited testing with the supercharged engine had been conducted. The engine delivered $50 \mathrm{~kW}$ with atmospheric intake. Efficiency and power targets were not met due to the lack of an appropriate turbocharger.

\section{Recommendations}

Progress has been made in this project, and complete development of a homogeneous charge compression ignition engine for stationary power meeting the advanced reciprocating internal combustion engine performance targets were achieved. The key remaining tasks are: Complete installation of software and actuators for fully automated engine control, conduct testing of the engine towards full load operation, and transition technology to a manufacturer or assembler through partnership and licensing. In the future, the engine will be used as a fully instrumented test bed for performance studies of homogeneous charge compression ignition combustion. Future research could focus further on basic research of homogeneous charge compression ignition control. This homogeneous charge compression ignition engine is an ideal test bed for testing control systems for inexpensive and robust combustion control in multi-cylinder engines. Various linear and nonlinear control methodologies were employed to develop control algorithms. Specifically, one method to be used is extremum, seeking control to provide online optimization of the engine efficiency and emissions. 


\subsection{Introduction}

\subsection{Project Rationale}

Homogeneous charge compression ignition (HCCI) engines have been often considered as an alternative prime mover for transportation and stationary applications.

Automobile and engine manufacturers are interested in HCCI engines due to their potential for high efficiency and low emissions. HCCI combustion is fundamentally different than combustion in spark-ignited (SI) engines and diesel engines. HCCI combustion is a thermal auto ignition of a premixed fuel-air mixture, with no flame propagation (as in SI engines) or mixing-controlled combustion (as in diesel engines) (Suzuki et al. 1998). HCCI engines can run extremely lean (equivalence ratio 0.4), yielding combustion temperatures low enough that the engine produces extremely low NOx emissions (a few parts per million [ppm]) with no need for after treatment. Lean, premixed combustion also results in near zero particulate matter emissions. Finally, HCCI engines do not require spark plugs or a three-way catalyst, and are therefore expected to have lower maintenance costs than SI engines. In summary, HCCI engines have a combination of potential characteristics that makes them desirable for power generation, including high brake thermal efficiency, low $\mathrm{NO}_{x}$ emissions and low maintenance requirements.

HCCI engines do present some technical challenges that have so far kept them from widespread commercialization. The main hurdles are combustion timing control, low specific power output, high emissions of hydrocarbon (HC) and carbon monoxide (CO), and difficulty to start when cold (Suzuki et al. 1998). These are formidable technical challenges for transportation applications, due to the fast transients required to meet the road load and due to the size restrictions inside a vehicle. However, for stationary applications, these issues may not be as challenging, because a stationary engine runs predominantly at a constant speed and the load changes relatively slowly. Under these conditions, combustion control becomes much more tractable. External components (e.g. a burner and heat exchanger for starting the engine) can easily be installed in stationary engines, since size restrictions are typically not as strict as for transportation applications.

This report describes the development of a 6-cylinder 14.6 liter HCCI engine (based on Caterpillar 3406 generator set) conducted as part of the California Energy Commission's Advanced Reciprocating Internal Combustion Engine (ARICE) Program. The report presents all the stages of the development process, starting with basic analysis and then describing all the necessary modifications in the different engine systems, including the thermal management and continuing with the starting system, the fueling system, the boosting system and the controls. 


\subsection{Project Objective}

This objective of this project was to meet the 2007 targets laid out in the ARICE Program by 2004 . These targets were $45 \%$ efficient engines achieving with 0.015 grams/brake horse power hour (g/bhp-hr) NOx and $0.02 \mathrm{~g} / \mathrm{bhp}-\mathrm{hr} \mathrm{CO}$, at $\leq \$ 700 / \mathrm{kW}$ cost and $\geq 10,000$ hours B10 durability ( $\geq 45,000$ hours between major overhauls). Table 1 shows the full list of targets. This specific project objective focused primarily on development of the ARICE HCCI engine system towards meeting the performance and emissions targets of the Energy Commission ARICE program, with a planned 1000 hours of testing to demonstrate a level of durability.

Table 1: Performance Targets for ARICE HCCI Engine System

\begin{tabular}{|c|c|c|c|c|}
\hline \multicolumn{5}{|c|}{\begin{tabular}{l} 
Performance Characteristics of \\
Advanced Reciprocating Internal Combustion Engine System (Production Prototype) \\
Rated Size: \\
\multicolumn{2}{c}{ Application(s): Distributed Generation }
\end{tabular}} \\
\hline $\begin{array}{cc}\text { Applicatio } \\
\text { Parameter }\end{array}$ & 2003 & 2005 & $2007(2004)^{*}$ & 2010 \\
\hline \multicolumn{5}{|l|}{ Efficiency } \\
\hline Brake Thermal Efficiency & & & $\geq 45 \%$ & \\
\hline Fuel-to-Electric Efficiency & & & $\geq 45 \%$ & \\
\hline Overall Efficiency (CHP) & & & $\mathrm{N} / \mathrm{A}$ & \\
\hline \multicolumn{5}{|l|}{ Emissions - shaft power (g/bhp-hr) } \\
\hline Oxides of Nitrogen (NOx) & & & $\leq 0.015$ & \\
\hline Carbon Monoxide $(\mathrm{CO})$ & & & $\leq 0.02$ & \\
\hline Volatile Organic Compounds (VOCs) & & & $\leq 0.006$ & \\
\hline Particulate Matter (PM10) & & & $\leq 0.01$ & \\
\hline \multicolumn{5}{|c|}{ Emissions - power generation (Ib/MWehr) } \\
\hline Oxides of Nitrogen (NOx) & & & $\leq 0.05$ & \\
\hline Carbon Monoxide (CO) & & & $\leq 0.08$ & \\
\hline Volatile Organic Compounds (VOCs) & & & $\leq 0.02$ & \\
\hline Particulate Matter (PM10) & & & $\leq 0.03$ & \\
\hline \multicolumn{5}{|l|}{ Cost } \\
\hline Complete Installed Cost (\$/kWe) & & & $\leq 700$ & \\
\hline O\&M Cost $(\$ / k W h)$ & & & $\leq 0.005$ & \\
\hline \multicolumn{5}{|l|}{ Availability \& Durability } \\
\hline Availability & & & $92 \%$ & \\
\hline B10 Durability (hours) & & & $\geq 10,000$ & \\
\hline $\begin{array}{l}\text { Mean Time Between Major Overhauls } \\
\text { (hours) }\end{array}$ & & & $\geq 45,000$ & \\
\hline
\end{tabular}

${ }^{*}$ Parenthetical (2004) refers to project goal of meeting 2007 target by 2004 


\subsection{Project Approach}

Homogeneous Charge Compression Ignition (HCCI) is an alternative engine technology under consideration due to its potential to lower emissions of $\mathrm{NO}_{x}$ while maintaining the high level of efficiency typical of modern direct injection (DI) Diesel engines (Suzuki et al. 1998). HCCI combustion has studied over since the late 1970's and given many names including Active Thermo-Atmosphere Combustion (ATAC, Onishi et al. 1979), Lean Homogeneous Combustion, Diesel Fumigation, Compression Ignited Homogeneous Charge Combustion (CIHC),Homogeneous Auto-Ignition Two Stroke(HAT), Toyota-Soken (TS) Combustion, Premix Charge Compression Ignition (PCCI, Flynn et al. 1999), Active-Radical (AR, Ishibashi et al. 1996) Combustion, Premixed Lean Diesel Combustion (PREDIC), Uniform Bulky Combustion System (UNIBUS, Yanagihara et al. 1996), Homogeneous Charge Compression Ignition Diesel Combustion (HCDC), Homogeneous Charge intelligent Multiple Injection Combustion System (HiMICS), Multiple Stage Diesel Combustion (MULDIC, Hashizume et al. 1998), and Premixed Compression Ignited Combustion (PCIC, Miyamoto et al. 1999).

While researchers of each of these systems have taken a slightly different approach to achieving HCCI combustion, the basic operating premise of each is essentially the same. HCCI combustion refers to an engine-operating regime in which a mixture with a high degree of homogeneity is made to auto ignite by compression ignition. This autoignition of a well-mixed charge produces a combustion event which differs significantly from either spark ignition (SI) or traditional compression ignition (CI) engines in that the timing of the ignition event is a function only of the state of the mixture and the combustion event proceeds at a rate that is controlled neither by flame propagation nor diffusion mixing processes but by chemical kinetics alone. The primary advantage of HCCI combustion is the possibility it offers to produce very low $\mathrm{NO}_{x}$ (less than $10 \mathrm{ppm}$ ) at high thermal efficiency due to the fact that highly diluted mixtures can be burned without the high peak flame temperatures produced in both CI and SI combustion.

The great potential of the HCCI combustion system lies in its homogeneous nature. SI engines typically have a single flame front which traverses the entire cylinder. The gases that burn early in the cycle are continually raised to higher temperatures, generating large concentrations of $\mathrm{NO}_{x}$ in the process. This highly stratified temperature distribution in the cylinder requires a reduction in the mean temperature to avoid peak temperatures which would lead to high $\mathrm{NO}_{x}$ formation rates. The need to reduce the mean in-cylinder temperature during combustion has led to the introduction of EGR and lean burn engines but the peak temperature to mean cylinder temperature problem persists. While dilution in spark ignited engines can reduce $\mathrm{NO}_{\mathrm{x}}$ emissions, the minimum level is dictated by the difficulty of realizing spark ignition and flame propagation in highly diluted mixtures. In traditional CI engines a similar problem arises for different reasons. While the overall charge equivalence ratio is well below stoichiometric, the equivalence ratio in the combustion zone is very near one. The result 
of this is a very high flame temperature, even in highly diluted mixtures, which by its very nature produces high $\mathrm{NO}_{x}$ emissions. $\mathrm{HCCI}$ combustion seeks to overcome this peak flame temperature issue by combusting the mixture without a flame front, with the entire mixture burning homogeneously at a controllable rate. In so doing, the peak combustion temperature is essentially equal to the mean in-cylinder temperature thus minimizing $\mathrm{NO}_{x}$ production at a given efficiency.

Much progress and many successes on single-cylinder research-type HCCI engines have been previously reported (Mirimoto et al. 2001, Law and Allen 2002, Yang et al. 2002). In most cases, these successes are focused on automotive power trains, an application that necessitates the ability of the engine to operate over a wide range of speed and load. Application of HCCI for generating electric power allows the HCCI control problems to be reduced, since the engine will operate at a constant 1800 revolutions per minute (rpm), and, at least in the beginning, at full power, as is done for base load generation and for peaking generation.

This project focused on applying the technological knowledge about HCCI to developing and demonstrating stationary operation of a multi-cylinder natural gas HCCI engine that meets the ARICE Program performance targets. Many tasks were involved in the development of the HCCI engine for this ARICE project. These tasks ranged from single-cylinder engine, numerical modeling of the operational strategy, system design and implementation, durability testing, and technology transfer. The goal of each of these various tasks areas as they apply to development of the ARICE HCCI engine are described in the following sections.

\subsection{Single Cylinder Engine Testing}

The goal of this task was to setup and operate a 2.4 liter single-cylinder Caterpillar 3401 (CAT3401) engine in HCCI mode with the view of developing a control system for the multi-cylinder engine. The control system was to be based upon exhaust gas recirculation (EGR) by use of an Exhaust Throttle Valve (ETV). The ETV was to be built and installed on the CAT3401 engine, and an ETV based combustion timing control system will be developed. Transition between spark-ignited operation and HCCI by use of EGR was to be investigated. This task was conducted at University of California Berkeley (UCB) using the CAT3401 research engine already operating in HCCI mode.

Successful completion of this task was measured by design and implementation of an EGR control system based upon the ETV that can be readily used on the multi-cylinder engine.

Meeting this goal helped to achieve the project objectives by providing the means to control combustion timing for the ARICE system. 


\subsection{Breathing Design for Multi-cylinder Engine}

The goal of this task was to optimize the engine breathing (intake valve timing, exhaust valve timing, turbocharger) of the multi-cylinder engine. This work was performed entirely under a subcontract to Ricardo, Inc. (experts modeling and design of engine breathing).

Successful completion of this task was measured by delivery of design specifications for camshaft and turbocharger for the multi-cylinder engine.

Meeting this goal helped to achieve the project objectives by optimizing the breathing of the engine and minimizing losses that would be associated with poor engine breathing.

\subsection{Multi-cylinder Engine Set-point Optimization}

The goal of this task was to use the Lawrence Livermore National Laboratory (LLNL) advanced numerical HCCI simulations tools to select the optimal operating point for the multi-cylinder engine. By using analytical methods, the number of engine tests required to identify the best engine operating point could be significantly reduced. This singlezone model was used to optimize the engine set-point (the point where engine will operate to meet ARICE specifications) with respect to brake thermal efficiency, power density, and $\mathrm{NO}_{x}$ emissions. Multi-zone modeling was to be used to further refine the optimization with additional consideration of combustion efficiency and hydrocarbon and carbon monoxide emissions.

Successful completion of this task was measured by specification of ARICE HCCI operating point.

Meeting this goal helped to achieve the project objectives by reducing the amount of testing required to select the best operating point.

\subsection{Siting and Installation of Multi-cylinder Engine}

The goal of this task was to site, install, and operate the multi-cylinder engine/generator set in stock spark-ignited mode.

Meeting this goal helped to achieve the project objectives by providing the platform for development of the ARICE system.

\subsection{Install ETV on Multi-cylinder engine and Initial $\mathrm{HCCl}$ Operation}

The goal of this task was to install the ETV system on each cylinder of the Multi-cylinder engine. The ETV system control system was to serve as the basis for the control system 
for HCCI operation. The engine was operated in naturally aspirated HCCI mode by the conclusion of the task.

Successful completion of this task was measured by initial operation of multi-cylinder engine in naturally aspirated HCCI mode.

Meeting this goal helped to achieve the project objectives by completing intermediate engine setup needed to develop the ARICE system.

\subsection{Design Integration and Review}

The goal of this task was to integrate data from tasks 2.1-5 into development of a design plan for the multi-cylinder HCCI engine. A plan was to be drafted, followed by a Critical Project Review (CPR). Comments from the CPR were to be incorporated into a final design plan for implementation of the HCCI ARICE system.

Successful completion of this task was measured by generation of a final design plan for the ARICE HCCI system.

Meeting this goal helped to achieve the project objectives by developing and reviewing the design for the HCCI ARICE system.

\subsection{Implement ARICE Design on Multi-cylinder HCCI Engine}

The goal of this task was to implement the Final Design Plan to make the necessary modifications to the multi-cylinder engine to achieve ARICE goals. Optimal cam design, turbocharger and catalyst was to be implemented onto the multi-cylinder engine, along with the optimal feedback control system. At the conclusion of this task the engine was to have been operated with demonstrated performance meeting ARICE goals.

Successful completion of this task was measured by completion of tests demonstrating the engine operating at or better than the ARICE performance specifications.

Meeting this goal helped to achieve the project objectives by demonstrating an ARICE EPAG system.

\subsection{Hours Operation of HCCI ARICE Multi-cylinder Engine}

The goal of this task was to demonstrate 1000 hours of reliable operation of a $200 \mathrm{~kW}$ Multi-cylinder ARICE EPAG system.

Successful completion of this task was to be measured by completion of 1000 hours of operation of the multi-cylinder ARICE EPAG system. 
Meeting this goal was to help to achieve the project objectives by demonstrating reliable performance of the ARICE EPAG system.

\subsection{Technology Transfer Activities}

The goal of this task was to develop a plan to make the knowledge gained, experimental results and lessons learned available to decision-makers in industry and government. 


\subsection{Results}

In this section of the report, the results of the efforts on the various tasks are presented and discussed in the following sections.

\subsection{Single Cylinder Engine Testing}

This section documents the single cylinder testing work done on the single-cylinder engine at UC Berkeley in support of the ARICE HCCI R\&D program. Engine testing was conducted on the single-cylinder engine at UC Berkeley to understand and help overcome the technical barriers towards HCCI engine operation. The following sections describe the experimental apparatus and the results of the experimental investigations.

\subsubsection{Experimental setup}

\section{Caterpillar 3401 Single Cylinder Test Engine}

Because Homogeneous Charge Compression Ignition is a reciprocating engine concept, nearly any engine may be adapted for this type of operation. Two and four stroke, gasoline, diesel and natural gas engines are all candidates for HCCI. Of course there are reasons to choose one engine type over another.

First of all, a single cylinder engine is ideal for proof of initial concepts, as it massively simplifies experimentation. Having multiple cylinders introduces many more issues that would be overwhelming when exploring new ideas. These issues include cylinder-tocylinder balancing, and intake and exhaust manifold effects. For example, uneven cooling water temperature distribution, compression ratios, and fuel/air mixtures can all significantly affect the combustion timing and amplitude in each cylinder.

The higher compression ratios required for auto-ignition of fuels such as natural gas, and the high, sharp peak cylinder pressures inherent to HCCI suggest a former diesel engine be used. The Caterpillar 3401 is intended for diesel engine lubricant testing, has a compression ratio of 16.25 (137 mm bore, $164 \mathrm{~mm}$ stroke), and is robustly made. Because it was designed as a test engine, certain aspects of it lend well to being modified, such as its intake and exhaust piping and combustion chamber access. Also, being a single cylinder of 2.44 liters provides a lower surface to volume ratio compared to typical automotive engines. In HCCI, heat loss to the cylinder wall may be a significant factor, so this is an important consideration.

\section{Fuel System}

The initial setup of the $3401 \mathrm{HCCI}$ engine at UC Berkeley was for basic operation in HCCI mode. It had simply a tee in the intake pipe through which gaseous fuels entered and mixed with the air prior to being inducted into the cylinder. A needle valve controlled the fuel flow, which was measured with a Sierra Instruments Side-Trak ${ }^{\mathrm{TM}} 840$ mass flow controller. Using this system, the fuel flow rate could change depending on intake air pressure and other factors even if one never touched the fuel valve. 


\section{Intake Air Systems}

Being that the quality of HCCI combustion is so sensitive to the conditions of its intake air, the Caterpillar 3401 engine at Berkeley was configured to allow flexibility and control of the inlet air temperature and pressure. The intake piping was designed such that the engine may be naturally aspirated or boosted, and the air temperature may be adjusted using an air heater.

\section{Manifold Air Pressure}

Positioning the air valves to the naturally aspirated mode simply draws the intake air from the room through an air filter. After traveling through the head losses of the intake piping and air heater, the charge is approximately 0.75 bar absolute at the manifold when running naturally aspirated.

If any more than 0.75 bar absolute is required, the engine must be boosted. On a blown production engine, a turbocharger or supercharger creates the increase in air pressure. These devices are parasitic losses to the engine because they draw their power from the exhaust stream and crankshaft, respectively. Of course the benefit of boosting the intake air more than makes up for these losses, but they are losses nonetheless.

On the Caterpillar 3401, the boosted intake air is drawn directly from the house compressed air system. It first goes through a pressure regulator, where the intake pressure for the engine may be adjusted from less than 1.0 bar to about 2.5 bar absolute. Next in line is a coalescing filter which removes the water that inherently lives in compressed air systems. The air compressor is a 100 horsepower blower that cycles on and off to meet the needs of the building's laboratories and stores air at approximately 90 psig in about 7 cubic meters of tanks.

The losses associated with driving a blower are not directly added to the engine system and a clearer picture of the engine performance can be obtained. Also, the boost can be provided at a constant level independent of the engine's running conditions. For examination of the effect a real turbocharger would have on the Caterpillar $3401 \mathrm{HCCI}$ engine, experiments may be performed in which the exhaust pressure is increased, modeling a non-ideal turbocharger providing the intake air boost.

\section{Intake Air Heating}

Once the intake air pressure is regulated to the test value, the air temperature must be controlled. As an example, for HCCI combustion of natural gas, the intake air temperature must be in the neighborhood of 200 degrees Celsius. Obtaining these temperatures with such a high flow rate of air requires the use of an OSRAM SYLVANIA Hot Air System (model 068588). The heater itself is a ceramic element in a pipe, and can draw up to $8 \mathrm{~kW}$ of electricity. A proportional-integral-derivative (PID) controller and Silicon-Controlled Rectifier (SCR) circuitry control the outlet temperature. The power electronics convert a 4 to 20 milliamp (mA) signal from the PID controller to heater power. 


\section{Exhaust Throttle}

Investigation into internal EGR control of an HCCI engine required that a modulating valve be installed in the exhaust stream of the engine. On the Caterpillar 3401 test engine, the exhaust pipe configuration was such that installation of a commercially available engine brake would be relatively simple. Made by companies such as Cummins and BD, these devices are simply robust butterfly valves with pneumatic actuators. They are typically installed at the turbocharger exhaust on a diesel truck. In this case, the throttle installed just beyond the exhaust valve results in the ability to control temperature of the mixture within the combustion chamber by adding more or less residual gasses to the cylinder. The exhaust throttle is shown in Figure 1.
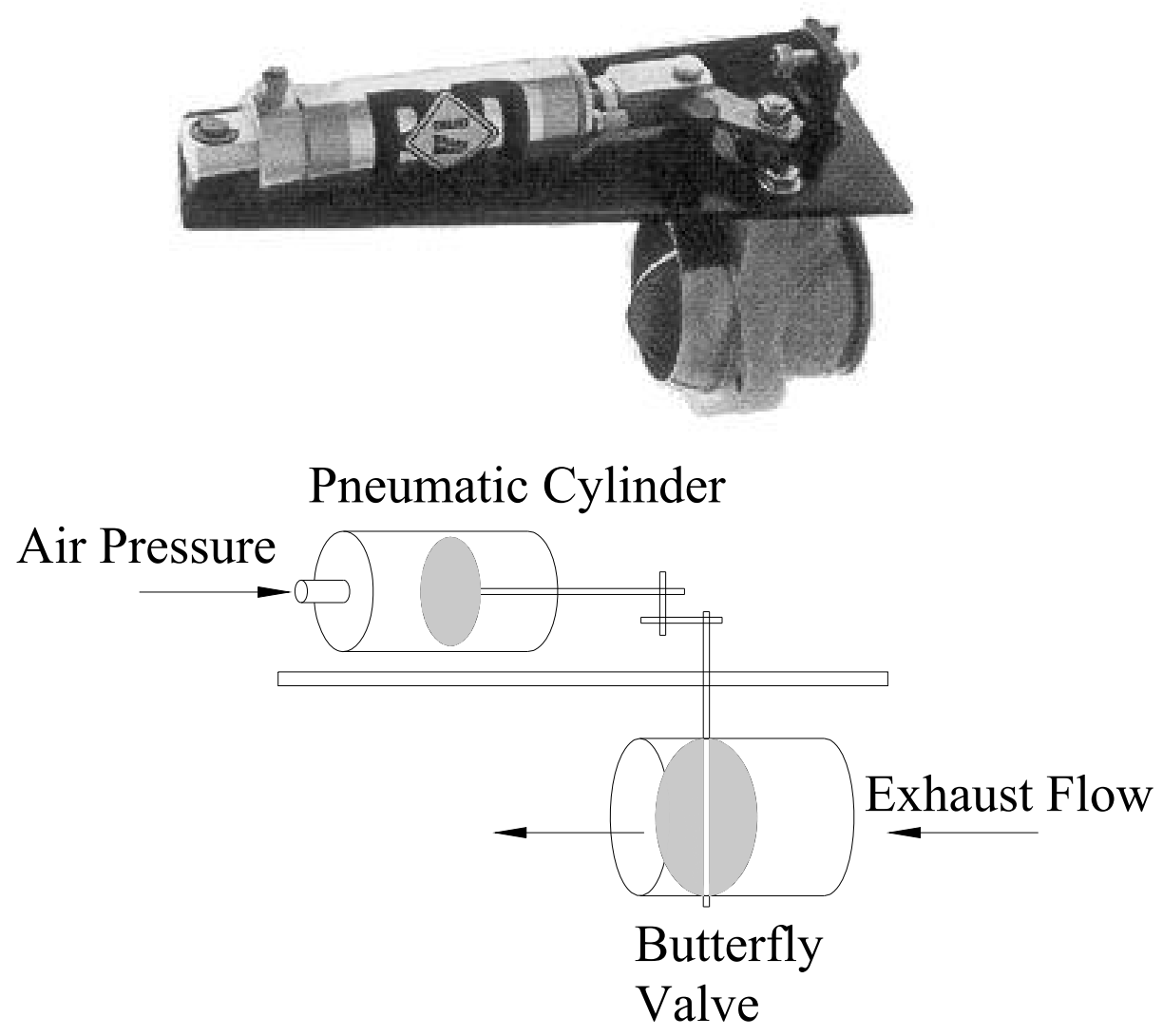

Figure 1: Picture and schematic of modified exhaust throttle

In this experimental application, the pneumatic actuator was altered for modulating operation instead of the stock on-off configuration. To make the throttle respond to a computer control system, an electronic pressure regulator was installed. This device linearly changes its output air pressure with input voltage. Thus, when connected to a direct current (DC) power supply or computer control board, the throttle position can be varied with a fully open to closed reaction time of much less than one second. A signal of 3.5 volts direct current (VDC) will produce a control air pressure of 50psig, moving the valve to its "fully closed" position. There is a physical stop on the actuator which 
keeps the throttle plate from fully seating against the valve body so that it does not stick shut and some exhaust is always allowed through. Given a zero-volt signal, the actuator spring pulls the throttle fully open.

\section{Data Acquisition and Computer Controls}

Providing a comprehensive record of the running conditions and performance of an engine during experiments is a computerized data acquisition system. The Caterpillar 3401 test stand at Berkeley has three separate and distinct computer systems. The first is a personal computer (PC) with a National Instruments ${ }^{\mathrm{TM}}$ PCI-6035E card and a LabVIEW ${ }^{\mathrm{TM}}$ virtual instrument program, which are used for low speed data acquisition. With a sampling frequency of 1 hertz $(\mathrm{Hz})$, this system records temperatures from all over the engine, intake and exhaust pressures, air and fuel flow rates, and other miscellaneous quantities in a spreadsheet with a time stamp.

The high-speed data acquisition system is a second computer with a PCI-6110E board. It uses code written in MATLAB ${ }^{\circledR}$ with the Data Acquisition Toolbox to acquire and process the in-cylinder pressures provided by the AVL pressure transducer system. An encoder on the camshaft triggers data point collection every 0.1 crank angle degrees. Because of the sheer quantity of data it is only saved 30 cycles at a time when the information is pertinent.

The third computer system has been largely set up for engine control. It includes a host PC running a Windows environment and a controller computer that has The MathWorks' xPC Target as an operating system. The operator may write code in Simulink ${ }^{\circledR}$ and MATLAB ${ }^{\circledR}$ which is compiled and downloaded to the controller computer via Ethernet. The controller computer has sufficient boards that it can process data from the shaft encoder, cylinder pressure transducer, and other inputs while driving its outputs to the ignition coils, fuel injectors, and throttle valves. The ultimate goal is a closed loop controller adjusting the exhaust throttle valve on the Caterpillar to provide an optimized operating point, but initially it has only been used for fuel injector operation and real-time $50 \%$ burn timing calculations.

\section{Emissions Analysis}

A Horiba emissions bench takes on the chemical analysis of the exhaust of all of the Combustion Analysis Lab's engines. A sample pump draws the gas from the exhaust duct and through an ice bath and condensate collector. The water removed from the exhaust may contain a few soluble species, but this is a necessary step, as the analyzers cannot process water vapor. The gas then takes a journey down a tube to the emissions bench, where it is heated and further dried before being analyzed.

Oxygen measurement is accomplished using magneto-dynamic paramagnetic analysis. Total hydrocarbon analysis is done through flame ionization detection. In order to take measurements of carbon monoxide and dioxide levels in the exhaust, a Horiba unit uses 
infrared absorption technology. Finally, NOx detection and measurement is done via chemiluminescence.

\subsubsection{Single-Cylinder Engine Results}

The control problem of an HCCI engine is rather different from that of a traditional spark ignited or diesel engine. In an SI engine, premixed fuel and air are drawn into the combustion chamber, but they do not auto-ignite. Only when a precisely timed spark is applied does a flame propagate across the chamber. In a traditional diesel engine, only fresh air is inducted into the cylinder. Near top dead center (TDC) it reaches pressures and temperatures at which diesel fuel would auto-ignite, but nothing happens until the fuel is injected.

In a homogeneous charge compression ignition engine, a premixed fuel-air charge is drawn into the cylinder. Instead of being spark ignited at a desirable time, the combustion event does not occur until the gases inside the cylinder reach the point of auto-ignition. This removes the ability to directly control the combustion timing with fuel injection or spark ignition. Furthermore, inserting the fuel far enough upstream of the engine to ensure proper mixing reduces the ability to control the fuel flow on a cycleby-cycle basis.

It has been shown that there are a vast number of variables that can change the combustion character in an HCCI engine. For example, changing the intake air temperature, intake air pressure, exhaust pressure, exhaust gas recirculation (EGR), equivalence ratio, engine coolant temperature and compression ratio all can vary the combustion timing from misfire to knocking.

Temperature is the most important parameter for tuning HCCI combustion timing. Adding fuel, for instance, increases the equivalence ratio, creating higher heat release during the combustion event. This, in turn, heats the cylinder walls and the temperature of the next charge, thus advancing the timing of the next combustion event. The challenge, then, is finding a "lever" on the temperature that allows predictable and robust control of the engine. The ideal case would be changing the combustion characteristics on a cycle-by-cycle basis, but first attempts should just try to be "fast."

\section{Internal EGR control}

One method of HCCI engine control involves increasing the internal exhaust gas recirculation through the use of a throttle valve in the exhaust pipe. Increasing the exhaust pressure forces more hot exhaust gas to remain in the cylinder after the completion of the exhaust stroke. When the next fuel-air mixture is brought in, it mixes with these hot residuals, causing an increase in the charge temperature and hence an advance of the combustion timing. Another factor contributing to the timing advance is that the air flow rate is reduced while fuel flow rate remains constant.

Initial tests were promising, as the combustion timing apparently varied as fast as the throttle could be positioned with a variable DC power supply. In one experiment, the throttle valve was used to adjust the timing of the combustion event from misfire to 
before TDC. Figure 2 below illustrates the steady state pressure traces at several throttle control voltages.

A second exhaust throttle experiment captured the transient operation of the throttle valve. The control computer acquired sequential pressure traces while a step input was applied to the throttle control voltage, taking the system from 3.5 volts (full air pressure applied) to zero volts (throttle fully open). As is shown in Figure 2 the major change in timing occurs within 200 milliseconds, which is on the order of two to three engine cycles. This result shows the great potential of the throttle as a means of control, especially when noting that during normal control situations, the throttle valve will only move through small portions of its full stroke.

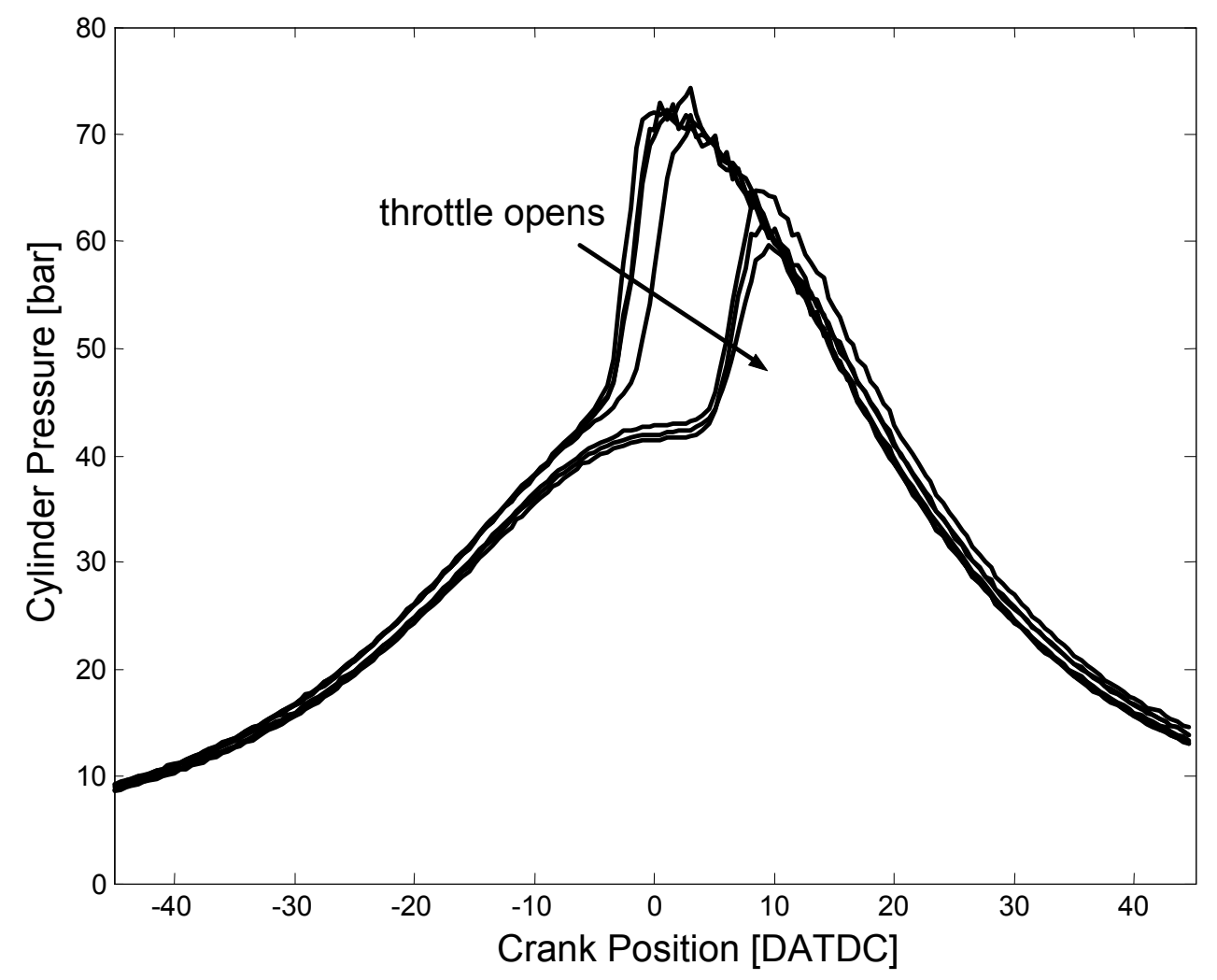

Figure 2: These seven sequential pressure traces are from a transient experiment when exhaust throttle was given a step input signal: fully closed to fully open

It may be noted that in this transient experiment, the throttle ends fully open. Checking Figure 3 for the equilibrium pressure trace with an open throttle valve and the same running conditions reveals that the combustion timing should be much later. When the transient experiment was allowed to continue to run after its major timing change, the thermal mass of the engine and intake air piping, as well as the slow response of the intake air heater and change in air flow rate, finally brought the engine to its steady state point in Figure 3. With this understanding of the process based on manual throttle valve 
control, the next step is to move to closed-loop control of the HCCI combustion using the exhaust throttle valve.

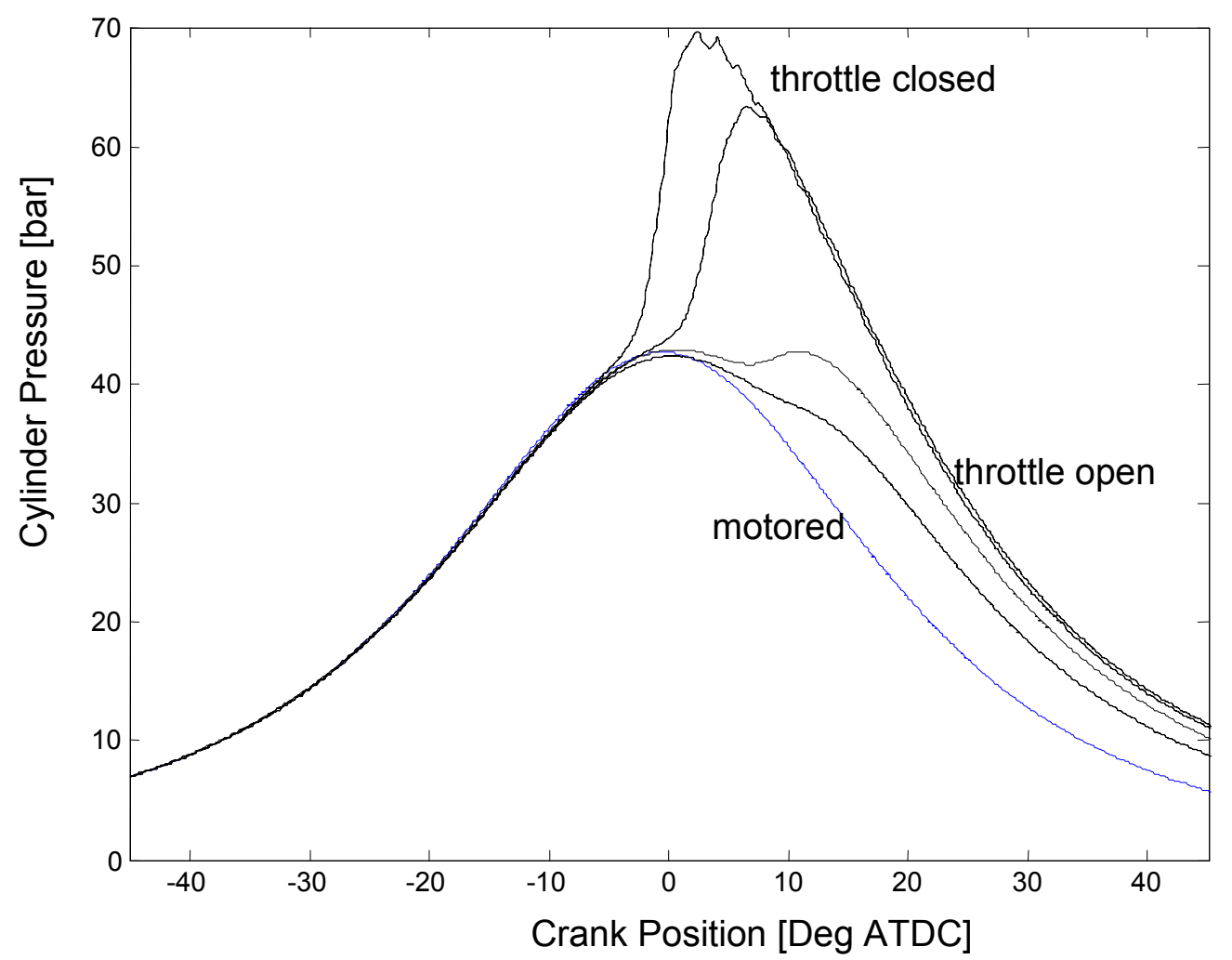

Figure 3: Variation of the steady-state pressure trace with varied exhaust throttle positions

\section{Closed Loop Control Using Exhaust Throttle Valve}

Automated control of HCCI combustion timing on a single cylinder Caterpillar 3401 was demonstrated using closed-loop proportional plus integral (PI) controller. This was experimentally tuned to maintain a fixed combustion timing, as measured by the $50 \%$ mass-fraction burned location (CA50). The pneumatic exhaust throttle was electronically closed (or opened) to increase (or decrease) the exhaust gas residuals and advance (or retard) the combustion timing. Cylinder pressure analysis calculations provided the CA50 feedback to the controller. Steady state and transient testing was conducted.

Figure 4 shows one of the transient experiments. The desired combustion timing (CA50) was set to 8 degrees after top dead center (ATDC). The intake air heater was at $150^{\circ}$ Celsius (C) before the experiment began. The top plot of Figure 4 shows the calculated CA50 (raw and filtered versions). The bottom plot shows the intake air heater temperature and the exhaust throttle position. The intake air heater was then turned off at time $t=0$ seconds, and the intake temperature measured at the heater dropped below $125^{\circ} \mathrm{C}$ at time $\mathrm{t}=450$ seconds. At this time, the control input saturated (the throttle was fully closed) and CA50 could not be advanced further to compensate for the drop in 
intake air temperature. CA50 began to deviate from the desired value. The intake air heater was turned back on at this time and CA50 tracking resumed.
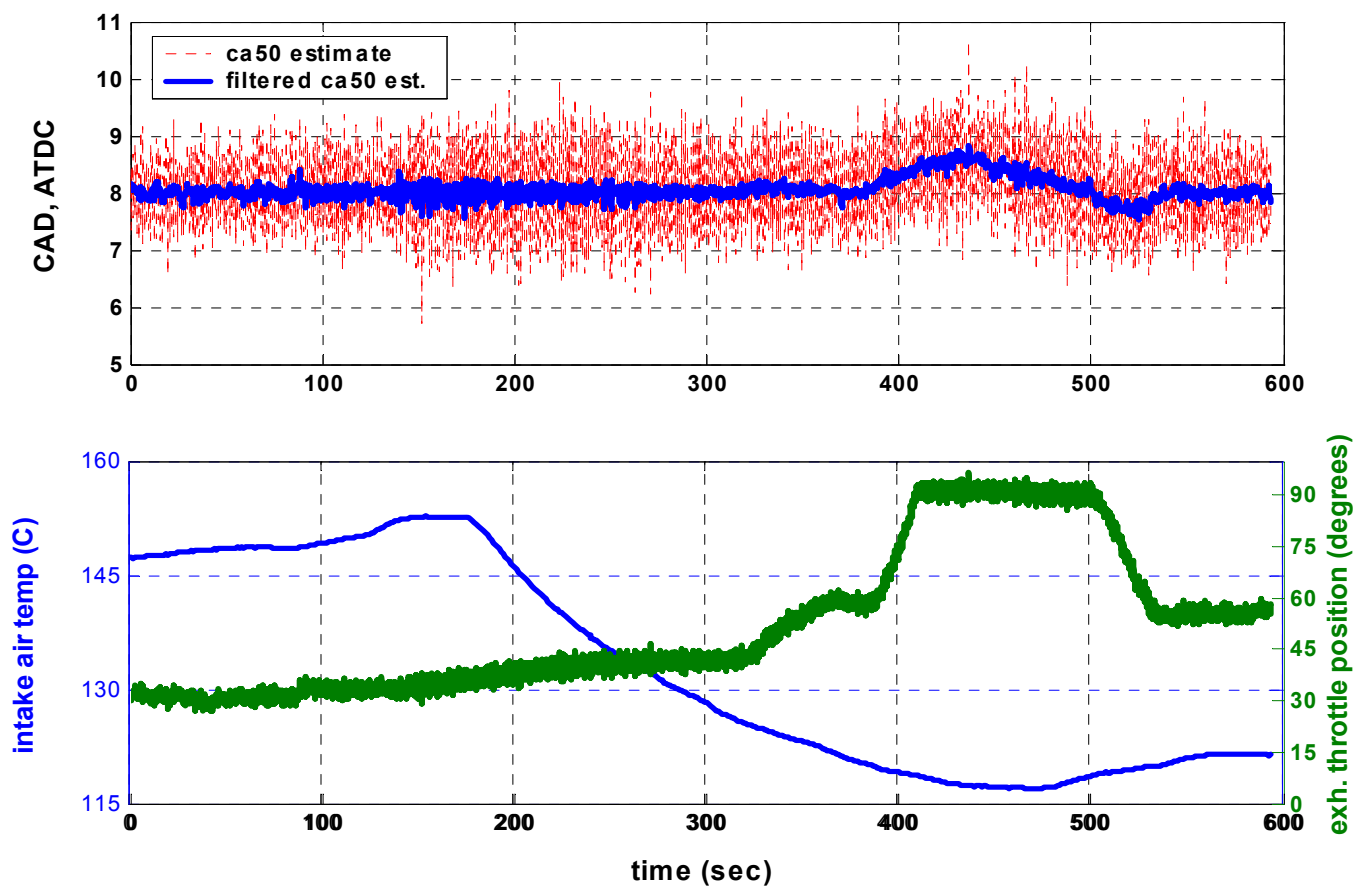

Figure 4: Closed loop control response of $\mathrm{HCCl}$ engine to transient intake temperature by means of exhaust throttle valve control

Another important feature of the controller is the ability to respond to changes in the engine combustion timing setpoint. Figure 5 shows the controller response for four different changes in the setpoint for HCCI operation. First, the engine setpoint is based on CA50 is 6 degrees ATDC, and the setpoint is suddenly changed to 1 degree ATDC. The controller rapidly adjusts the exhaust throttle valve to respond to this change in combustion timing. Next, the setpoint is adjusted back to 6 degrees ATDC, and the controller again is able to smoothly respond to the change in setpoint from early to later timing. The next tests are to change CA50 setpoint from 8 degrees ATDC to 2 degrees ATDC and then back to 8 degrees ATDC. The change from 8 degrees ATDC to 2 degrees ATDC is a smooth transition, but some overshoot is apparent in the transition from 2 degrees to 8 degrees ATDC. This suggests that the controller may be under damped, allowing some overshoot before settling out. Under damped systems tend to have faster response, but care must be taken because these have more susceptibility to instability. 

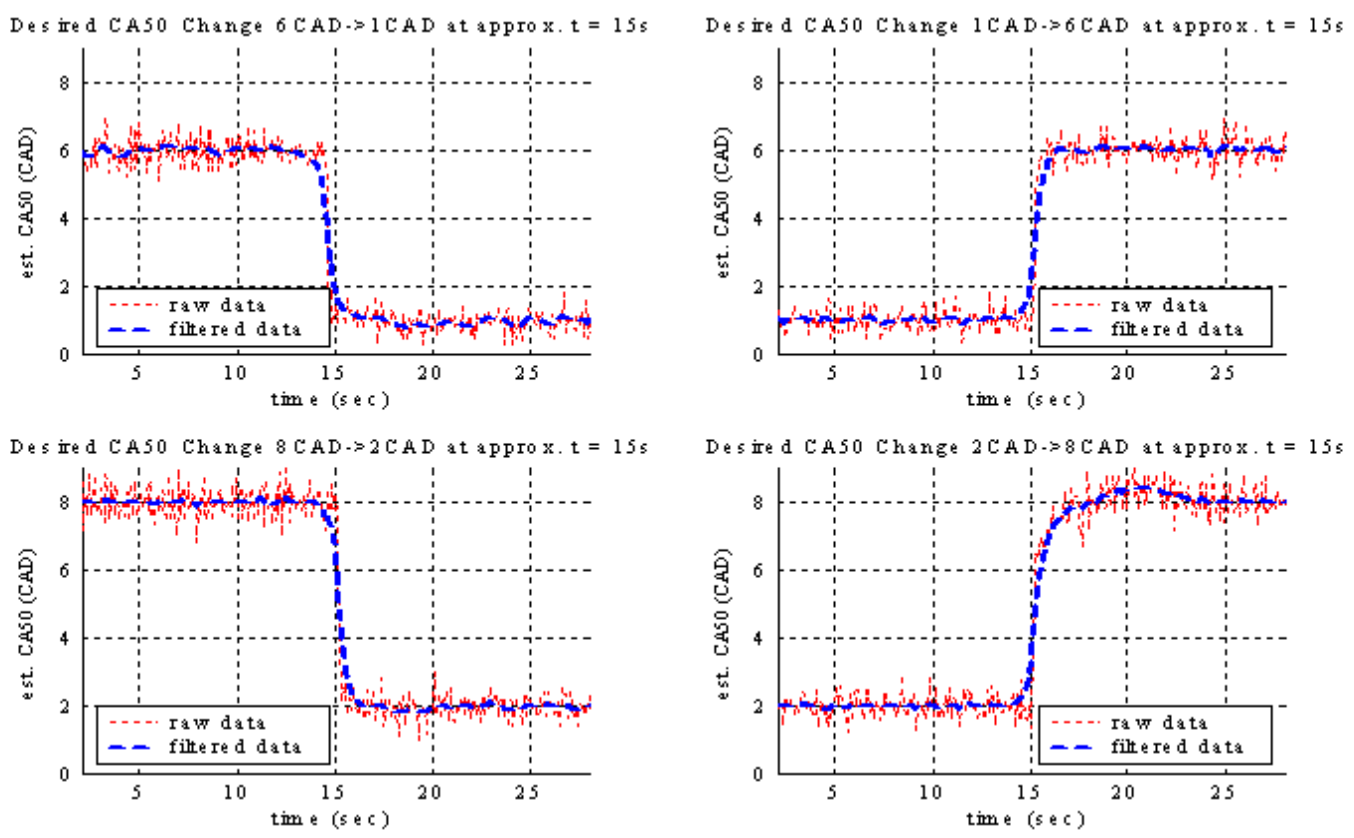

Figure 5: Closed loop control response to change in operational set-point

\subsection{Breathing Design for Multi-Cylinder Engine}

\subsubsection{Boost System Configurations}

For the multi-cylinder ARICE HCCI Engine, two alternatives are considered for engine boosting: turbocharging and supercharging. The schematics of the systems corresponding to these two options are shown in Figure 6 and Figure 7, where $\mathrm{C}=$ compressor, $\mathrm{T}=$ turbine, $\mathrm{I}=$ intercooler, and $\mathrm{EC}=$ exhaust catalyst. 


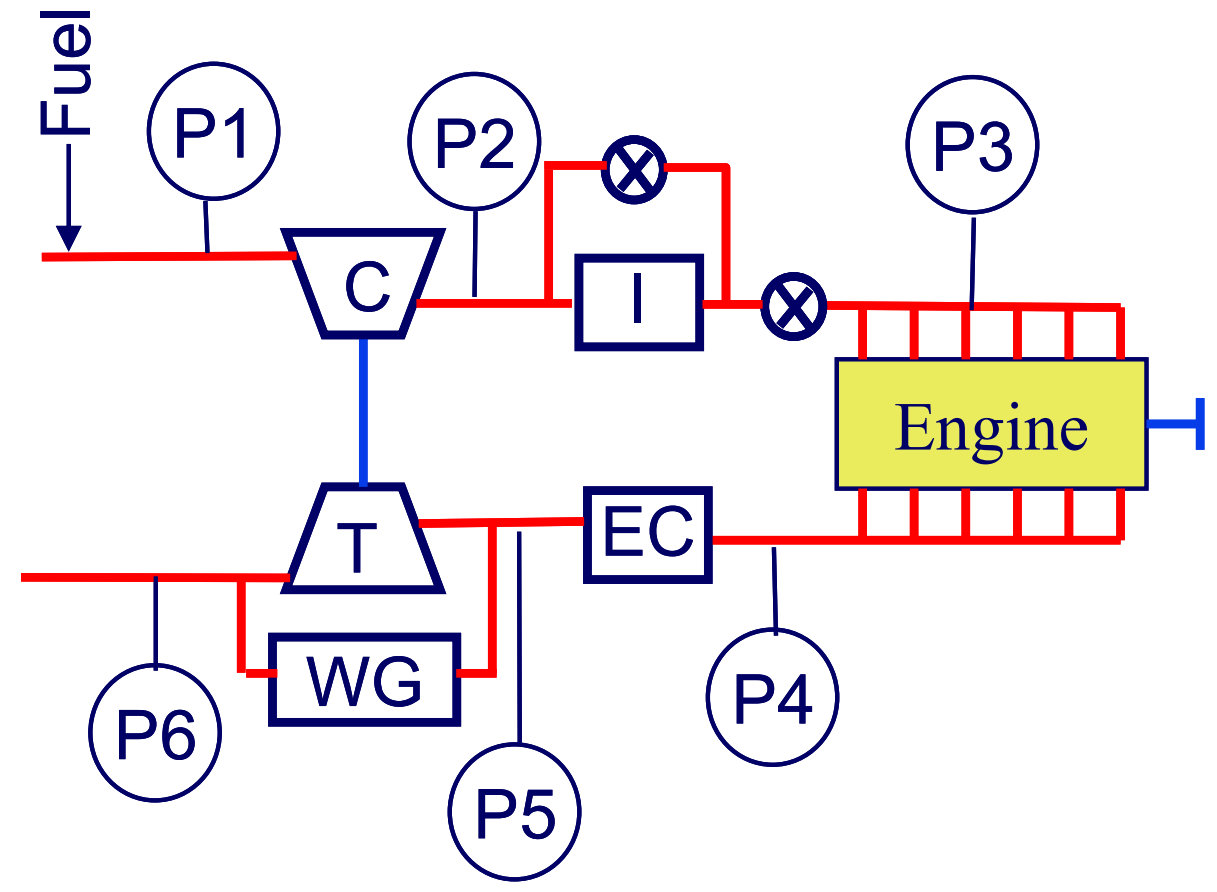

Figure 6: Schematic of the system considered for $\mathrm{HCCl}$ engine turbo charging

For the turbocharged system (Figure 6), the following applies:

- Boost system consists of single stage turbocharger with intercooler.

- Fuel mixed with fresh air upstream of compressor.

- Plenum temperature control (combustion timing) accomplished via intercooler bypass.

- Load following accomplished with combined turbine waste gate and throttle.

- Exhaust catalyst used to increase exhaust gas energy prior to entering turbine. 


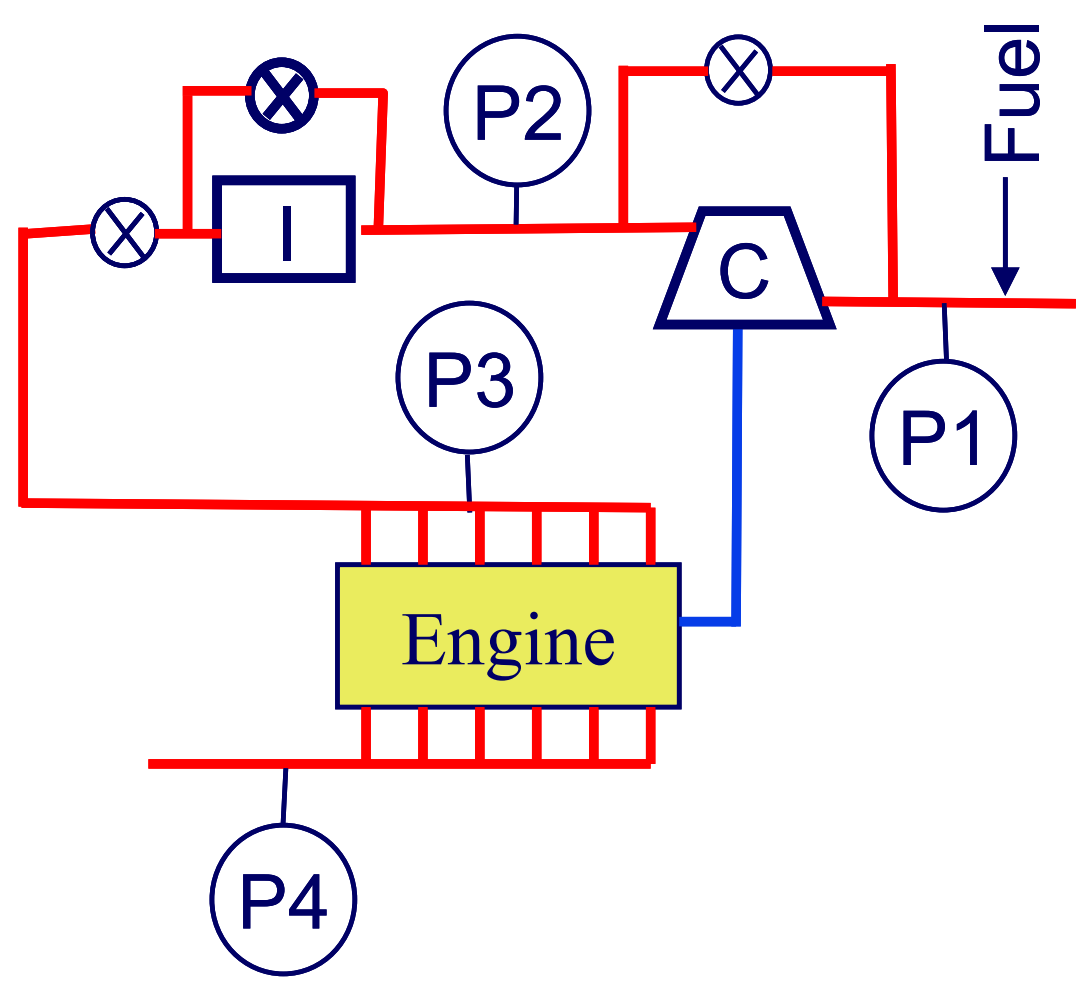

Figure 7: Schematic of the system considered for $\mathrm{HCCl}$ engine supercharging For the supercharged system (Figure 7), the following applies:

- Boost system consists of single supercharger with intercooler.

- Supercharger may be centrifugal, twin screw or roots style

- Twin screw and roots style blowers are "positive displacement" machines

- Fuel mixed with fresh air upstream of compressor.

- Plenum temperature control (combustion timing) accomplished via intercooler bypass.

- Load following accomplished with combined compressor bypass and throttle.

\subsection{2. $\mathrm{HCCl}$ Operation with Existing Turbocharger}

The Caterpillar 3406 was designed to run in spark-ignited mode at a high equivalence ratio $(\sim 1)$ and with a low compression ratio (11:1). It is therefore expected that the existing turbocharger will not be appropriate for HCCI operation. This was quickly verified with WAVE (WAVE is a one-dimensional gas-dynamics model for simulation of engine breathing, developed and licensed by Ricardo Inc.) as it was determined that the existing turbocharger would only provide 1.2-1.3 pressure ratio across the compressor, down from 1.8-2 that is available in SI mode. The pressure ratio in HCCI mode is extremely low. A different turbocharger design has to be used to obtain reasonable performance. 


\subsubsection{Defining $\mathrm{HCCl}$ Turbocharger Performance Targets}

Considering that the existing turbocharger designed for SI operation is not appropriate for HCCI combustion, a thorough performance analysis was conducted using the WAVE code. The main results are shown in Figure 8. Figure 8 shows color contours of brake power in $\mathrm{kW}$, as a function of turbine pressure ratio and compressor pressure ratio., and also shows dotted lines showing brake thermal efficiency and dashed lines with peak cylinder pressure. The production SI engine has a 160 bar peak cylinder pressure limit. However, for a demonstrator, the peak cylinder pressure limit may be increased to the 180-200 bar limit. However, mechanical issues may need to be addressed to increase the peak cylinder pressure limits for a production program.

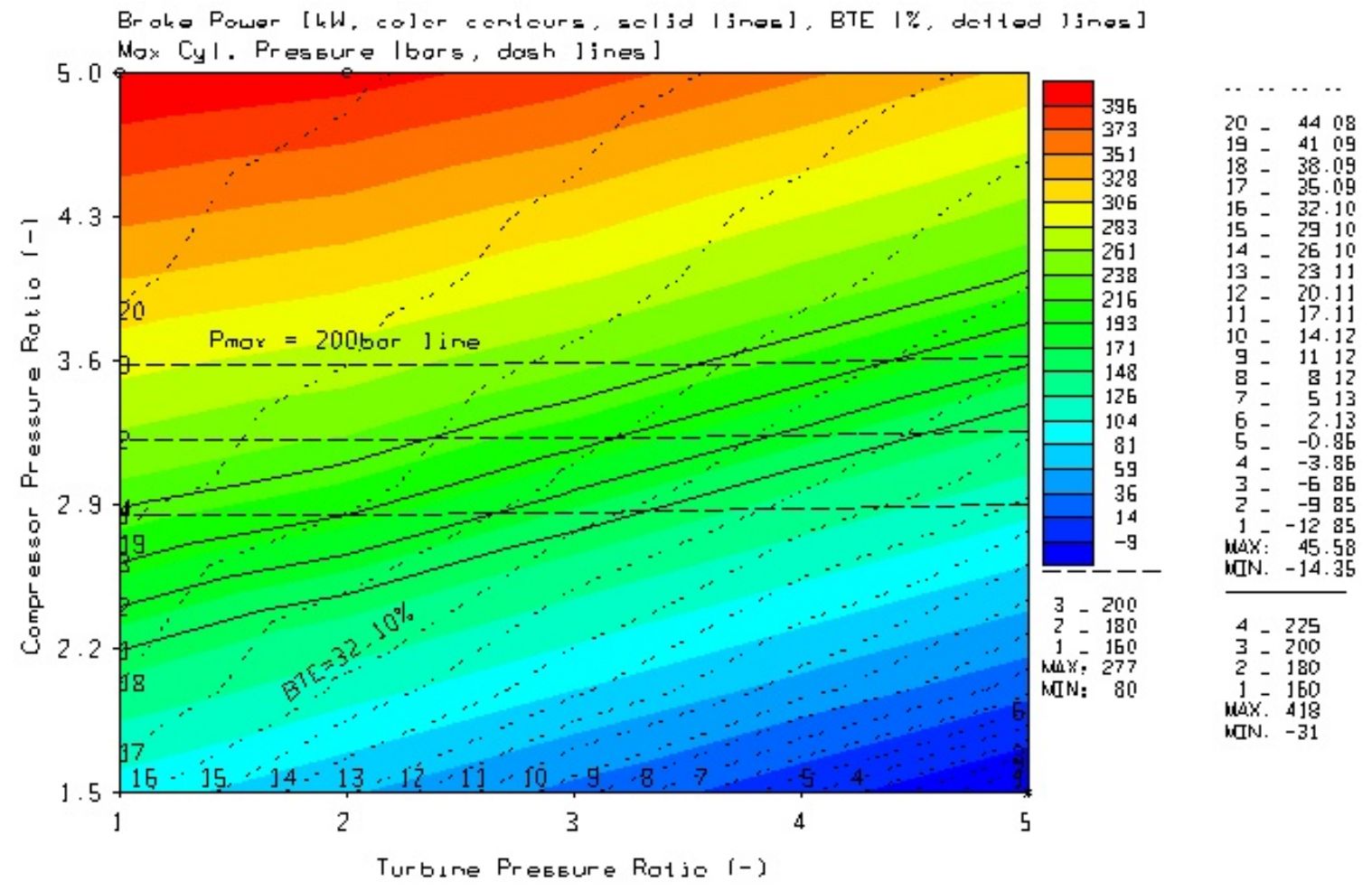

Figure 8: Color contours of engine brake power in $\mathrm{kW}$, as a function of turbine pressure ratio and compressor pressure ratio, with dotted lines showing brake thermal efficiency and dashed lines peak cylinder pressure

Figure 8 shows that no combination of boost pressure or back pressure will produce 225 brake-kilowatts $(\mathrm{bkW})$ without exceeding the 160 bar peak cylinder pressure. Neglecting turbocharger energy balance constraints and increasing the maximum cylinder limit to 200 bar shows that $225 \mathrm{bkW}$ is still possible. However, the engine BTE falls below $36 \%$ for all cases. Increasing to 180 bar is also viable, however, the boost pressure / back pressure trade shows that increasing to only 180 bar will be significantly more challenging for the turbocharger energy balance constraint.

Table 2 shows a summary of the results obtained from WAVE for the HCCI turbocharger. Two cases are analyzed: a conservative case, with a turbocharger 
efficiency known to be obtainable for engines of this size, and an aggressive case, that may be obtained through careful matching of the characteristics of the unit. The table shows that in both cases the engine has considerable power output (165 and $180 \mathrm{~kW}$ ) at reasonable efficiency.

Table 2: Summary of the Results Obtained from WAVE for the $\mathrm{HCCl}$ Turbocharger

\begin{tabular}{|l|c|c|}
\hline \multicolumn{1}{|c|}{ Metric } & Conservative & Aggressive \\
\hline Turbocharger Efficiency & $49 \%$ & $56 \%$ \\
\hline Exhaust Catalysis & Installed & Installed \\
\hline Brake Power & $165 \mathrm{bkW}$ & $180 \mathrm{bkW}$ \\
\hline BTE & $32 \%$ & $32 \%$ \\
\hline Peak Cylinder Pressure & $160 \mathrm{bar}$ & $180 \mathrm{bar}$ \\
\hline Compressor Pressure Ratio & 2.85 & 3.25 \\
\hline Turbine Pressure Ratio & 3.2 & 3.8 \\
\hline Compressor Mass Flow Rate & $0.51 \mathrm{~kg} / \mathrm{sec}$ & $0.57 \mathrm{~kg} / \mathrm{sec}$ \\
\hline Pre-turbine Exhaust Temperature & $385 \mathrm{C}$ & $400 \mathrm{C}$ \\
\hline
\end{tabular}

\subsubsection{Evaluating off-the-Shelf Turbochargers}

Five off-the-shelf turbochargers are evaluated for application to this engine. These are Honeywell, BorgWarner, Holset, Holset as used by the Lund Institute of Technology and Turbonetics. The results of the analysis are summarized next:

- Option 2 (BorgWarner) and Option 3 (Holset HX82) both result in low brake power and BTE. For both cases, the compressor has a reasonable efficiency at the conservative target boost pressure and mass flow, however, the turbine was unable to spin the compressor at the required speed.

- Even though Option 1 (Honeywell) was sized for 33\% of the mass flow, the higher turbine speed offered by the smaller turbine $(55,676 \mathrm{rpm})$ resulted in more power than Option 2 or Option 3.

- Option 4 (Holset HX50 - Lund Institute) did not meet the conservative target of $165 \mathrm{~kW}$ and 32\% Brake Thermal Efficiency (BTE), however did produce $146 \mathrm{~kW}$ and $31 \%$ BTE. The small nozzle area of the prototype turbine resulted in a relative high turbine speed $(\sim 96,000 \mathrm{rpm})$ which enables the compressor to produce boost and the engine to make power. Availability of this option may be an issues as Holset was unable to find the performance maps with the provided Turbine ID number. Discussions with Lund Institute of Technology indicate that the turbine was a prototype unit for a diesel program.

- Option 5 (Turbonetics Super T72 compressor and T04 turbine) performance could not be evaluated because no detailed maps were available. 
As a conclusion, none of the commercially available turbochargers delivered on the desired performance. The best performing turbocharger is Option 4, which is a custom design and therefore not commercially available.

\subsubsection{Defining $\mathrm{HCCl}$ Supercharger Performance Targets}

Looking for a better off the shelf option for the HCCI engine, the WAVE analysis was turned into superchargers. The results are summarized in Figure 9. Figure 9 shows color contours (and solid lines) of engine brake power in $\mathrm{kW}$, as a function of supercharger aerodynamic efficiency and boost pressure, and also includes dotted lines showing brake thermal efficiency and dashed lines with peak cylinder pressure. For typical centrifugal supercharger efficiencies ( $70 \%$ peak efficiency, aerodynamic gear), it appears that $\sim 145 \mathrm{bkW}$ is obtainable with a BTE of $\sim 25.5 \%$, a maximum cylinder pressure of $\sim 170$ bar and a boost pressure of $\sim 3.1$ bar. Increasing boost pressure above $\sim 3.1$ bar can generate slightly more power; however, this increase occurs at the expense of peak cylinder pressure and BTE.

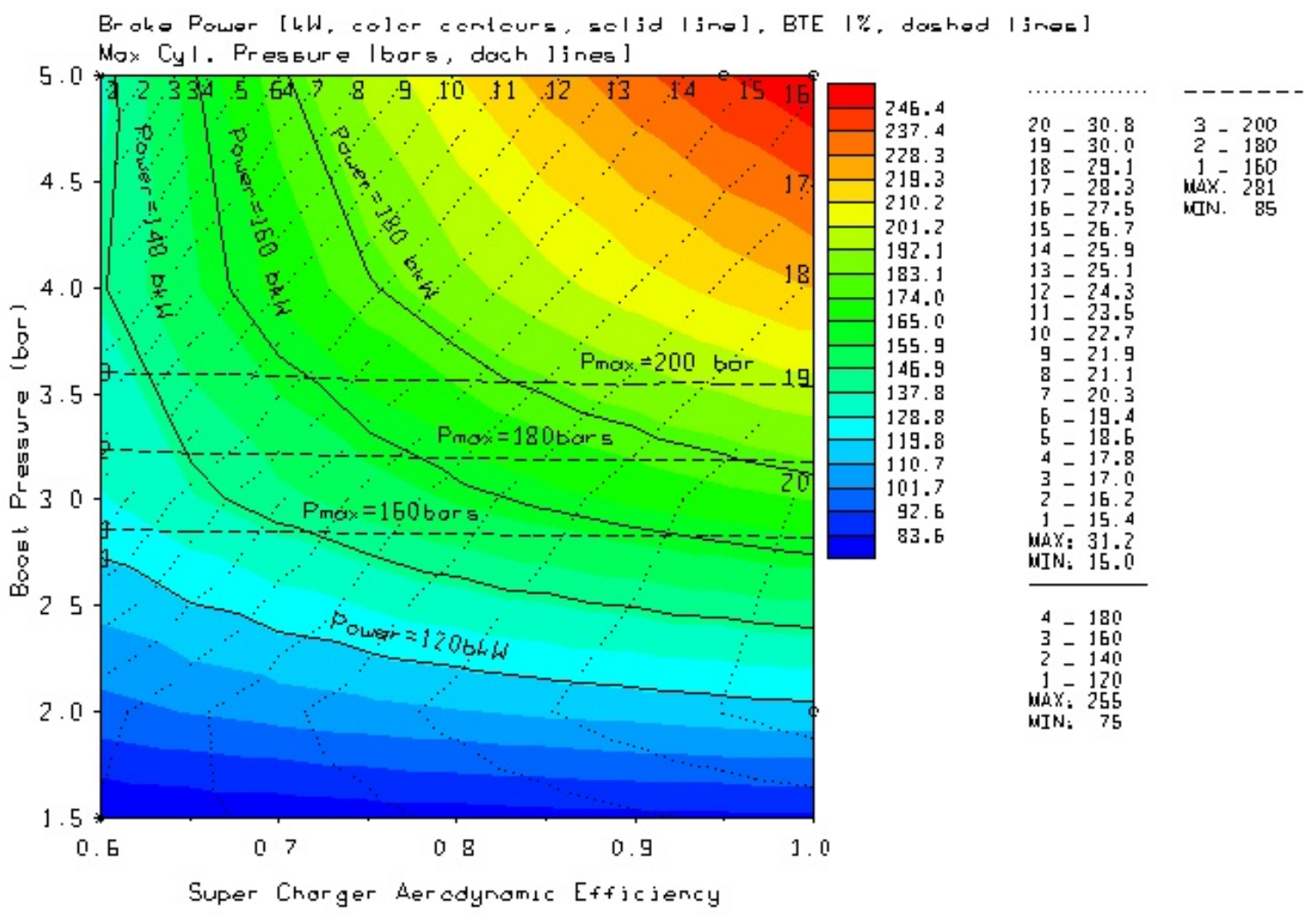

Figure 9: Color contours (and solid lines) of engine brake power in kW, as a function of supercharger aerodynamic efficiency and boost pressure, with dotted lines showing brake thermal efficiency and dashed lines peak cylinder pressure 
For typical roots blower style and twin screw supercharger efficiencies ( $60 \%$ peak efficiency), it appears that $\sim 130 \mathrm{bkW}$ is obtainable with a BTE of $\sim 23 \%$, a maximum cylinder pressure of $\sim 170$ bar and a boost pressure of $\sim 3.1$ bar.

The performance offered by typical supercharger efficiencies is well below the $224 \mathrm{bkW} /$ $44 \%$ BTE program targets due to the shaft power requirements of the supercharger. Increasing supercharger efficiencies would improve the performance of the engine, however, even a 100\% aerodynamic efficiency supercharger would be limited by peak cylinder pressure to $\sim 180 \mathrm{bkW}$ and $\sim 31 \%$ BTE. Supercharged solutions appear only viable with a modification of program goals.

\subsubsection{Evaluating off-the-Shelf Superchargers}

Three types of superchargers are typically available. These are centrifugal, roots or twin screw. Multiple off-the-shelf models of these three designs were evaluated for applicability to the HCCI engine. The designs being investigated are described in Table 3.

A performance map was available for the Rotrex C38-71. Although the operating point for the HCCI engine is not in the "sweet spot" of the map, the unit is capable of meeting flow and pressure targets with a reasonable efficiency. There are potential long term durability concerns.

For the Eaton M112 roots style supercharger, there is a 2.0 bar limit, and therefore this unit cannot meet power target for roots style supercharger (130 bkW). A single M112 unit has low efficiency (44\%) thus leading to reduced engine power and BTE.

Dual M112 units can be used to increase supercharger efficiency to 53\%. However, engine will be limited to $100 \mathrm{bkW}$.

For the Lysholm LYS3300AX twin screw supercharger compressor, there is a 2.2 bar limit. Therefore, this unit cannot meet power target for twin screw style supercharger $(130 \mathrm{bkW})$. There is no performance benefit from using two units in parallel. A single LYS3300AX unit operating point has $66 \%$ efficiency and can produce $\sim 110 \mathrm{bkW}$ engine power and $26.7 \%$ BTE.

The Autorotor OA $3150 \mathrm{M}$ twin screw supercharger compressor has a 3.0 bar limit (with special seal), and it almost meets the 3.1 bar boost pressure target for a screw style supercharger. There is a slight performance benefit when using two units in parallel. The single OA $3150 \mathrm{M}$ unit operating point has $62 \%$ efficiency and can produce $\sim 130$ bkW engine power and $23.5 \%$ BTE.

The Autorotor OA MX424 twin screw supercharger compressor has a 2.3 bar limit (with special seal). Therefore it cannot meet power target for twin screw style supercharger $(130 \mathrm{bkW})$. No performance benefit exists when using two units in parallel. The single MX424 unit operating point has 58\% efficiency and can produce $\sim 105 \mathrm{bkW}$ engine power and 25\% BTE. 
Table 3: Supercharger Models Being Investigated

\begin{tabular}{|c|c|c|c|}
\hline Type & Supplier & Recommended Unit & Comment \\
\hline \multirow{4}{*}{ Centrifugal } & ATI Procharger & None & $\begin{array}{l}\text { Supplier products tailored to provide boost at much higher flows and lower } \\
\text { endurance. No hardware that matches requirements }\end{array}$ \\
\hline & Powerdyne & None & $\begin{array}{l}\text { Supplier focuses on street applications, flow and pressure targets higher than } \\
\text { products offered. }\end{array}$ \\
\hline & Paxton / Vortech & None & No response to requests \\
\hline & Rotrex & C38-81 & Denmark based company. 6 weeks lead time. \\
\hline \multirow{5}{*}{ Roots } & $\mathrm{DDC}$ & $\begin{array}{c}\text { 8V92 } \\
\text { PN } 8927041\end{array}$ & $\begin{array}{l}\text { DDC considers all data on their roots style blower proprietary. Review of engine } \\
\text { data using } 8 V 92 \text { indicates that it can provide sufficient flow at } 1 \text { bar gauge boost } \\
\text { pressure and reasonable blower speeds. DDC has confirmed it can operate with } \\
\text { higher pressure ratios. }\end{array}$ \\
\hline & Eaton & M112 & $\begin{array}{l}\text { Industry standard for roots style blower. Performance data is available and units } \\
\text { have proven reliability. Units are limited to } 2.0 \text { bars boost. Recommended units are } \\
\text { largest units available. Even with reduced boost level, two units in parallel will be } \\
\text { required to meet flow targets and achieve reasonable efficiency. }\end{array}$ \\
\hline & Kuhl & $14-71$ & $\begin{array}{l}\text { MotorSports focused company. No performance data to verify recommended size. } \\
\text { Largest units available. Able to run "dry" with reduced efficiency (increased tip } \\
\text { clearances). Willing to modify casting for improved performance at high boosts. } \\
\text { Willing to work on "research type" program. }\end{array}$ \\
\hline & Kocoa & $16-71$ & $\begin{array}{l}\text { MotorSports focused company. No performance data to verify recommended size. } \\
\text { Largest units available. Unable to run "dry". Not a viable solution since unit can not } \\
\text { run "dry" }\end{array}$ \\
\hline & $\begin{array}{l}\text { Blower drive } \\
\text { service }\end{array}$ & $16-71$ & $\begin{array}{l}\text { No performance data to verify recommended size. Largest units available. Unable } \\
\text { to run "dry". Company focuses on street applications. Not a viable solution since } \\
\text { unit can not run "dry" }\end{array}$ \\
\hline \multirow{3}{*}{ Twin screw } & Lysholm & LYS3300AX & $\begin{array}{l}\text { Industry standard for twin screw supercharger. Maximum pressure ratio of stock } \\
\text { unit is } 2.2 \text { Bar/Abs. Largest units is ideal as peak efficiency is at lower part of map. } \\
\text { Circulating oil to compressor gear-box Even with reduced boost level, two units in } \\
\text { parallel will be required to meet flow targets and achieve reasonable efficiency. }\end{array}$ \\
\hline & Autorotor & QA 3150 & $\begin{array}{l}\text { Industry standard for twin screw supercharger. With special seal, can go provide } \\
\text { boost upto } 3.0 \text { bars. Would require } 2 \text { units to meet flow target. }\end{array}$ \\
\hline & Autorotor & QA424MX & $\begin{array}{l}\text { Industry standard for twin screw supercharger. With special seal, can provide boost } \\
\text { upto } 2.3 \text { Bars. }\end{array}$ \\
\hline
\end{tabular}

In summary, the Rotrex C38 trim 81 and single Autorotor OA3150 with special high pressure seal appear to be the best options for a supercharger. The Rotrex C38 trim 81 internal gear ratio of 7.5:1 and $100 \mathrm{k}$ operating speeds will require a significant step up from the engine crank. Plus, the $100 \mathrm{k}$ speed is in excess of the $90 \mathrm{k}$ speed limit quoted on the supplier's website. The Single Autorotor OA3150 has a maximum boost pressure of 3.0 bar which is slightly below the target boost pressure. The input speed of this unit is similar to the input speed of the Rotrex C38 trim 81 unit. Control issues may be the deciding factor in identifying the best supercharger for the research program.

\subsubsection{Evaluating the Benefits of Modified Intake/Exhaust Manifold}

Conventional wisdom for boosted engines is that designing a manifold for tuning provides small benefits compared to incurred pumping losses and, hence, it is best to keep pipe runner lengths short to minimize pumping losses. In addition, intake manifold plenum volumes are typically as small as possible to improve transient response.

Considering that HCCI engines are very sensitive to cylinder-to-cylinder variations, designing the intake and exhaust system to achieve reduced cylinder-to-cylinder variations may be an acceptable trade-off for increased pumping loses. Plus, larger intake manifold plenum volumes can be used to reduce the interaction between cylinder runners. 
For a concept HCCI intake and exhaust manifolds, several manifold dimensions can be varied on an intake or exhaust manifold to improve cylinder-to-cylinder variations. These attributes are identified below.

- Intake runner length

- Intake runner inlet diameter

- Intake plenum

- Exhaust primary runner length

- Exhaust secondary runner length

The HCCI WAVE models were modified to reflect two intake/exhaust manifold configurations and sensitivity studies were conducted to quantify the relationship between performance and manifold dimensions with a $\sim 50^{\circ} \mathrm{C}$ manifold air temperature.

The results indicate that with a 14.6 liter intake plenum and a 72 millimeter $(\mathrm{mm})$ intake primary runner diameter (no taper), a tuning point was identified with a $775 \mathrm{~mm}$ primary intake runner length and $100 \mathrm{~mm}-300 \mathrm{~mm}$ primary exhaust runner length. This point also has relatively low cylinder-to-cylinder volumetric efficiency and residual variations. The short primary exhaust runner length may indicate that a production SI manifold may also result in good performance. The volumetric efficiency and residual cylinder to cylinder variations were significantly lower than the variations noted with the production SI manifolds and the same turbocharger. This indicates that the conceptual manifolds are effective at reducing cylinder to cylinder variations

\subsubsection{Boost System Selection Recommendations}

Multiple boost systems and manifold configurations for the Lawrence Livermore National Laboratory CAT 3406 HCCI research engine have been evaluated using the 1-D gas dynamics code WAVE. Estimated engine level performance and boost system performance targets have been identified based on reasonable boost system component performance parameter and are summarized in Table 4.

No boost system investigated exceeded either the brake power or brake thermal efficiency program target with the given constraints. It is recommended that program targets be revised to reflect insights obtained during this investigation. 
Table 4: Summary of the Options Evaluated for Turbocharging and Supercharging of the HCCl Engine.
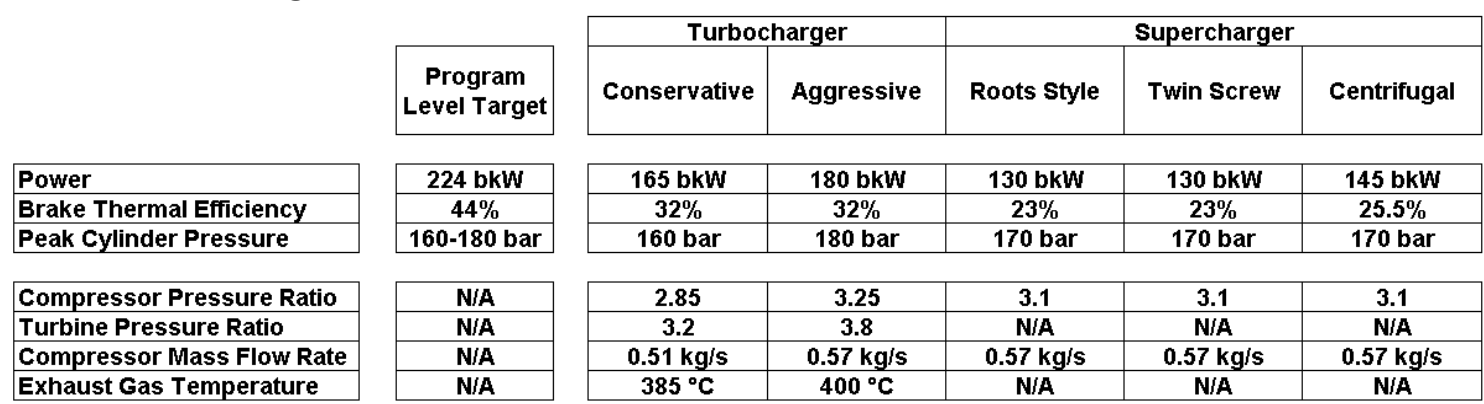

\begin{tabular}{|c|c|c|c|c|}
\hline $165 \mathrm{bkW}$ & $180 \mathrm{bkW}$ & $130 \mathrm{bkW}$ & $130 \mathrm{bkW}$ & $145 \mathrm{bkW}$ \\
\hline $32 \%$ & $32 \%$ & $23 \%$ & $23 \%$ & $25.5 \%$ \\
\hline $160 \mathrm{bar}$ & $180 \mathrm{bar}$ & $170 \mathrm{bar}$ & $170 \mathrm{bar}$ & $170 \mathrm{bar}$ \\
\hline \multicolumn{5}{|c|}{} \\
\hline 2.85 & 3.25 & 3.1 & 3.1 & 3.1 \\
\hline 3.2 & 3.8 & N/A & N/A & N/A \\
\hline $0.51 \mathrm{~kg} / \mathrm{s}$ & $0.57 \mathrm{~kg} / \mathrm{s}$ & $0.57 \mathrm{~kg} / \mathrm{s}$ & $0.57 \mathrm{~kg} / \mathrm{s}$ & $0.57 \mathrm{~kg} / \mathrm{s}$ \\
\hline $385^{\circ} \mathrm{C}$ & $400^{\circ} \mathrm{C}$ & N/A & N/A & N/A \\
\hline
\end{tabular}

Several turbocharger and supercharger boost system options have been identified for the CAT 3406 HCCI research engine. For the HCCI research engine, there appears to be no clear "best" boost system as some approaches have better performance, but also higher technical risks for this project. The down selection process will require a program level decision considering the cost, schedule, performance, and risk elements associated with each option.

Given the low exhaust gas energy associated and the high unburned hydrocarbons with HCCI combustion systems, using a pre-turbine exhaust catalysis to maximize turbine work was beneficial and is recommended for the test program.

Intake and exhaust manifolds designs were evaluated and it was shown that significant reductions in cylinder to cylinder variations and an increase in brake power could be obtained at a cost of reduced brake thermal efficiency. Given the sensitivity of HCCI combustion to cylinder-to-cylinder variations, this tradeoff is considered reasonable for the research program. However, it should be evaluated again at a later date. Key manifold dimensions were identified to provide the best trade-off between cylinder-tocylinder variations, engine power, and brake thermal efficiency.

\subsection{Multi-Cylinder Engine Set-Point Optimization}

A numerical model has been applied to optimizing the operational set point for the multi-cylinder HCCI engine. Figure 10 shows a schematic of the thermal control system for the stationary ARICE HCCI engine. While the system looks complex, it should be noticed that stationary engines typically include a turbocharger, intercooler, and catalytic converter. Only the heater is introduced in addition to typical engine components. The system is analyzed under the following set of assumptions.

- The engine operates at steady-state conditions. The problem of transitioning between operating points is not considered.

- The engine runs at a constant speed (1800 rpm). 
- The volumetric efficiency is $100 \%$. This is assumed because the engine operates at a constant speed and the intake manifold can be designed for optimum breathing at this speed.

- Thermal losses in ducts are assumed negligible.

- Pressure drop in heat exchangers is negligible.

The combustion efficiency is given by the following expression:

$$
\begin{array}{ll}
\eta_{c}=0.94 & \text { if } \theta_{\max }<0 \\
\eta_{c}=0.94-0.00667 \theta_{\max } & \text { if } \theta \max \geq 0
\end{array}
$$

where $\eta_{c}$ is the combustion efficiency and $\theta_{\max }$ is the crank angle in degrees for maximum heat release $\left(\theta_{\max }=0\right.$ at TDC, $\theta_{\max }>0$ after TDC). This expression is obtained from the experimental results (Christensen et al. 1998).

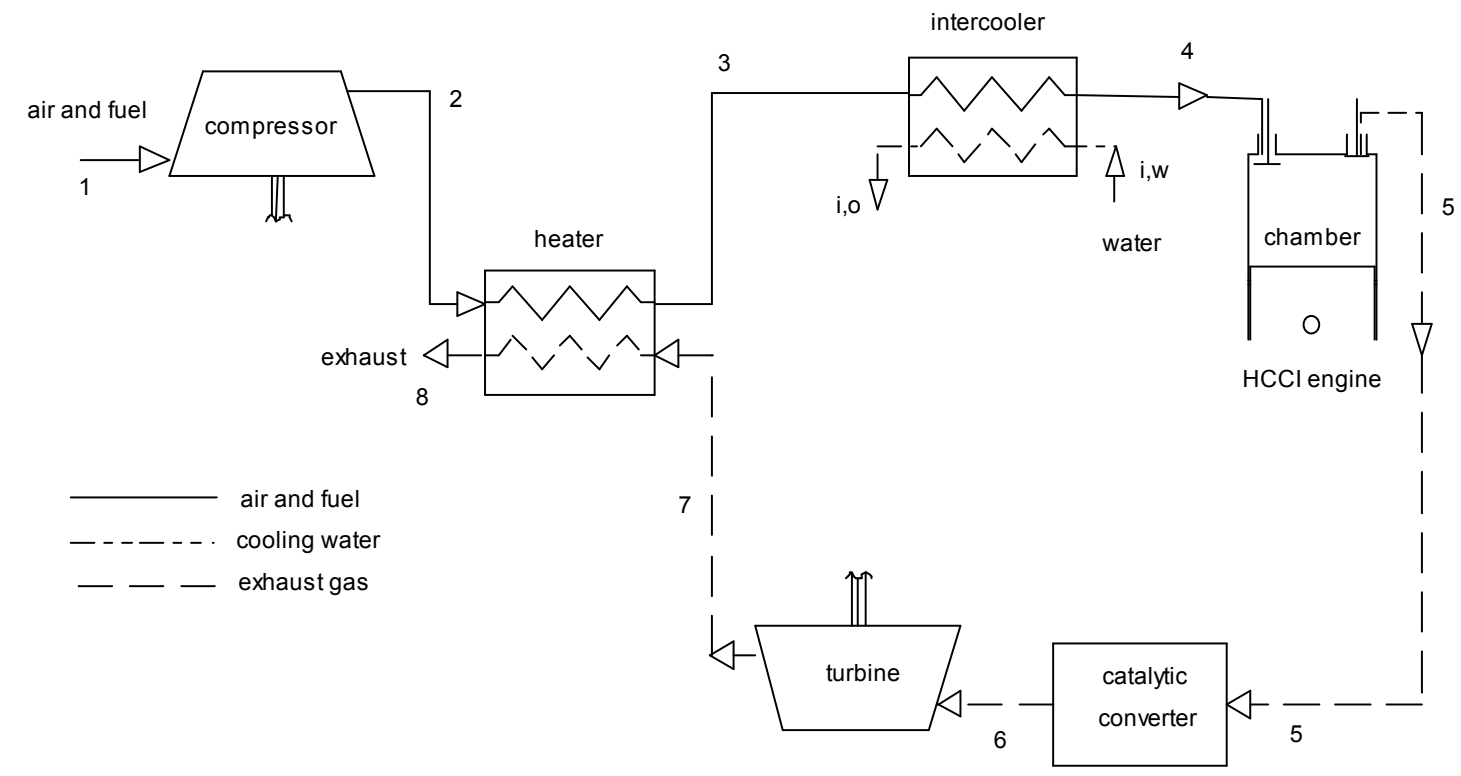

Figure 10: Schematic of the thermal control system for the $\mathrm{HCCl}$ engine

The characteristics of the engine and the natural gas fuel used in the analysis are given in Table 5. The dimensions of the engine correspond to the Caterpillar 3406 engine, which is the engine being converted to HCCI mode at LLNL. The following sections describe the models used for analyzing the different system components. 
Table 5: Main Characteristics of the Caterpillar 3406 6-Cylinder Engine Used for the $\mathrm{HCCl}$ Experiments and Composition of the Natural Gas Fuel

\begin{tabular}{|l|c|}
\hline \multicolumn{2}{|c|}{ Characteristics } \\
\hline \multicolumn{2}{|c|}{ Engine Geometric Properties } \\
\hline Displaced volume per cylinder & $2400 \mathrm{~cm}^{3}$ \\
\hline Bore & $137 \mathrm{~mm}$ \\
\hline Stroke & $165 \mathrm{~mm}$ \\
\hline Connecting rod length & $262 \mathrm{~mm}$ \\
\hline Engine speed & $1800 \mathrm{rpm}$ \\
\hline Geometric compression ratio & $16: 1$ \\
\hline Natural Gas Composition, Volume \% & \\
\hline Methane & 91.1 \\
\hline Ethane & 4.7 \\
\hline Propane & 1.7 \\
\hline n-Butane & 1.4 \\
\hline Nitrogen & 0.6 \\
\hline Carbon dioxide & 0.5 \\
\hline
\end{tabular}

\subsection{1. $\mathrm{HCCl}$ Engine Model}

Combustion in the HCCI engine is analyzed using the chemical kinetics code CHEMKIN (Kee et al. 1996). The reaction mechanism used in this work includes species through $C_{4}$ (Pitz et al. 1991), and models natural gas auto ignition chemistry. The mechanism includes $\mathrm{NO}_{x}$ kinetics from the Gas Research Institute mechanism version 1.2, (Frenklach et al. 1995). The chemical kinetic reaction mechanisms used by the model for natural gas ignition and $\mathrm{NO}_{x}$ production have been extremely well established and are widely used. The mechanism includes 179 species and 1125 chemical reactions.

For this analysis, CHEMKIN is used in single zone mode. This assumes that the mass inside the cylinder is at a uniform temperature and composition. Previous publications (Aceves et al. 2000) have shown that a multi-zone model can yield better predictions for engine performance than a single zone model. However, the computational requirements of the multi-zone model make it impossible to conduct the great number of runs required to generate an engine performance map. The single zone model can predict the conditions necessary for HCCI ignition, and it is therefore appropriate for 
this application. However, it is necessary to keep in mind that the single zone model overestimates peak cylinder pressure and $\mathrm{NO}_{x}$ emissions (Aceves et al. 2000).

The computational model treats the combustion chamber as a homogeneous reactor with a variable volume. The mixed temperature of the residual gases and the fresh charge is estimated by a published procedure (Heywood 1988). The volume is changed with time using a Slider-Crank equation. The heat transfer submodel employed in the CHEMKIN code simulations uses the Woschni correlation (Woschni 1967). The cylinder wall, piston and head are all assumed to be at a uniform $430 \mathrm{~K}$. The model calculates the fraction of residual gases, which is a function of the operating conditions. There is no intentional EGR. Exhaust temperature is determined from the temperature of the combustion products at the time of exhaust valve opening (obtained from CHEMKIN) and a thermodynamic model for the gas expansion into the exhaust (Woschni 1967). Engine friction calculations are based on a literature method (Patton et al. 1989). This model generates an estimate for FMEP, which is then subtracted from the engine IMEP to obtain the engine BMEP.

\subsubsection{Exhaust Heat Recovery}

The heater is a heat exchanger located between the exhaust gas and the intake mixture of air and fuel. Intake air flows into the heater after flowing through the compressor. Thermal energy of the exhaust gas is used to increase the temperature of the intake mixture. The heater is used mainly at low power conditions or at idle, where the intake air is not heated enough by compression. Under these conditions, the intake air may be too cold to react if it is not heated. The performance of the heater is specified through its effectiveness, defined as:

$$
\varepsilon_{h}=\frac{\left(\dot{m} c_{p}\right)_{0}\left(T_{3}-T_{2}\right)}{\left(\dot{m} c_{p}\right)_{\text {min }}\left(T_{7}-T_{2}\right)}
$$

where subscripts 2, 3 and 7 indicate locations in Figure 10, and $\left(\mathrm{mc}_{\mathrm{p}}\right)_{\mathrm{min}}$ is the minimum of $\left(\mathrm{mc}_{\mathrm{p}}\right)_{2}$ and $\left(\mathrm{mc}_{\mathrm{p}}\right)_{7}$. In this case the minimum heat capacity rate $\left(\mathrm{mc}_{\mathrm{p}}\right)_{\mathrm{min}}$ is equal to the heat capacity rate of the intake fuel-air mixture $\left(\mathrm{mc}_{\mathrm{p}}\right)_{0}$. Therefore Eq. $(2)$ can be expressed as,

$$
\mathrm{T}_{3}=\mathrm{T}_{7} * \varepsilon_{\mathrm{h}}+\mathrm{T}_{2}\left(1-\varepsilon_{\mathrm{h}}\right)
$$

Pressure drop through the heater is neglected.

\subsubsection{Turbocharger}

The turbocharger is necessary to increase the engine power output. The compressor has the additional effect of heating the engine charge, which may be necessary to obtain combustion under some conditions. Equation (4) relates conditions upstream (state 1 in Figure 10) and downstream (state 2) of the compressor, 


$$
T_{2}=T_{1}\left(\frac{P_{2}}{P_{1}}\right)^{\frac{\gamma_{1}-1}{\gamma_{1} \eta_{p c}}}
$$

where $\gamma_{1}$ is the ratio $c_{\mathrm{p}} / \mathrm{c}_{\mathrm{v}}$ in state 1 , and $\eta_{\mathrm{pc}}$ is the polytropic efficiency, assumed to be equal to 0.8 (Wilson 1993). A polytropic efficiency of $80 \%$ corresponds to an isentropic efficiency in the range of $55-70 \%$, which is similar to the range of isentropic efficiencies found in automotive compressors (Heywood 1988). For the turbine, a similar equation is used (Eq. 5), with the same polytropic efficiency $\eta_{\mathrm{pt}}=0.8$.

$$
\mathrm{T}_{7}=\mathrm{T}_{6}\left(\frac{\mathrm{P}_{7}}{\mathrm{P}_{6}}\right)^{\frac{\left(\gamma_{6}-1\right)^{*} \eta_{\mathrm{p}} \mathrm{t}}{\gamma_{6}}}
$$

\subsubsection{Intercooler}

The intercooler is necessary under some conditions to control the auto ignition timing. The compressor increases the pressure and temperature of the fuel-air mixture and this may excessively advance heat release. Under these conditions, it is necessary to cool the mixture to obtain auto ignition at the right time. In the intercooler, the hot intake gases cool down by transferring heat to the water from the cooling system. The intercooler effectiveness is given by:

$$
\varepsilon_{i}=\frac{\left(\dot{m} c_{p}\right)_{4}\left(T_{3}-T_{4}\right)}{\left(\dot{m} c_{p}\right)_{\min }\left(T_{3}-T_{i, w}\right)}
$$

in this case the minimum heat capacity rate $\left(\mathrm{mc}_{\mathrm{p}}\right)_{\mathrm{min}}$ is equal to the heat capacity rate of the mixture at the intercooler intake, $\left(\mathrm{mc}_{\mathrm{p}}\right)$ 4. Eq. (6) then reduces to,

$$
T_{4}=T_{i, w} * \varepsilon_{i}+T_{3}\left(1-\varepsilon_{i}\right)
$$

The analysis neglects pressure drop through the intercooler. The cooling water temperature $\left(\mathrm{T}_{\mathrm{i}, \mathrm{w}}\right)$ is assumed constant and equal to $373 \mathrm{~K}$.

\subsubsection{System Optimization}

Optimizations were conducted for twenty different operating points by following the next procedure.

1. CHEMKIN was used to generate a lookup table that produces results for engine brake thermal efficiency, combustion timing, peak cylinder pressure and $\mathrm{NO}_{\mathrm{x}}$ emissions when the conditions for the run are provided (pressure and temperature at the beginning of the compression stroke, equivalence ratio, and EGR). The ranges used to create the lookup table are: temperature from 420-490 
$\mathrm{K}$, pressure from 50 kilopascals $(\mathrm{kPa})$ to $350 \mathrm{kPa}$, equivalence ratio from 0.2 to 0.45 , and EGR from 0.01 to 0.1 . The lookup table has 3024 data points.

2. A four-dimensional linear interpolation was developed to use the lookup table information in the system simulation computer code.

3. An optimizer is used to determine operating conditions that result in optimum brake thermal efficiency for $1800 \mathrm{rpm}$ and different values of brake power.

For optimization of engine operating conditions, the lookup table from CHEMKIN is linked to an equation solver and optimizer (Klein and Alvarado 2002). The optimization is conducted with four decision variables that can be adjusted to obtain the desired power output, while maintaining satisfactory combustion and emissions. The four decision variables and their allowable ranges are:

1. Fuel-air equivalence ratio, $0.1 \leq \phi \leq 0.45$

2. Heater effectiveness (Eq. 2), $0 \leq \varepsilon_{\mathrm{h}} \leq 0.6$

3. Turbocharger outlet pressure (Eq. 4$), 1$ bar $\leq \mathrm{P}_{3} \leq 3.5$ bar

4. Intercooler effectiveness (Eq. 6), $0 \leq \varepsilon_{i} \leq 0.6$

The heater and the intercooler are not used at the same time. When $\varepsilon_{\mathrm{h}}>0, \varepsilon_{\mathrm{i}}=0$, and when $\varepsilon_{\mathrm{i}}>0, \varepsilon_{\mathrm{h}}=0$. Two constraints are also introduced in the analysis. These are:

1. NOx concentration in the exhaust is less than 2 parts per million (ppm), which converts to $0.015 \mathrm{~g} / \mathrm{bhp}-\mathrm{hr}(=0.02 \mathrm{~g} / \mathrm{kWh}$, the emissions target).

2. The peak cylinder pressure is less than 220 bar. This value is the reported maximum allowable pressure for the Caterpillar 3406 (Hiltner et al 2002).

Three different optimizations are done for different operating conditions.

1. For zero power (idle), the optimizer finds the conditions for minimum fuel consumption.

2. For any given non-zero power, the optimizer maximizes the brake thermal efficiency of the system.

3. To determine the maximum power, the optimizer maximizes power with no concern for efficiency. However, the peak cylinder pressure and $\mathrm{NO}_{x}$ restrictions still have to be met.

The analysis presented here uses simplified models for turbocharger, heater, and intercooler, and the engine is analyzed with a single-zone detailed chemical kinetics 
code (CHEMKIN). It is recognized that the simplifying assumptions introduced here may not reflect actual conditions in a real engine. However, the results are expected to guide the experiments to be conducted in the LLNL engine operating in HCCI mode. If more accuracy is desired, the simplified component models can be replaced by detailed models or by empirical performance maps, resulting in an engine system model that can make accurate predictions for the engine.

\subsubsection{Analysis Results}

Figure 11, Figure 12, and Figure 13 show the values of the decision variables that result in optimum engine efficiency. Figure 11 shows heater effectiveness and intercooler effectiveness as a function of brake power. For idle operation, the intake temperature has to be increased to obtain satisfactory combustion. This requires a high heater effectiveness (0.6). From this point, the heater effectiveness decreases steadily. Operation of the turbocharger compresses the charge and increases its temperature. Therefore, less heating is required as the intake pressure increases. For high intake pressures, the temperature after compression is high, and the heater is no longer needed. Instead, the intercooler has to be operated to achieve satisfactory combustion. The intercooler is first

operated when the brake power is $151 \mathrm{~kW}$, and the maximum intercooler effectiveness is 0.58 at maximum power. 


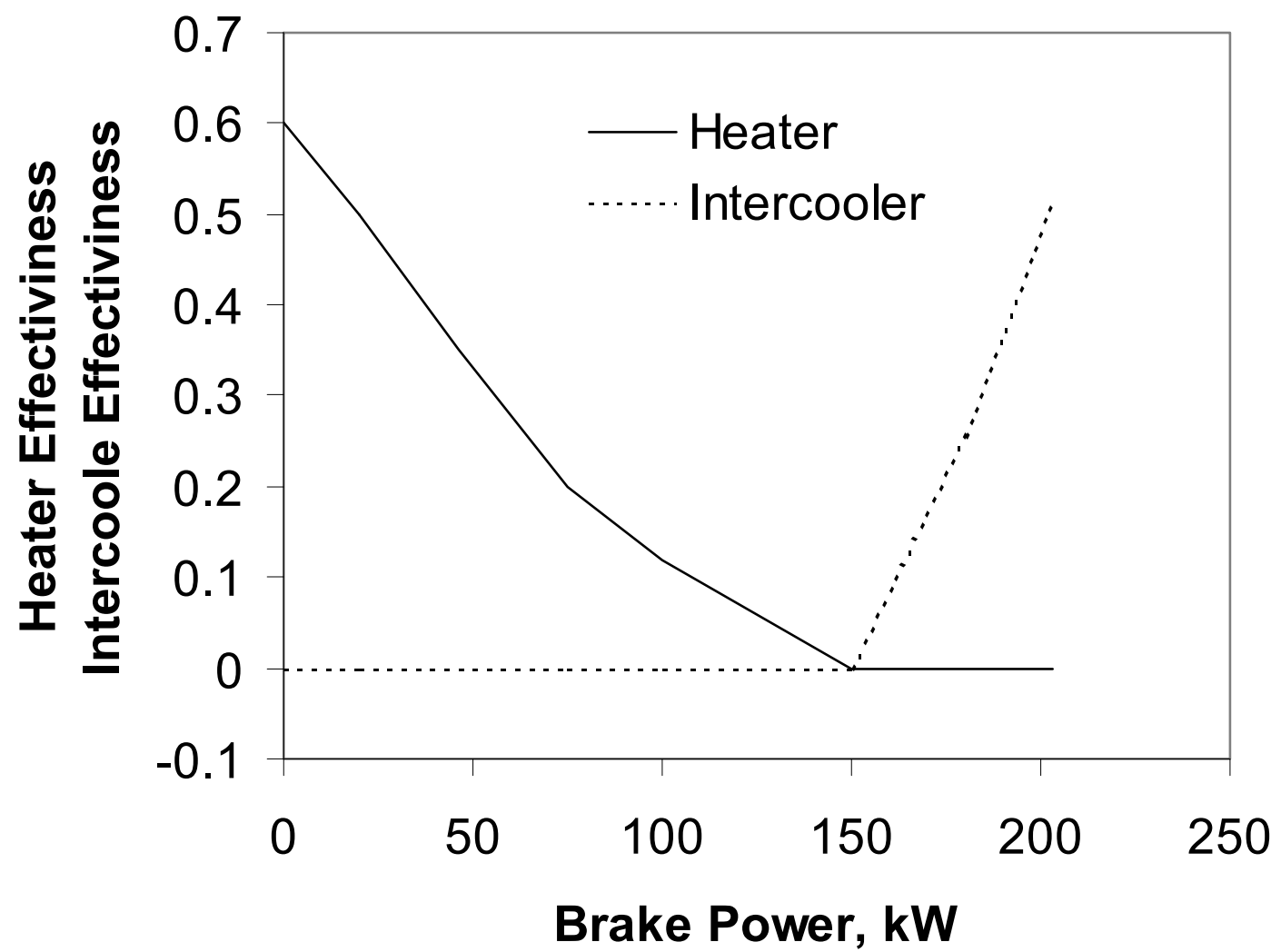

Figure 11: Optimum heater and intercooler effectiveness as a function of brake power for $1800 \mathrm{rpm}$, where solid line shows the heater effectiveness and the dotted line shows the intercooler effectiveness

The equivalence ratio that results in optimum engine efficiency is shown in Figure 12 as a function of engine brake power. The equivalence ratio is kept at a low value (0.22) until the power reaches $80 \mathrm{~kW}$, and then it increases smoothly, reaching a maximum value of 0.28 for maximum power $(203 \mathrm{~kW})$. The equivalence ratio remains extremely low throughout the whole operating range due to the very strict restriction on $\mathrm{NO}_{x}$ emissions ( $2 \mathrm{ppm}$ ). As previously discussed, the single zone model used here to analyze HCCI combustion tends to predict a very sudden combustion, and therefore it is likely to overpredict $\mathrm{NO}_{x}$ emissions. Therefore, in the experimental engine it is likely that the equivalence ratio can be increased above 0.3 while still meeting the $\mathrm{NO}_{x}$ restriction. 


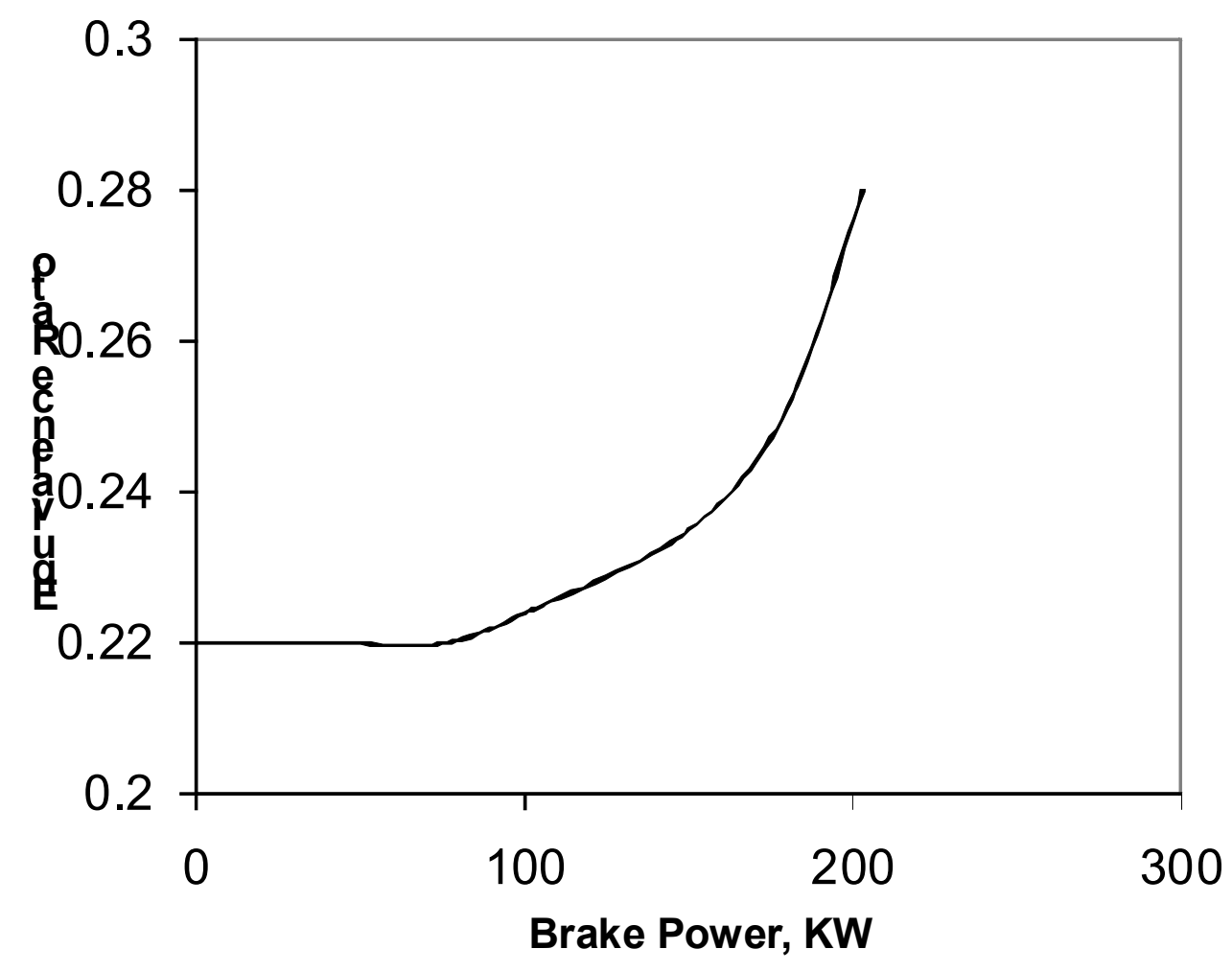

Figure 12: Equivalence ratio as a function of brake power for optimum operating conditions for the engine, at $1800 \mathrm{rpm}$

Figure 13 shows the HCCI engine intake pressure (turbocharger outlet pressure) and the intake gas temperature as a function of engine brake power. Intake pressure is shown with a dotted line and temperature is shown with a solid line. The pressure line (dotted) shows that from idle to $20 \mathrm{~kW}$ it is optimum to operate the engine with atmospheric intake. The turbocharger is then used to increase the intake pressure as power increases. The maximum allowable inlet pressure $(350 \mathrm{kPa})$ is reached at $160 \mathrm{~kW}$, and the inlet pressure remains constant as the power is further increased.

The temperature (solid) line in Figure 13 shows that substantial preheating is required to achieve ignition at low power conditions, due to the low equivalence ratio (Figure 12) and low intake pressure. As the power increases, the intake temperature drops from 498 $\mathrm{K}$ at idle to $425 \mathrm{~K}$ for maximum power $(203 \mathrm{~kW})$. This is due to the higher equivalence ratio, the high intake pressure, and the high temperature of the residual gases. 


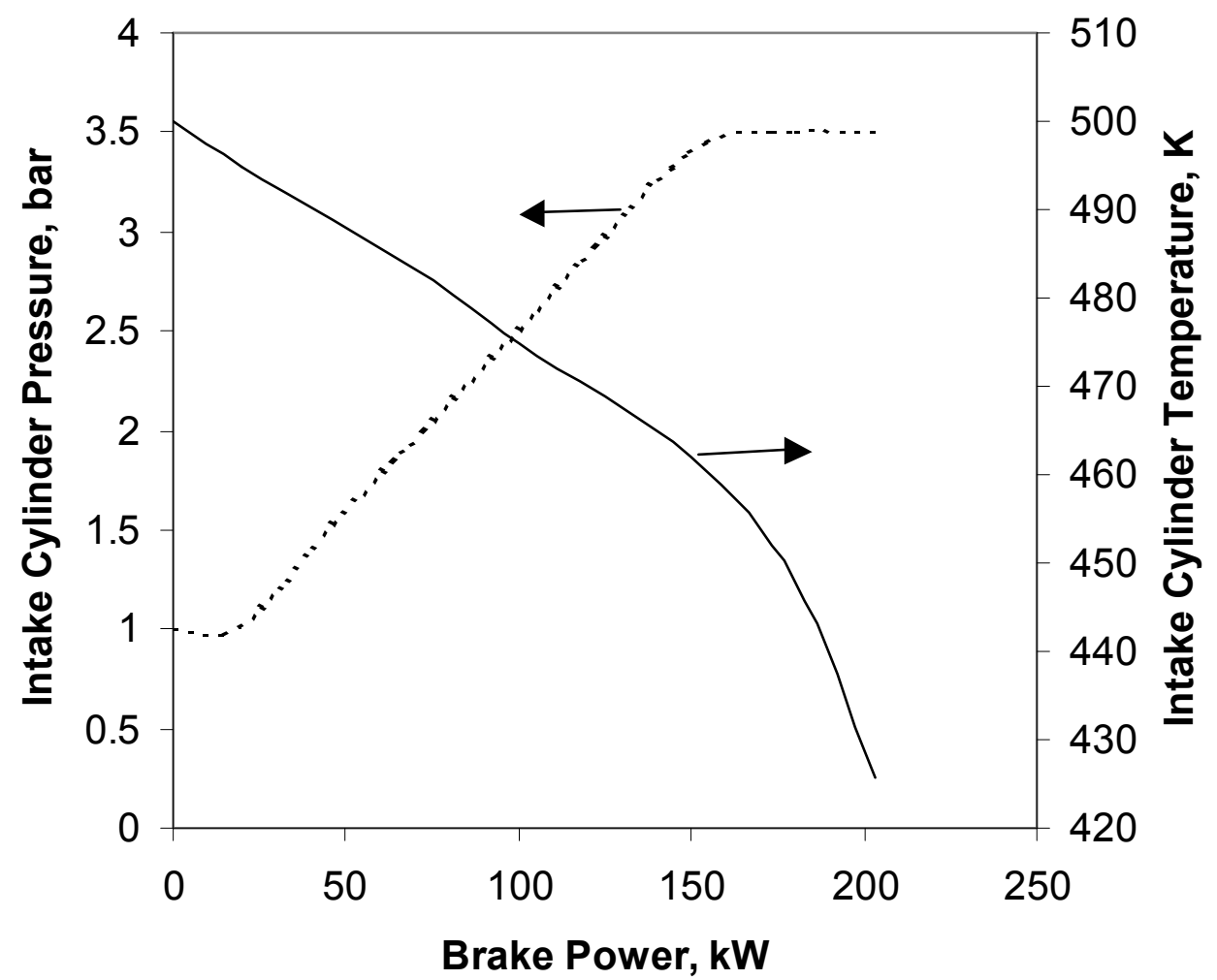

Figure 13: Optimum intake cylinder pressure and intake cylinder temperature as a function of brake power, for $1800 \mathrm{rpm}$, where dotted line shows the intake cylinder pressure and solid line shows intake cylinder temperature

The values for the decision variables shown in Figure 11, Figure 12, and Figure 13 result in optimum engine efficiency while meeting the constraints for maximum $\mathrm{NO}_{x}$ emissions and maximum peak cylinder pressure. Figure 14 shows the values of the two restrictions used in the optimization. Figure 14 shows $\mathrm{NO}_{x}$ emissions in parts per million (ppm) as a solid line and peak cylinder pressure in bar as a dotted line, both as a function of brake power, for the optimum operating conditions for the engine operating at $1800 \mathrm{rpm}$. Figure 14 shows that both $\mathrm{NO}_{\mathrm{x}}$ emissions and peak cylinder pressure increase as the power increases. $\mathrm{NO}_{x}$ emissions reach their higher bound (2 ppm) at 50 $\mathrm{kW}$. From this point, $\mathrm{NO}_{\mathrm{x}}$ emissions remain steady at $2 \mathrm{ppm}$ as the power is increased, while the peak cylinder pressure increases rapidly. At maximum power, the peak cylinder pressure reaches its higher bound (220 bar). 


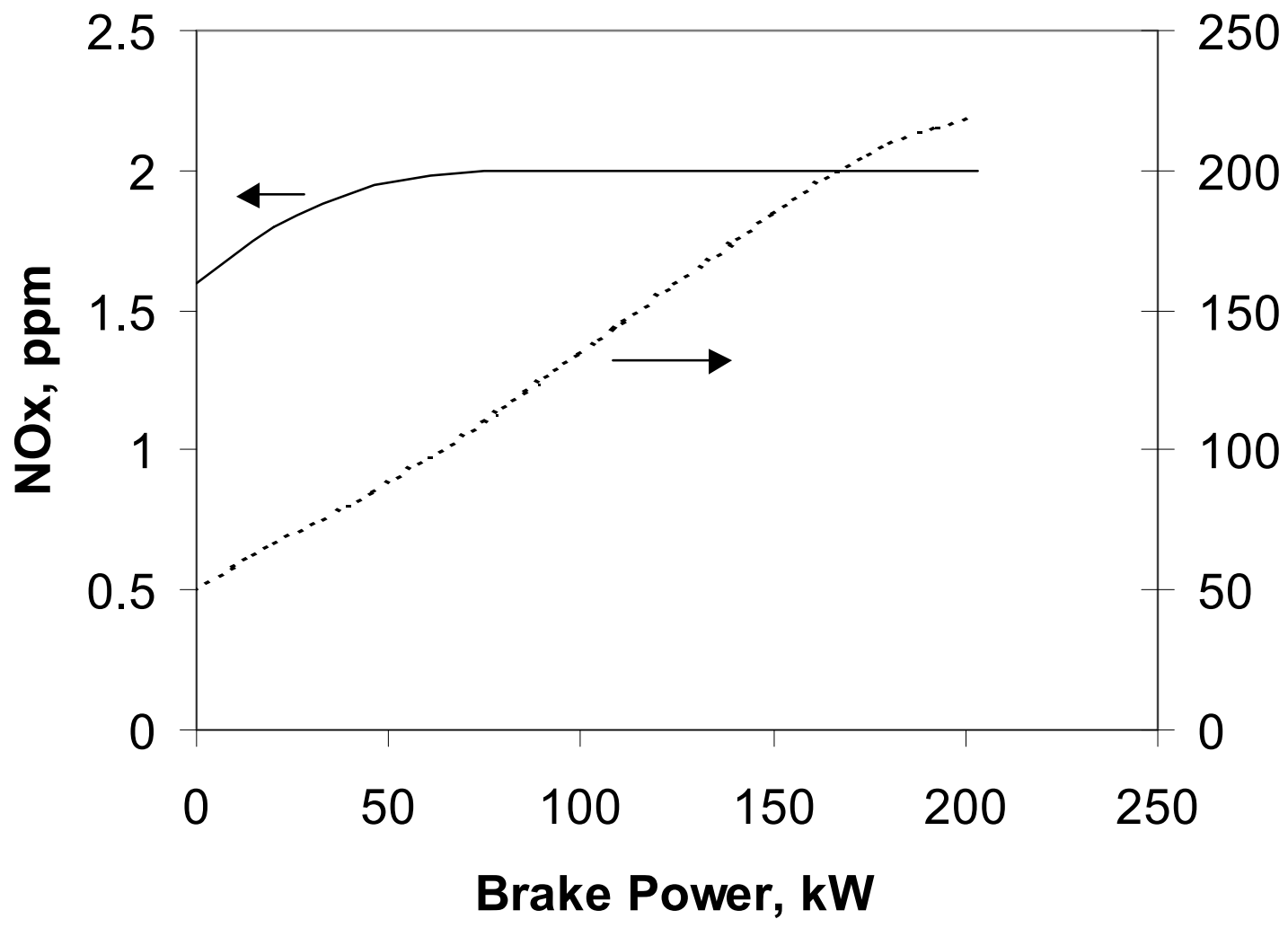

Figure 14: NOx emissions in parts per million (ppm, solid line) and peak cylinder pressure in bar (dotted line) as a function of brake power, for the optimum operating conditions for the engine, at $1800 \mathrm{rpm}$

Figure 15 shows the optimum engine brake thermal efficiency as a function of engine output power. The solid line represents the optimum brake thermal efficiency when the heater is used to condition the charge (up to $151 \mathrm{~kW}$ output power, see Figure 10). The dotted line represents the optimum brake thermal efficiency when the intercooler is used. Figure 15 shows that the efficiency increases rapidly as the power is increased, reaching a maximum of $42 \%$ at a brake power of $181 \mathrm{~kW}$. The efficiency then drops slightly (down to $40 \%$ ) as the power output is further increased to its maximum value $(203 \mathrm{~kW})$. Maximum brake power is simultaneously limited by the two restrictions: $\mathrm{NO}_{\mathrm{x}}$ is $2 \mathrm{ppm}$ and maximum pressure is 220 bar (Figure 14). 


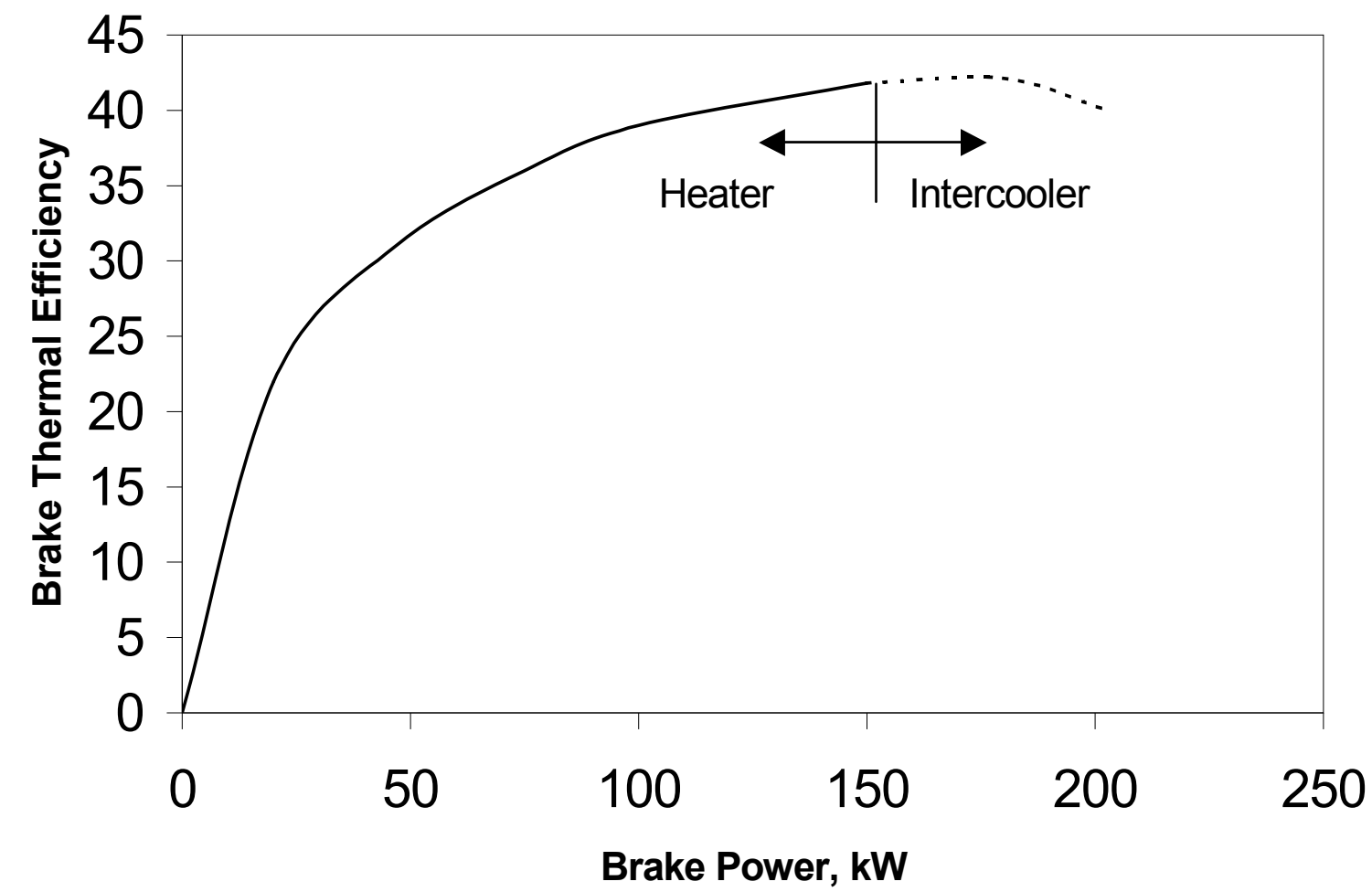

Figure 15: Optimum brake thermal efficiency as a function of brake power, for $1800 \mathrm{rpm}$, where the solid line shows $\mathrm{HCCl}$ engine efficiency of the operating with the heater and the dotted line shows the efficiency of the $\mathrm{HCCl}$ engine with the intercooler

The results of the analysis show that the HCCI engine can produce the engine rated power of $203 \mathrm{~kW}$ with $\mathrm{NO}_{\mathrm{x}}$ emissions under $0.015 \mathrm{~g} / \mathrm{bhp}-\mathrm{hr}$ at $42 \%$ efficiency. These values represent feasible goals for the ongoing experimental effort. If achieved, the results will open the door to clean, efficient and inexpensive stationary power generation based on HCCI engines, with multiple applications to power generation and cogeneration (Aceves et al. 2004) in urban areas and impacted basins with strict emissions standards. Future work will focus on achieving the $45 \%$ ARICE efficiency target. This may be achieved by increasing the specific power through very high boost ( $\sim 6$ bar intake) while the compression ratio and other decision variables are optimally selected to maximize efficiency.

\subsection{Siting and Installation of Multi-cylinder Engine}

\subsubsection{Engine Acquisition}

An engine-generator set was acquired through the grace of the Caterpillar Engine Company. Caterpillar provided a natural gas fueled G3406 genset in support of longterm HCCI R\&D at LLNL. The engine is ideally suited for conversion to HCCI operation 
for the purposes of developing the ARICE EPAG system. The engine was delivered by Caterpillar to the LLNL site on May 1, 2003.

Table 6 below shows the performance parameters for the G3406 Engine in spark ignition modes as reported in Caterpillar literature (Caterpillar Engine Company 2001a, 2001b). Figure 16 shows the engine in the Caterpillar Facility, prior to delivery to LLNL. This engine was selected as an appropriate engine for the conversion to HCCI mode based upon a variety of criteria. The selection of this specific engine was done after a great deal of consultation with Dr. Scott Fiveland, technical lead of HCCI research activities at Caterpillar, Dr. Joel Hiltner of Hiltner Combustion Systems, an expert in engine systems for power generation, and Prof. Robert Dibble of UC Berkeley, a leading combustion research and longtime LLNL partner on HCCI research, including this project. This genset has many features that are appropriate for the HCCI ARICE EPAG application. The target power output for this HCCI application is $200 \mathrm{~kW}$, and the G3406 genset selected here nominally operates at $190 \mathrm{~kW}$ in continuous operation, and up to $240 \mathrm{~kW}$ in standby mode. Diesel 3406 engines with identical displacement engines gensets can operate up to $350 \mathrm{~kW}$ of power output. Based on previous experience and performance estimates, the conclusion is that sufficient margin exists to be able to achieve the target $200 \mathrm{~kW}$ power output.

Table 6 :Summary of Important Performance Specifications for Base Engine, a Natural Gas 3406 Generator Set Operating on Natural Gas

\begin{tabular}{|l|l|}
\hline \multicolumn{2}{|c|}{ Specifications } \\
\hline Performance Parameters & $190 \mathrm{~kW}$ \\
\hline Power rating (Continuous Duty) & $14.6 \mathrm{Liters}$ \\
\hline Displacement & $137 \mathrm{~mm}$ \\
\hline Bore & $164 \mathrm{~mm}$ \\
\hline Stroke & $10.3: 1$ \\
\hline Compression Ratio & $64 \mathrm{~N}-\mathrm{m} 3 / \mathrm{hr}$ \\
\hline Fuel Consumption @ 100\% Load & $29.5 \%$ \\
\hline Engine efficiency @ 100\% Load & $19.7 \mathrm{~g} / \mathrm{bhp}-\mathrm{hr}$ \\
\hline NOx emission & $1 \mathrm{~g} / \mathrm{bhp}-\mathrm{hr}$ \\
\hline CO & $4.2 \mathrm{~g} / \mathrm{bhp}-\mathrm{hr}$ \\
\hline HC (Total) & $0.63 \mathrm{~g} / \mathrm{bhp}-\mathrm{hr}$ \\
\hline HC (Non-methane) & Turbocharged-Aftercooled \\
\hline Aspiration & \\
\hline Package Dimensions &
\end{tabular}




\begin{tabular}{|l|l|}
\hline \multicolumn{2}{|c|}{ Specifications } \\
\hline Length & $4.0 \mathrm{~m}$ \\
\hline Width & $1.4 \mathrm{~m}$ \\
\hline Height & $2.1 \mathrm{~m}$ \\
\hline Mass & $4318 \mathrm{~kg}$ \\
\hline
\end{tabular}

This engine is appropriate for the distributed generation and backup power markets, often considered to be the $50 \mathrm{~kW}$ to $10 \mathrm{MW}$ range of operation. The industrial package engine gensets, as supplied by companies such as Caterpillar, Cummins, or Waukesha in the US, typically range from $100 \mathrm{~kW}-3 \mathrm{MW}$ for a single engine-generator set unit. The G3406 selected is at the lower end of this range, which for research and development purposes gives many advantages. The $200 \mathrm{~kW}$ size class has lower fuel supply and energy dissipation requirements relative to the larger scale machines, so resources are significantly less taxed. Fuel supply is a key issue because a larger genset might require access to higher capacity gas supply, which might result in significant time and expense to access. The G3406 is of a scale that fuel supply can be handled with typical readily available industrial supply systems. The dissipation system for a $200 \mathrm{~kW}$ class engine is very typical and commonly available load dissipation systems, i.e. a resistive load bank. Modifications, maintenance, and repair require significantly lower effort. The basic size of the engine is an advantage relative to larger frame machines, as disassembly can by handled with a typical light duty shop hoist. In addition, the 3406 engine benefits from being a widely used engine frame for diesel truck engines. Thus, stock parts and aftermarket parts are widely available from engine parts suppliers at significantly lower cost than would be for the substantially less common larger frame engines. 


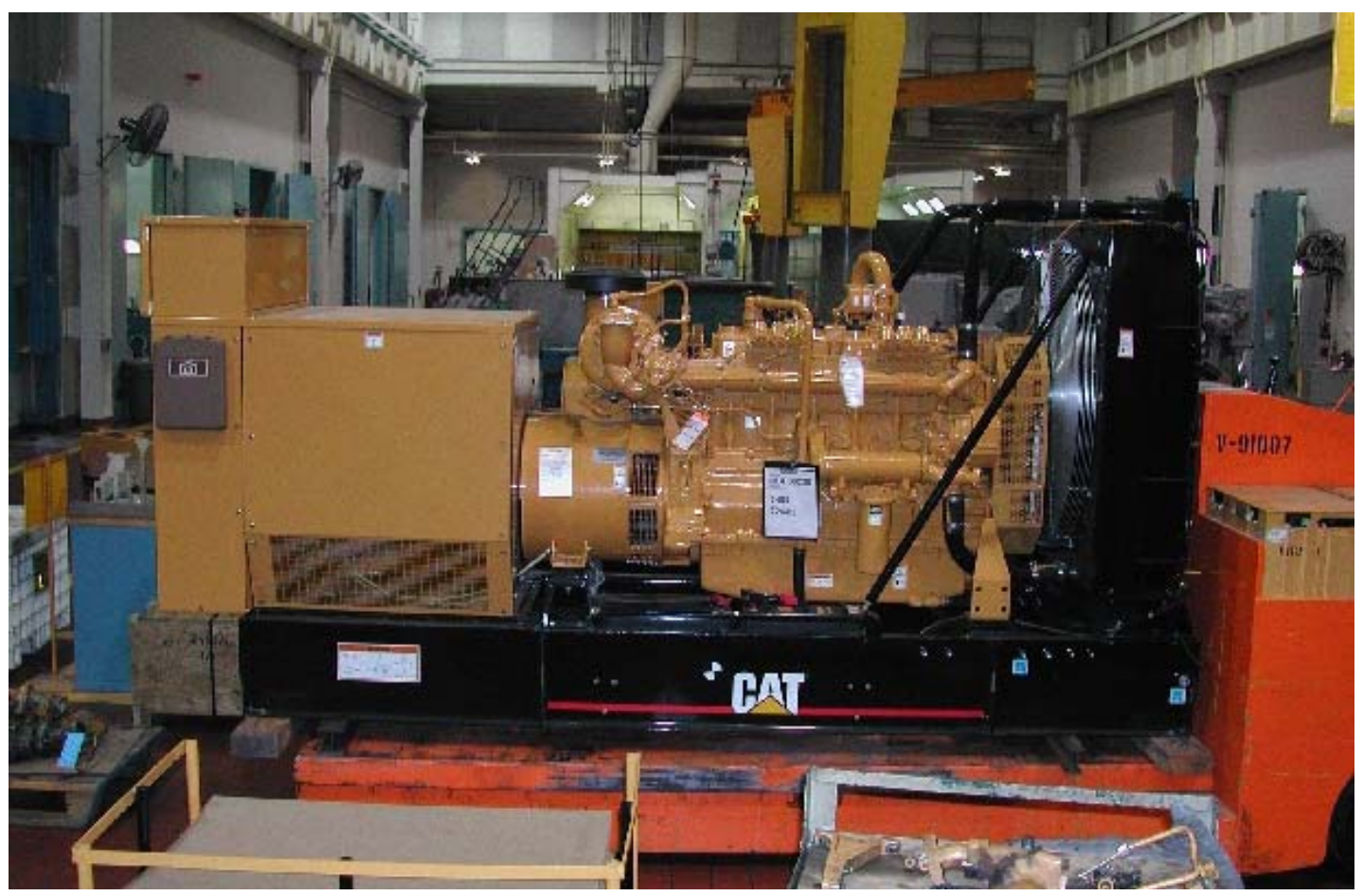

Figure 16:Caterpillar 3406 Genset before delivery to LLNL

Photo Credit: Lawrence Livermore National Laboratory

In regard to $\mathrm{HCCI}$ engine operation, engines with larger displacement per cylinder engines are actually better suited to operation in HCCI mode, due to lower heat transfer and typically higher surface to volume ratio. Thus the results from this HCCI 3406 engine can be readily applied to larger displacement engines. Even neglecting the potential to scale this engine to higher power output, the $200 \mathrm{~kW}$ class is a significant potential market in itself for industrial power generation, power and combined heat and power applications for hotels and commercial establishments, backup power and other applications. The natural gas spark-ignited version of the 3406 has a combustion chamber nearly identical to the Diesel version of this engine. Thus, the engine is designed to withstand Diesel peak pressure loads; pressure loads significantly greater what would be required if the engine were designed to withstand loads required for a spark ignited natural gas engine operation. This is of great benefit for conversion to HCCI operation because the peak pressures are more typical of Diesel operation than of spark ignition operation.

\subsubsection{Materials Acquisition and Site Selection}

After identifying the engine, a conceptual layout of the engine system in HCCI operation was developed. Figure 17 shows a detailed layout of the various design groups that need to be addressed for the operating design. The site selection was conducted to accommodate the specific needs identified in this system layout, as well as the package dimensions specified in Table 6. For basic engine setup, the site needs to accommodate the package dimensions and mass, have ready access to sufficient supply of natural gas, 
and have accommodations for removing the exhaust gas. It is also necessary to consider the impact of the work on other ongoing projects in the area, as the work calls for 1000 hours of running in later tasks of the project.

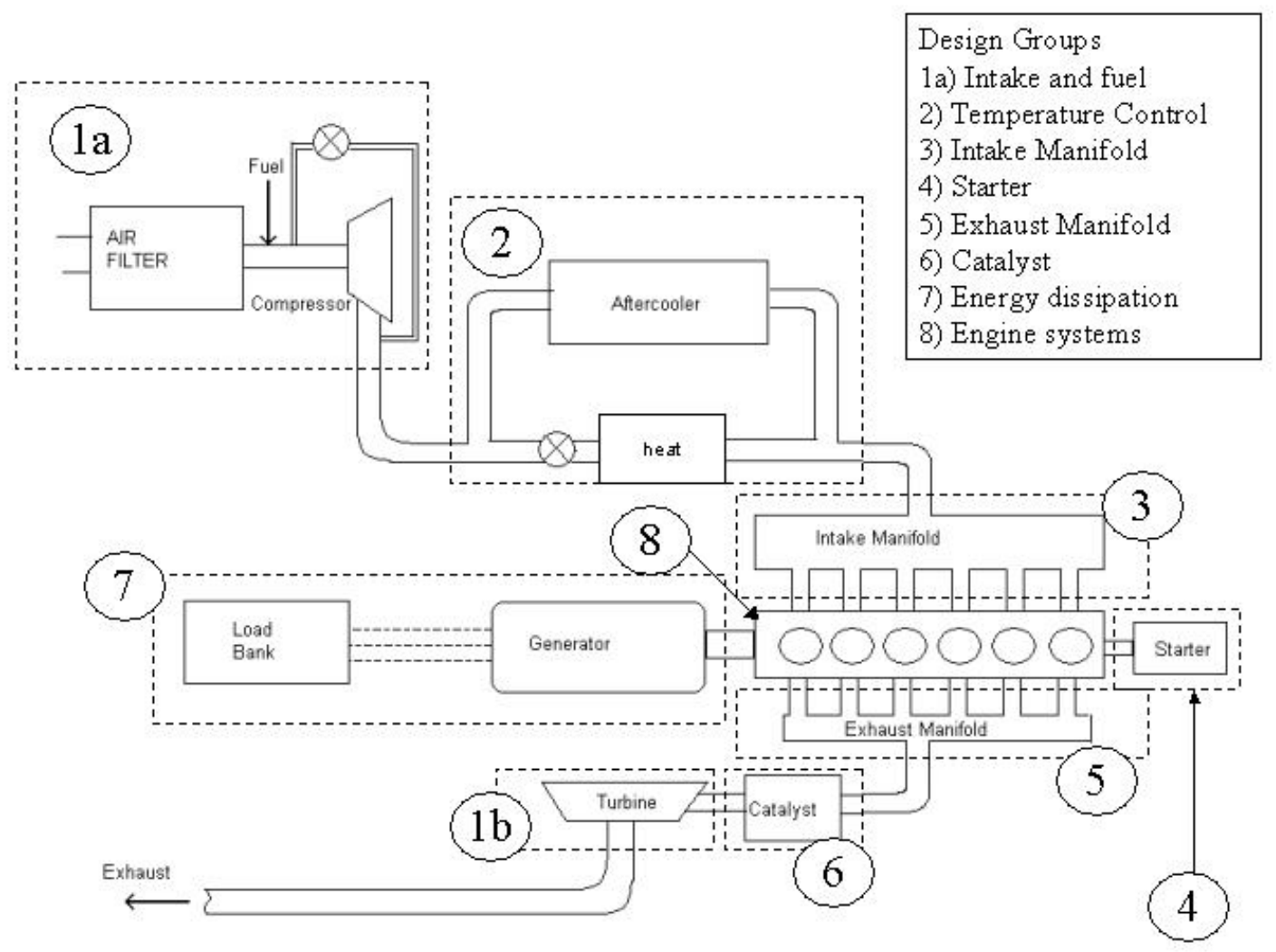

Figure 17:Design system breakdown for the $\mathrm{HCCl}$ conversion of the 3406 Engine

An issue unique to this project is the starter system. The starter will be used in this system to "motor" the engine, or establish sustained rotation of the engine prior to generation of power by combustion. Because a conventional electric starter can be operated in sustained rotation for less than 30 seconds, it is deemed inadequate for the needs of this project. For the purposes this project, especially in investigating early startup strategies, it is desirable to be able to have sustained rotation for up to several minutes. Alternatives are an electric motor, or an air starter. An AC induction electric motor can effectively start and sustain rotation of the engine. For this engine, it would be necessary to have at least $30 \mathrm{hp}$ for startup. The motor would need to be clutched to be disengaged once power is generated, and would need to have appropriate power electronics to prevent reverse current flow through the electrical system. This electric motor system is estimated to cost $\$ 15,000-\$ 20,000$ for the hardware and additional cost for installation. The electric motor system would also need to be designed and certified for use on this engine, possibly adding cost. An air starter system uses a high capacity air line or a large pressurized air reservoir to drive an air turbine. Air start systems are commercially available for the 3406 engine family with a cost of $\$ 2,000-\$ 3,000$ for the 
hardware. The air starter system is self contained with an internal clutch that automatically disengages when power generation neutrally balances the friction. Thus the air starter was selected as the best choice and site selection must be able to accommodate an air starter through a high capacity air system or a large air reservoir tank.

Selecting the best site for installation of the engine involves balancing the several factors involved in successful testing. Several sites were considered, a variety of location at LLNL, as well as offsite locations including a facility at UC Berkeley. The LLNL site was chosen because of the resources available to best support the development and testing under this contract. Siting the engine at LLNL provides the best access to technician support, including access to engine mechanics at LLNL's motor shop. A variety of locations at LLNL with features appropriate for this work were explored. Two sites in particular were considered because of access to a low conductivity water cooling circuit with a cooling tower, a large capacity compressed air system, and a high volume flow natural gas supply. These sites also had heavy duty concrete pads suitable for mounting the engine and necessary access for exhaust. One of the sites was initially selected and preliminary scoping work was performed. This site was chosen because it was more separated from other research projects. But an unforeseen circumstance made this site ineligible soon after the preliminary scoping work was completed; the site was unexpectedly designated by the Department of Energy for demolition. Thus, the site selection reverted to the alternate site, and scoping work began. This site is on a semienclosed pad located adjacent to a building containing a variety of research projects. Some accommodations were necessary to ensure minimum impact on other research projects in the building, such as exhaust noise mitigation with a high attenuation muffler and sheet metal screening adjacent to the engine.

\subsubsection{Engine Installation}

Work began on site preparation in anticipation of the arrival of the engine. A collaborative agreement was established with Caterpillar Engine company. Caterpillar agreed to provide LLNL with a genset and engineering guidance on development of the engine. Caterpillar's benefit from this agreement is support on modeling HCCI combustion and multi-cylinder HCCI control system development. Again, delivery of the engine to the LLNL site occurred May 1, 2003.

Prior to the arrival of the engine site preparations began at LLNL. A senior mechanical engineering technician was involved in coordinating all of the site preparation process. The major resources that needed to be brought to the site were natural gas, high pressure air, and low conductivity water (LCW). The exhaust system also needed to be installed. Fortuitously, a natural gas supply with significant excess capacity (9 psig, 2 inch diameter line) was located very near the site. Also located nearby was a high capacity compressed air supply (90 psig, 2 inch diameter line). The pressurized air supply is sufficient for continuous operation of an air start system. 
Figure 18 and Figure 19 show the systems installed for engine operation. The natural gas was tapped upstream of the building regulator to have natural gas available at the highest pressure. Compressed air was tapped inside the building from the high capacity supply. In addition LCW lines were extended onto the pad to be available for the engine. The high attenuation muffler was installed in the exhaust line for sound abatement. These modifications involved changes to building systems and utilities, and as such had to be largely handled by LLNL plant engineering in coordination with the project technician. Note that the right-hand-side wall shown in Figure 18 corresponds to the left hand side wall in Figure 19.

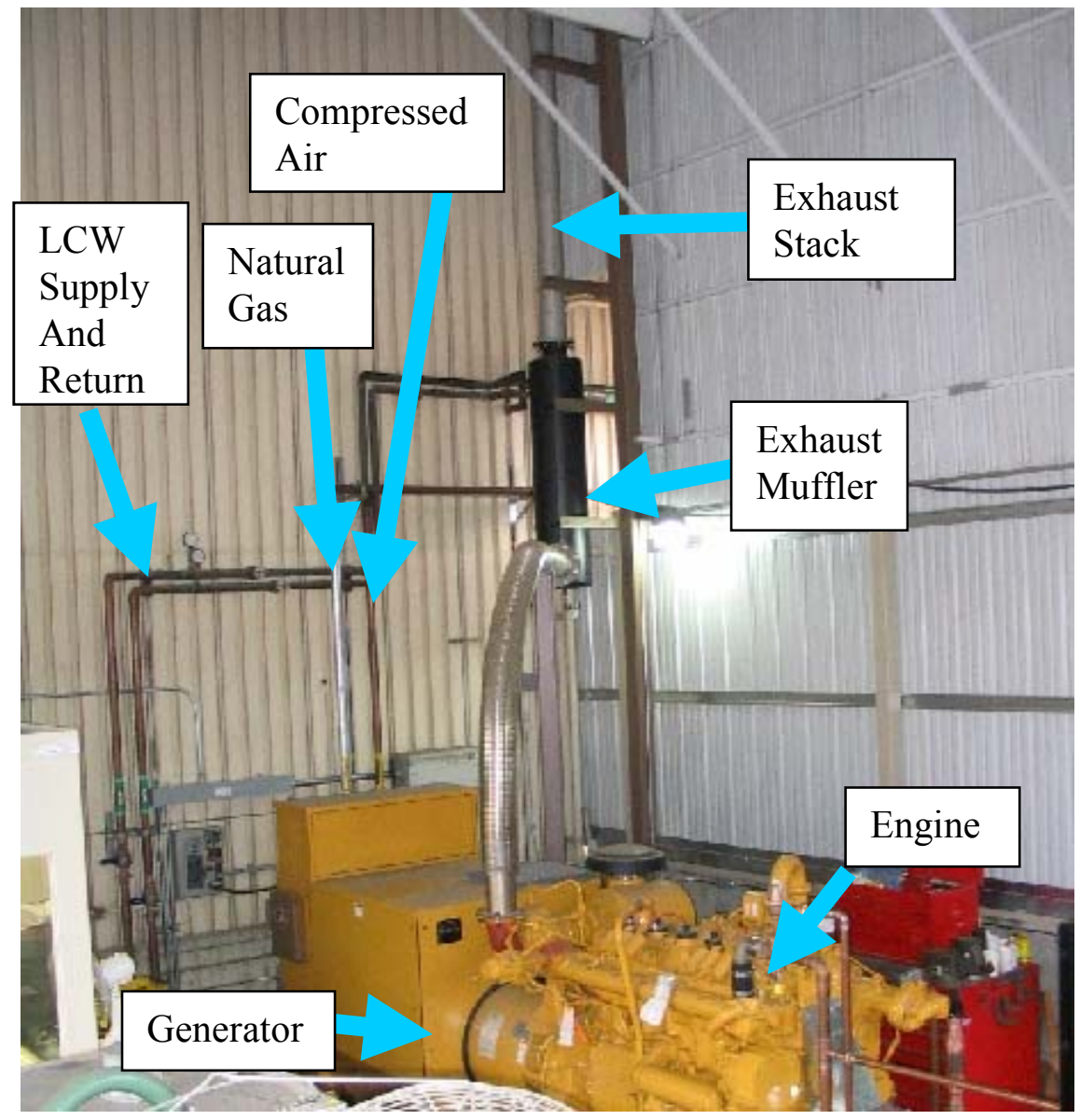

Figure 18: Test engine installed on LLNL Site

Photo Credit: Lawrence Livermore National Laboratory 


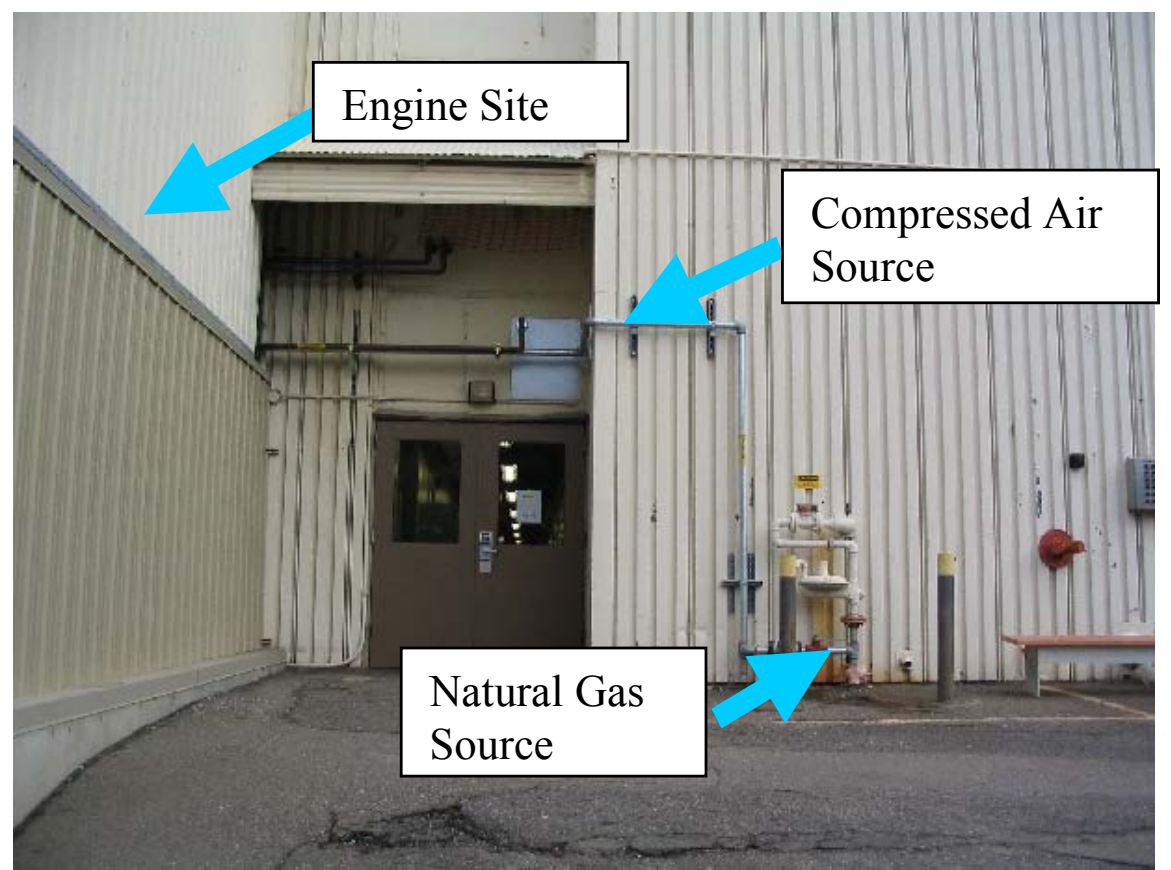

Figure 19: Gas and air supply installation to engine site

Photo Credit: Lawrence Livermore National Laboratory

\subsubsection{Initial Engine Operation}

The infrastructural systems for installing the engine were mostly handled prior to the arrival of the engine (gas, exhaust). Once the engine arrived on May 1, it was moved into place by LLNL riggers, then secured to the concrete pad. The gas line was extended to the engine fuel intake, and the engine exhaust was connected by flexible stainless steel pipe to the exhaust stack. The engine was delivered fitted with a radiator type cooling system, used for initial firing. A test firing of the engine in spark-ignited mode was conducted in late May 2003 to verify all systems were properly functioning prior to making modifications to the engine for HCCI operation. The engine was operated for a total of approximately one hour with several starts and stops. Overall, all engine systems operated satisfactorily.

\subsection{Install ETV on Multi-cylinder engine and Initial $\mathrm{HCCl}$ Operation}

Based on the results of the single-cylinder testing (section 3.1) and the set-point optimization (section 3.3 a thermal management system that follows closely the configuration of Figure 10 and Figure 17 above, was analytically evaluated and is expected to yield appropriate HCCI combustion. This thermal management approach effectively accomplishes the role of the Exhaust Throttle Valves (ETVs) to control combustion timing on a cylinder-by-cylinder basis. To accomplish initial HCCI 
operation, three major area had to be addressed: Starting system, fuel system and control system.

\subsubsection{Starting System}

HCCI engines are often difficult to start. At cold start, the compressed gas temperature in an HCCI engine is reduced because the charge receives no preheating from the intake manifold and the compressed charge is rapidly cooled by heat transfer to the cold combustion chamber walls. Without some compensating mechanism, the low compressed charge temperatures could prevent an HCCI engine from firing. A common approach has been to start the engine in spark ignition mode or diesel mode and transition to HCCI mode after warm up. However, successful transition typically requires advanced engines equipped with variable compression ratio (VCR) or variable valve timing (VVT), which may be expensive or difficult to implement for heavy duty engines. In practice operation in SI mode requires equivalence ratio of 0.6-0.65 or greater (Flynn et al. 2000), which is high enough to damage the engine if thermal auto ignition or knock occurs during the transition.

Instead of attempting to start the engine in SI mode and transition to HCCI mode, a brand new approach is used: start the engine directly in HCCI mode by preheating the intake with a gas fired burner. This was easy to implement by adding a burner to the preheater. The burner is run for a period of time (30 minutes) until the preheater reaches a high temperature $\left(300^{\circ} \mathrm{C}\right)$. At this condition, running the intake charge through the preheater while simultaneously spinning the engine with an air starter is enough to achieve HCCI ignition. After ignition, combustion is self-sustaining and the burner can be turned off, as the intake gases are heated by the hot exhaust. The burner is a source of emissions and a consumer of fuel, and as such in a practical deployment of an HCCI engine for stationary power generation this would have to be considered as a contributor to the overall system emissions and fuel consumption.

\subsubsection{Fueling system}

The fueling system presents several challenges, because HCCI combustion is extremely sensitive to equivalence ratio. Just a few cycles of HCCI combustion at high equivalence ratio $(\phi>0.5)$ are enough to cause physical damage to the engine. Therefore, the fueling system has to guarantee that no equivalence ratio excursions will occur beyond a "safe" equivalence ratio $(\phi \sim 0.45)$ under any circumstances. It may also be desirable to run at low equivalence ratio for low load operation.

These difficult requirements were met with a novel solution: the stock carburetor tuned for natural gas was replaced with a carburetor tuned for liquid petroleum gas (LPG). Considering that the average composition of natural gas is approximately $\mathrm{C}_{1.2} \mathrm{H}_{3.5}$ and the average composition of LPG is $\mathrm{C}_{3.5} \mathrm{H}_{8.5}$, a carburetor tuned for operating at equivalence ratio 0.9 on LPG will run at $\phi \sim 0.3-0.4$ when fueled with natural gas. This is ideal for HCCI, as the carburetor is quite efficient at maintaining the established equivalence ratio. The equivalence ratio is reduced below 0.4 with an electronic control valve that reduces the pressure in the natural gas line (Figure 20). 


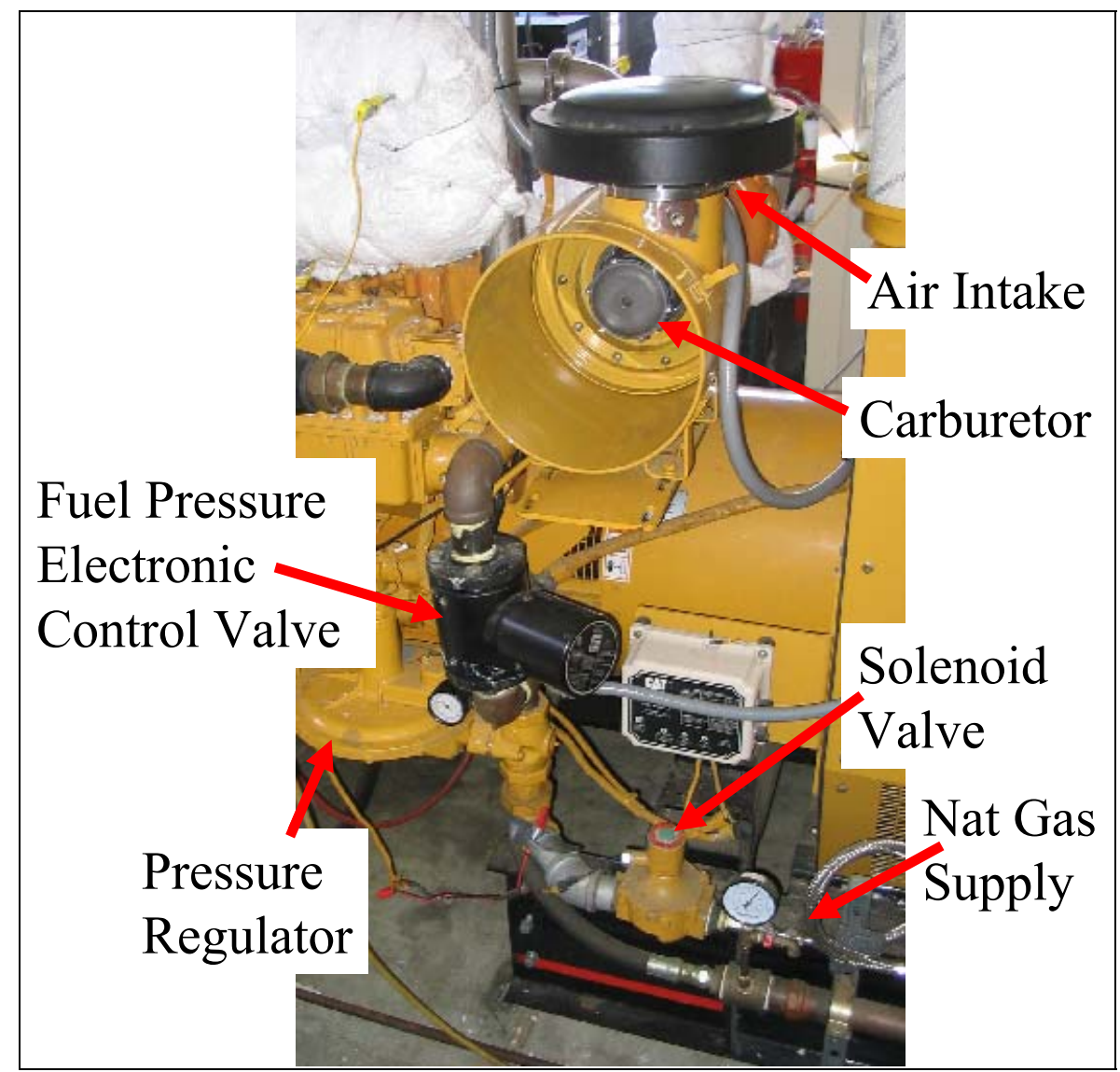

Figure 20:Engine picture showing the fueling system components.

Photo Credit: Lawrence Livermore National Laboratory

\subsubsection{Control System}

It is typically considered that combustion control is the most challenging problem for widespread commercialization of HCCI engines. The HCCI process gives up two important control aspects: (1) the timing of the start of ignition is not directly controlled by any external event such as the beginning of injection in the standard diesel engine or the sparking of the spark plug in the SI engine, and (2) the heat release rate is not controlled by either the rate and duration of the fuel injection process as in the diesel engine or by the finite turbulent flame propagation time in the SI engine. Instead, HCCI ignition is determined by the charge mixture composition and its temperature history (and to a lesser extent, its pressure history). Changing the power output of an HCCI engine requires a change in the fueling rate and, hence, the charge mixture. As a result, the temperature history must be adjusted to maintain proper combustion timing. Similarly, changing the engine speed changes the amount of time for the auto ignition chemistry to occur relative to the piston motion. Again, the temperature history of the mixture must be adjusted to compensate. These control issues become particularly challenging during rapid transients. 
Multi-cylinder engines pose an additional challenge, since there are always small cylinder to cylinder differences in charge pressure and temperature at intake valve closing, due to differences in volumetric efficiency or coolant temperature. In addition to this, there may be differences in compression ratio between cylinders due to geometric tolerances. These differences are small enough to be negligible in SI and diesel engines. However, HCCI combustion is controlled by thermal autoignition, and is extremely sensitive to temperature. A very small temperature difference can result in a considerable difference in ignition timing. It is therefore necessary to develop a controller that can detect cylinder to cylinder differences in ignition timing and adjust conditions in the individual cylinders so that optimum combustion timing can be achieved in all cylinders under all operating conditions.

Several potential control methods have been proposed to provide the compensation required for changes in speed and load. These include varying the amount of hot EGR introduced into the incoming charge, using a fuel additive to enhance ignition, using a variable compression ratio (VCR) mechanism to alter TDC temperatures, and using variable valve timing (VVT) to change the effective compression ratio and/or the amount of hot residual retained in the cylinder. VVT appears most promising for transportation applications, because its time response could be made sufficiently fast to handle rapid transients.

For stationary applications, HCCI combustion control is not nearly as challenging, because a stationary engine runs predominantly at a constant speed and the load changes relatively slowly. Under these conditions, combustion control becomes much more tractable, and can be accomplished without advanced engine technology such as VVT or VCR. In this application, combustion control is achieved by blending hot and cold intake with control valves. This control system has the additional advantage of being able to independently regulate the intake temperature of each cylinder, to obtain optimum ignition timing in all cylinders (Figure 21).

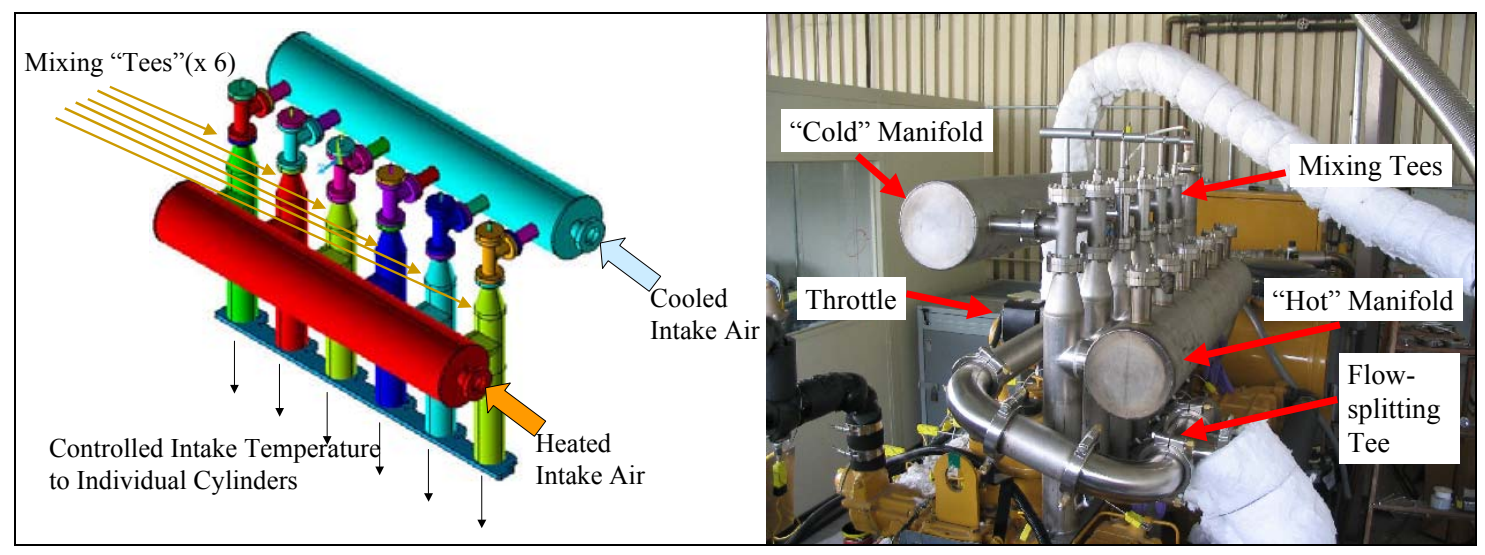

Figure 21: Dual manifold intake system allows for controlling intake temperature on a cylinder-by-cylinder basis

Photo Credit: Lawrence Livermore National Laboratory 


\subsubsection{Engine Operation}

The engine was successfully run in HCCI mode, even without the supercharger and without the computerized controller. While closed loop feedback control offers the greatest flexibility, cylinder pressure balancing can be achieved by passive tuning of cylinder-by-cylinder mixing valves. Figure 22 shows in-cylinder pressure traces for engine operation with no cylinder-by cylinder-balancing, all cylinders receiving fuel-air mixture only from the hot reservoir. Clearly, the combustion phasing is not well matched for all cylinders. This imbalance can lead to undesirable occurrences, such as greater propensity for misfire of later firing cylinders when a small change in intake parameters occurs, such as slight variation in load or outside air temperature.

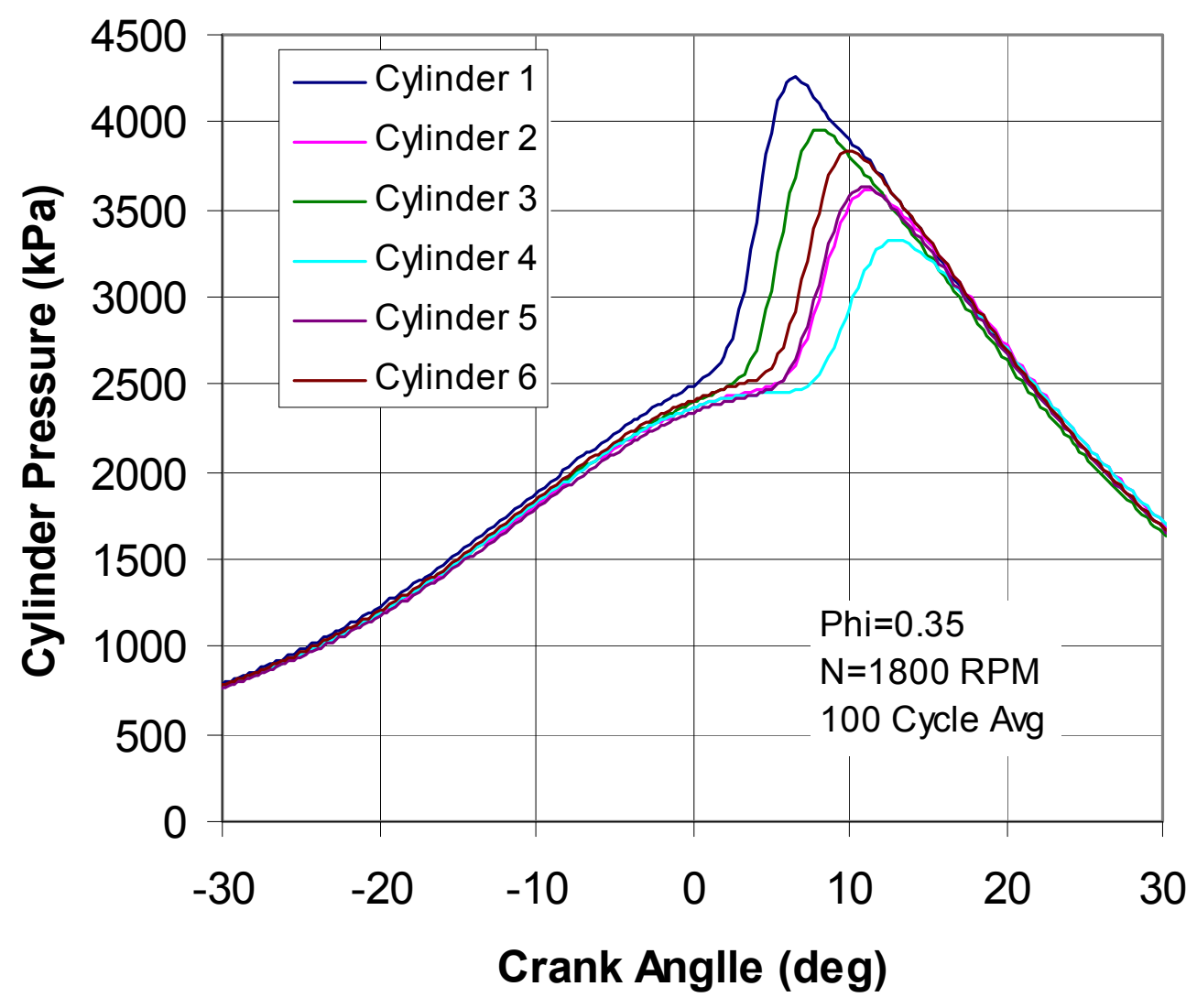

Figure 22: Pressure versus crank angle for each cylinder during initial $\mathrm{HCCl}$ operation with new intake manifold, but no attempt to compensate for cylinder-bycylinder variations.

\subsection{Design Integration and Review}

Because of the iterative nature of the design process, especially in a research environment, the development of the final ARICE engine design overlaps significantly with the implementation efforts documented in sections 3.5 and 3.7. Figure 23 below shows the basis for the ARICE HCCI engine design developed, following along the lines of the thermal control system layouts shown out in Figure 10 and Figure 17. Nearly 
every system on the engine-generator set had to be modified in some way to implement the design. Each of the modified components required a significant engineering design process, as well as implementation of the designs by fabrication, modification, and installation. Many of these designs were quite complex, and required multiple iterations to realize the final design.

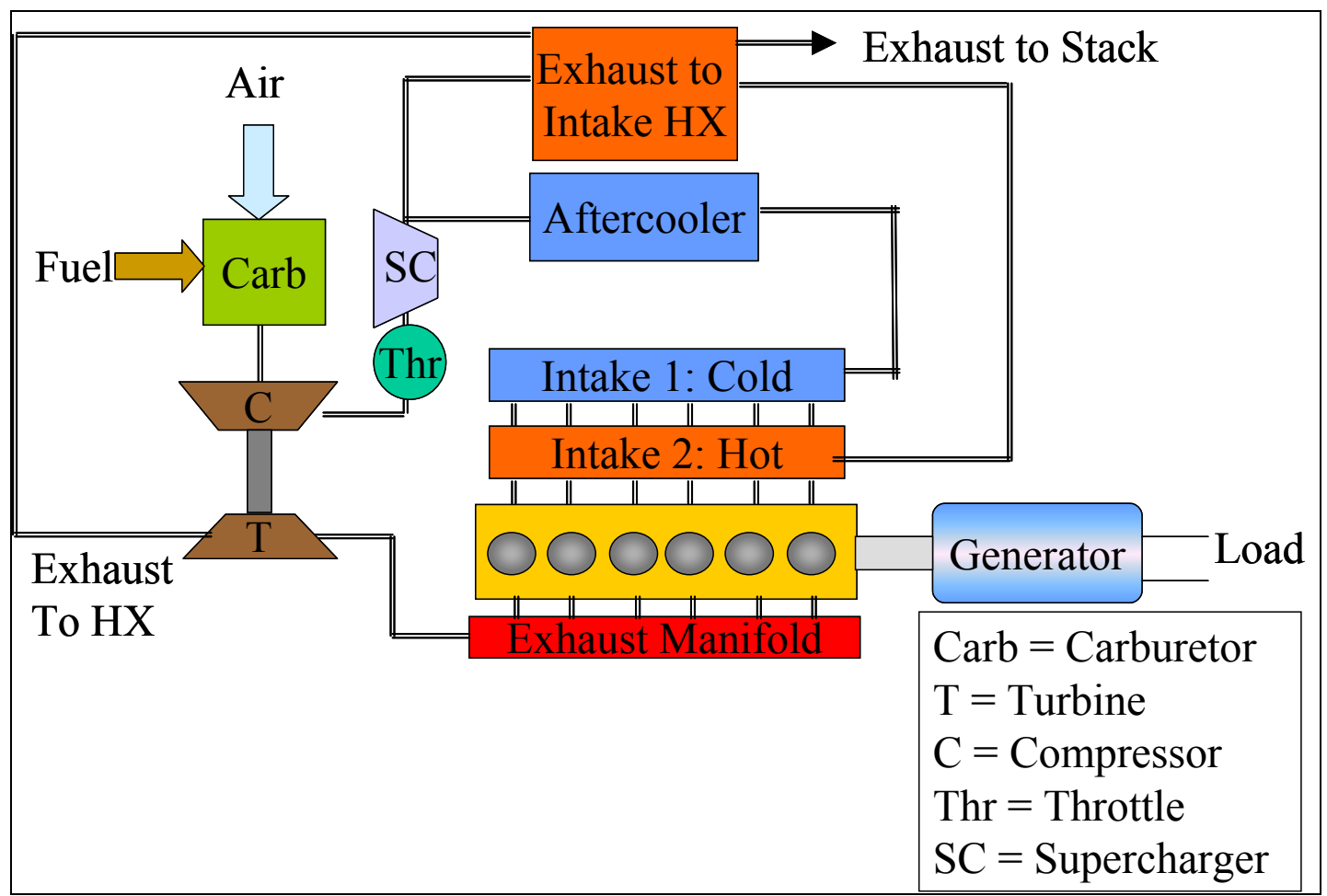

Figure 23: ARICE HCCI Engine schematic showing implementation of the thermal combustion management system.

The development of the ARICE engine design for the 6-cylinder 14.6 L ARICE HCCI engine resulted in the thermal combustion management approach for controlling combustion timing shown in Figure 23. Many systems were added or modified to implement the ARICE engine design. The following is a list of the major component groups that have been added to the engine or significantly modified to implement this design:

1. Fuel induction

2. Turbocharger

3. Engine throttle

4. Supercharger, supercharger drive assembly

5. Exhaust-to-intake-air heat exchanger and burner preheat system

6. Intake flow system 
7. Split intake-manifold cylinder-by-cylinder control

8. Engine combustion chamber

9. Engine cooling water management

10. Engine starter

11. Generator load dissipation (load bank connection)

12. Exhaust manifold and exhaust flow system

13. On-board controller

14. Instrumentation

15. Data-acquisition and control hardware and software

The design and implementation of these various systems will be described in more detail in section 3.7.

\subsection{Implement ARICE Design on Multi-cylinder $\mathrm{HCCl}$ Engine}

This section describes implementing the ARICE HCCI Engine design developed and testing the redesigned engine. Following, briefly summarized is the work supporting this task on these various component groups. Specific component design work presented in this section does overlap with design activities of section 3.6. Then, experimental testing efforts will be described.

\subsubsection{Design Implementation}

\section{Fuel Induction}

As described earlier (section 3.5.2), the fuel induction system (Figure 24) was significantly reengineered and modified to allow for implementation of an active feedback control that would yield the fuel-air ratios needed for HCCI operation. After extensive research and deliberation a solution was developed that would allow for accurate feedback control of fuel-air ratio. This design involved controlling fuel pressure supplied to a modified natural-gas carburetor. The stock natural gas carburetor was modified with a new smaller orifice to restrict the maximum fuel-air equivalence ratio to 0.4, which is the upper limit of safe HCCI operation but below flammability limits for the fuel-air mixture. The fuel pressure to the carburetor was regulated using a custom electronic control valve provided by Continental Controls of San Diego, CA. This valve allowed regulation of the fuel pressure supplied to the carburetor based on a signal from the data acquisition and control computer. The fuel supply regulator and fuel cutoff switch were also modified to implement this design. 


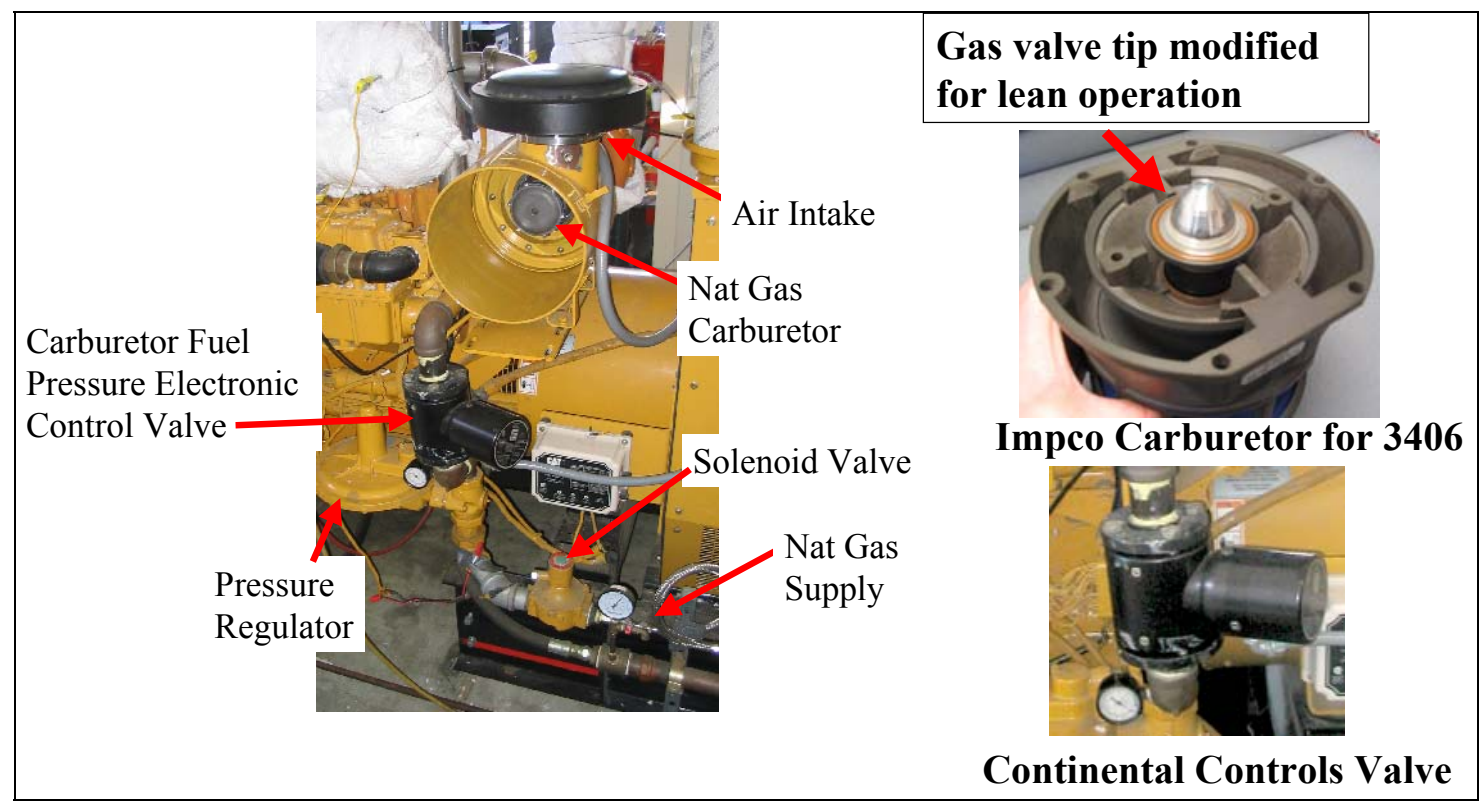

Figure 24: The natural gas carburetor (rugged and low cost) maintains ultra-lean equivalence ratio

Photo Credit: Lawrence Livermore National Laboratory

\section{Turbocharger}

The turbocharger required several modifications. Pressure and temperature instrumentation were added to the compressor outlet and turbine inlet. The intake ports were modified and redirected so that they could receive the new ducting design. The turbine wastegate control port was reconfigured, and waste gate setting adjusted. The oil lines to the turbine also had to be rerouted. Lastly, the cooling water flowing to the turbine had to be disabled because it significantly reduced exhaust enthalpy needed for the thermal control system.

\section{Engine Throttle}

A Woodward Engine throttle control was used to set the overall flow through the engine. The location of this throttle is critical to the engine stability, and it was determined that it had to be located downstream of the turbocharger's compressor outlet and wastegate port in the intake system (to enable waste gate speed control for the turbocharger), but upstream of the supercharger (to prevent supercharger surge). It also was also necessary to remove the throttle from the engine control loop and directly control the throttle with the data acquisition and control system.

\section{Supercharger}

The supercharger was selected as the best off-the-shelf solution to meeting the ARICE $\mathrm{HCCI}$ engine boost requirements. After extensive analysis and consultation, Vortech Engineering of Channel Islands, CA, was identified to provide a custom supercharger that provides 3:1 pressure boost. In concert with the turbocharger, the combined boost system could provide as much as 4 bar intake manifold pressure to the engine, required to meet the power output targets. The supercharger mounting on the engine was critical 
for stable safe operation, as the bracket had to support the loads on the supercharger while avoiding vibration (supercharger compressor rotates at 55,000 rpm). Engineering analysis and design of the supercharger mounting bracket was conducted, then this engineered bracket was fabricated by an outside shop.

To drive the supercharger (Figure 25), the approach chosen was coupling the supercharger directly to the engine crankshaft. A belt drive system selected was selected, utilizing a preexisting drive pulley present on the engine (originally used to drive a large fan for the engine radiator). The belt drive system needed to transfer up to $100 \mathrm{~kW}$ from the engine crankshaft to the supercharger, which meant that all belts operate just below maximum operating speed and load. This design involved many iterations, but evolved into a two-step system, with the first step a v-belt drive, which transitioned to a timing belt that drove the supercharger. In these two steps, the rotational speed of the crank shaft had to be increased from $1800 \mathrm{rpm}$ to $13,000 \mathrm{rpm}$ at the supercharger. A complex v-belt-sheave/timing-belt-pulley assembly had to be engineered. A sophisticated coupling was engineered with bearing supports to withstand the loads. The assembly had to be manufactured, balanced, installed and tested. Testing showed initial misalignment, which had to be corrected. Once misalignment was corrected, further testing showed modifications to the coupling assembly were needed. This was the typical iterative engineering and design process that one expects when developing a device this complex, but it cannot be stressed enough the significant effort required to engineer the entire supercharger assembly.

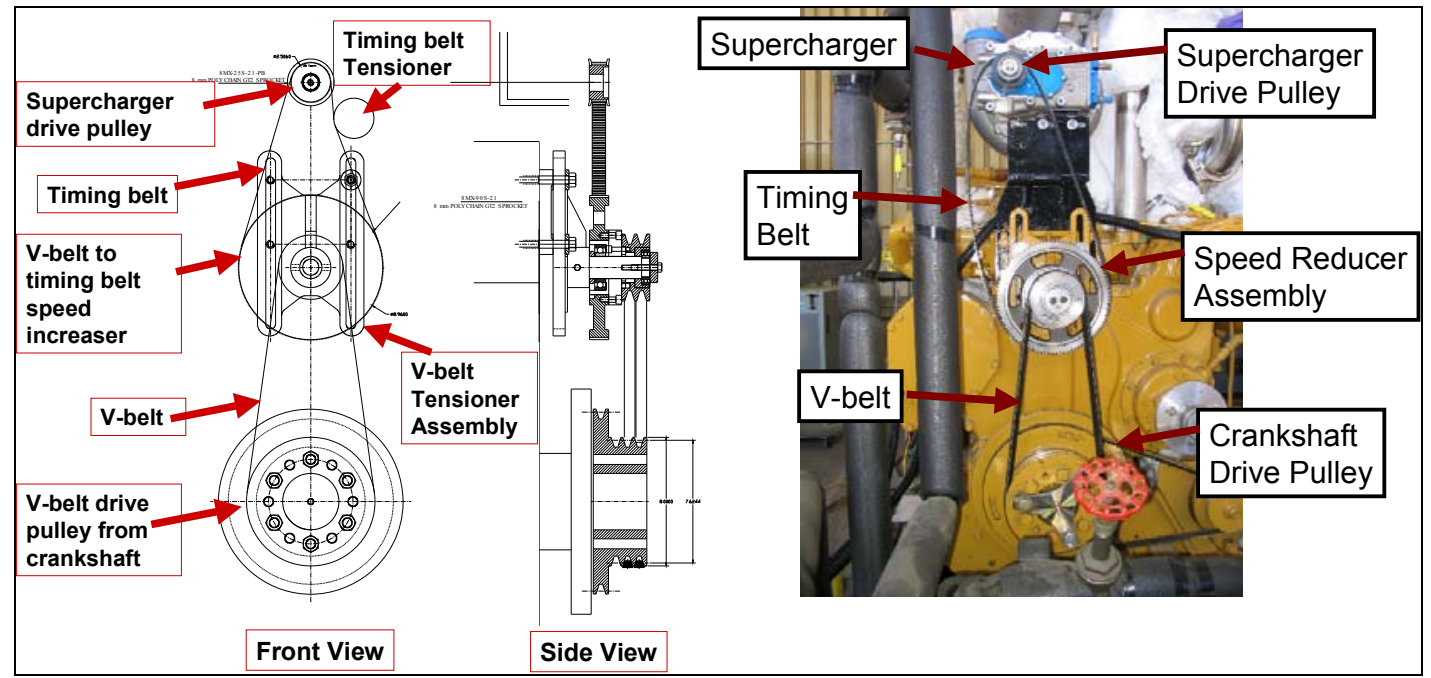

Figure 25: The Supercharger Drive transmission was designed, fabricated, and installed on the 3406 engine.

Photo Credit: Lawrence Livermore National Laboratory

\section{Exhaust-to-intake-air heat exchanger and burner preheat system}

The key to the thermal control system is the exhaust-to-intake-air heat exchanger (EIHX, Figure 26). The EIHX is a large heat exchanger (approx $1 \mathrm{~m}$ by $1 \mathrm{~m}$ by $0.6 \mathrm{~m}$, and $200 \mathrm{~kg}$ ), 
originally a recuperator for $500 \mathrm{~kW}$ class gas turbine engine. Two large plenums were engineered and built to allow for engine exhaust gas to enter and exit the heat exchanger effectively. In addition, a burner system was developed to allow for preheating the EIHX. This burner system required the design of a secondary vessel and an isolation valve. The isolation valve was necessary to isolate the burner from engine exhaust once the engine was started. Preheating the burner allows for direct startup in HCCI mode, which was deemed safer than other alternatives (e.g. start in spark-ignited mode, and transition to $\mathrm{HCCI}$ ).

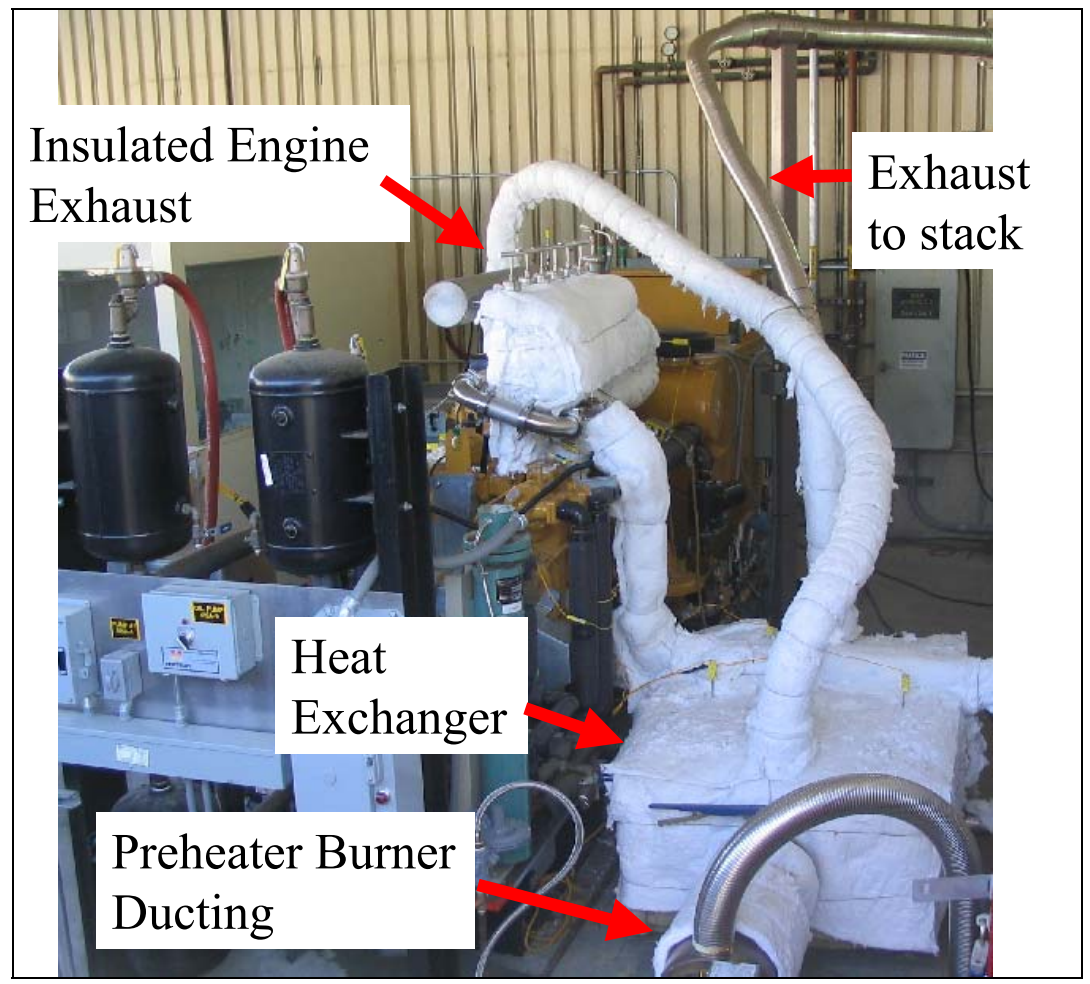

Figure 26: Intake gasses are preheated by exchanging heat with exhaust gasses Photo Credit: Lawrence Livermore National Laboratory

\section{Intake Flow System}

Extensive effort focused on coupling the intake flow system to the many intake system components, requiring approximately several meters of intake ducting and approximately 40 individual pieces of ducting. Stainless steel tubing was required because of the high pressure environment containing air and natural gas (due to turbo/supercharging). Off-the-shelf tubing components were used as much as possible, and a modular coupling system was developed to make rapid system modifications possible. Still, every piece of pipe in the intake system was unique and required unique welds, with additional welds for instrumentation. Special couplings had to be adapted to match the inlets and outlets of each major system component (Turbocharger, Supercharger, Throttle, EIHX, after cooler, intake manifolds). In addition, the route of the piping is complicated, with ducting traveling back-and-forth along the engine. This 
design accommodates two flow loops, a hot loop (through the EIHX) and a cold loop through the aftercooler, and all hot loop tubing was insulated with high temperature insulation.

\section{Split Intake-Manifold Cylinder-By-Cylinder Control}

Cylinder-by-cylinder control of temperature in the engine was accomplished by using two separate intake manifolds (Figure 21, section 3.5.3 above), one with hot fuel-air from the EIHX and the other with cool fuel-air from the after cooler. A mixing valve design was developed and engineered to allow for precise mixing of hot and cold air from each cylinder. After the concept for the manifolds and mixing valve were developed, the two manifolds were designed and fabricated, as mere the mixing valve assemblies for the six cylinders. An engineered mounting plate to couple intake manifold system to the engine was designed at LLNL, then fabricated by a computer-numerical-control machine shop. This system represents a unique design, and the installation of the manifold assembly and integration of the intake flow system was lengthy and involved, requiring on-the-fly modifications to the intake manifold system and related components.

The mixing valves are computer controlled. A control system based on Labview's realtime software is used. This system utilizes a dedicated PC as the target, which allows deterministic closed-loop control. Control algorithms can then be easily developed on a host computer connected to the target PC via an Ethernet connection and downloaded onto the target PC for implementation. The control algorithm computes the combustion timing based on the pressure signal from each cylinder. The valve position is then scheduled by the control algorithm to yield the desired combustion timing. The hardware side of this control system consists of an electric motor teamed with a rotary position sensor per each cylinder to control the valve position. The control system inputs consist of pressure signals from each cylinder in conjunction with the output from a crankshaft encoder. The electric motors and sensors necessary for actuation of the valves have been recently purchased and are being installed. This will allow the development and implementation of efficient and robust control strategies on the HCCI engine.

\section{Engine combustion chamber}

The engine combustion chamber was modified in two ways. First, the original pistons were removed and replaced with higher compression ratio pistons. Higher compression ratio pistons (16:1 relative to the original 10:1) were essential to achieving HCCI combustion with natural gas. Second, the fuel injector/spark plug hole was modified to accommodate in-cylinder pressure transducers. The in-cylinder pressure transducers were used to monitor combustion and in the feedback for combustion control.

\section{Engine cooling water management}

Stable water temperature is very important to achieving consistent HCCI combustion. The original air-to-water radiator and thermostat arrangement could not maintain engine cooling water to within acceptable bounds. The radiator system was replaced with an engine-cooling-water to low-conductivity-water (LCW) heat exchanger (Figure 27). The engine was modified to remove the gear driven water pumps (the engine has 
two water pumps, one for the aftercooler circuit, one for the engine jacket cooling water), replacing them with external, electrically driven pumps. The external water plumbing was completely reconfigured, including several meters of new piping, reservoir tanks, relief valves, pressure regulation valves, and the two heat exchangers. Temperature control valves adjust LCW flow to regulate heat exchange from engine jacket water to LCW. This configuration allowed for the engine jacket water to be circulated and preheated prior to starting the engine, using an electrical preheater installed in the water system.

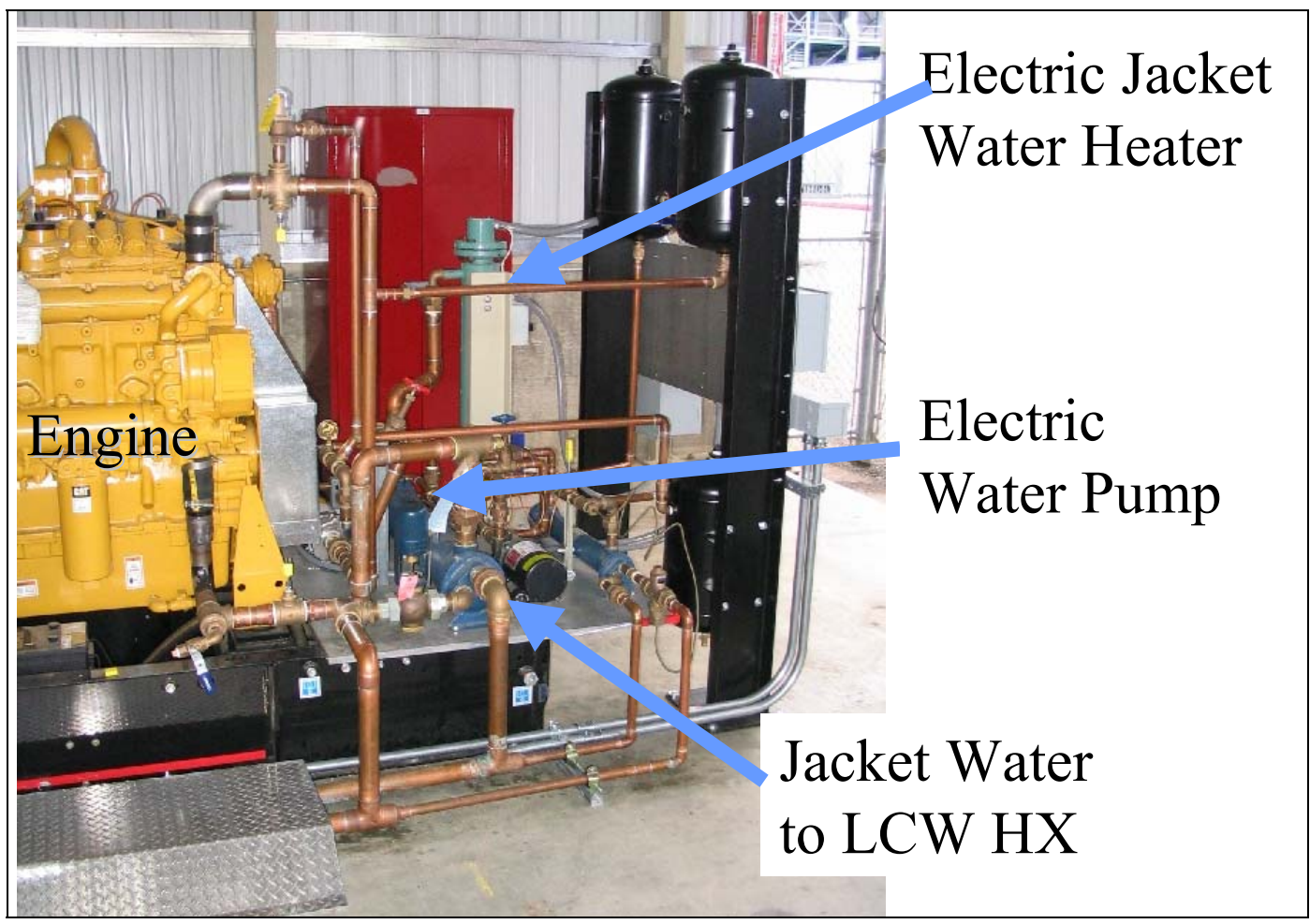

Figure 27: Independent jacket water circulation system allows for preheating jacket water, engine block, and assists $\mathrm{HCCl}$ startup

Photo Credit: Lawrence Livermore National Laboratory

\section{Engine starter}

Starting the engine in HCCI mode can, under some circumstances, require the ability to rotate the engine for 60 seconds or more before combustion starts. The conventional electric starter on the engine is inadequate for this task; electrical starters can fail if turning the engine for longer than 20-30 seconds. An air-driven pneumatic starter can be engaged for 60 seconds or more without issue, and one was procured and installed on the engine. To drive the starter, a high-capacity 90 psi air system was accessed, and ran high pressure piping to the starter. This arrangement allows for continuous operation of the air start system. To control the starter, an electrically-controlled pressure switch system was engineered and implemented. 


\section{Generator load dissipation (load bank connection)}

A resistive load bank was used to dissipate electrical power generated by the engine's generator. The generator output wiring was modified to connect to a high-voltage circuit breaker, which in turn was connected to the load bank (440 volts alternating current [VAC], $60 \mathrm{~Hz} 3$ phase). High voltage wiring required a specialized electrician to install and certify the system.

\section{Exhaust Manifold And Exhaust Flow System}

The original exhaust manifold was water cooled and presented a significant sink for thermal energy from the exhaust. Cooling water was accommodated by a double jacketing on the manifold. Several options were considered, including modifying the existing manifold, making a new, customized, manifold, or purchasing a new, off-theshelf, manifold. After reviewing all options, modifying the existing manifold was deemed the best approach. Several modifications were made to the original exhaust manifold. First, the outer jacket of the manifold was partially removed. The water connections to the manifold were rerouted. Several ports were also added to the manifold to accommodate instrumentation. The exhaust ducting was modified to allow for flow from the turbocharger turbine outlet to the EIHX. Exhaust from the EIHX was then routed to a Muffler and exhaust stack.

\section{On-Board Controller}

The engine-generator-set onboard controller was modified extensively. The controller, which began as a spark-ignition engine controller, was modified to accommodate external control of the throttle and startup system for the engine. The safety relays were maintained as well as generator controls. Spark-ignition controls and radiator system safeties were disabled.

\section{Instrumentation}

A great deal of instrumentation was installed on the engine for monitoring and control. The most critical diagnostic of combustion was the in-cylinder pressure transducers and charge amplifiers. These piezoelectric pressure sensors are coupled to an optical crank shaft encoder, to yield pressure as a function of the crank-shaft position in the engine. Another critical component was the coriolis flow meter, which gives highly accurate measurement of natural gas mass flow rate. Thermocouples were installed throughout the engine system, measuring water and intake and exhaust system temperatures at various locations. Low-speed pressure transducers were used at various locations to determine intake and exhaust system pressure. Instrumentation for determining exhaust gas composition and combustion efficiency was also installed.

\section{Data-Acquisition and Control Hardware and Software}

The data acquisition system (Figure 28) consisted of two systems, a high speed data acquisition system for in-cylinder pressure, and a low speed system for all other measurements (temperature, intake and exhaust pressure, fuel flow, rpm, etc). Customized low-speed data-acquisition software was developed based on Labview, and associated hardware was selected. The low speed data acquisition software and 
hardware was used to implement control of RPM with both the throttle valve and the fuel flow valve. The end result software and hardware are quite sophisticated and flexible for HCCI engine generator speed and load control.

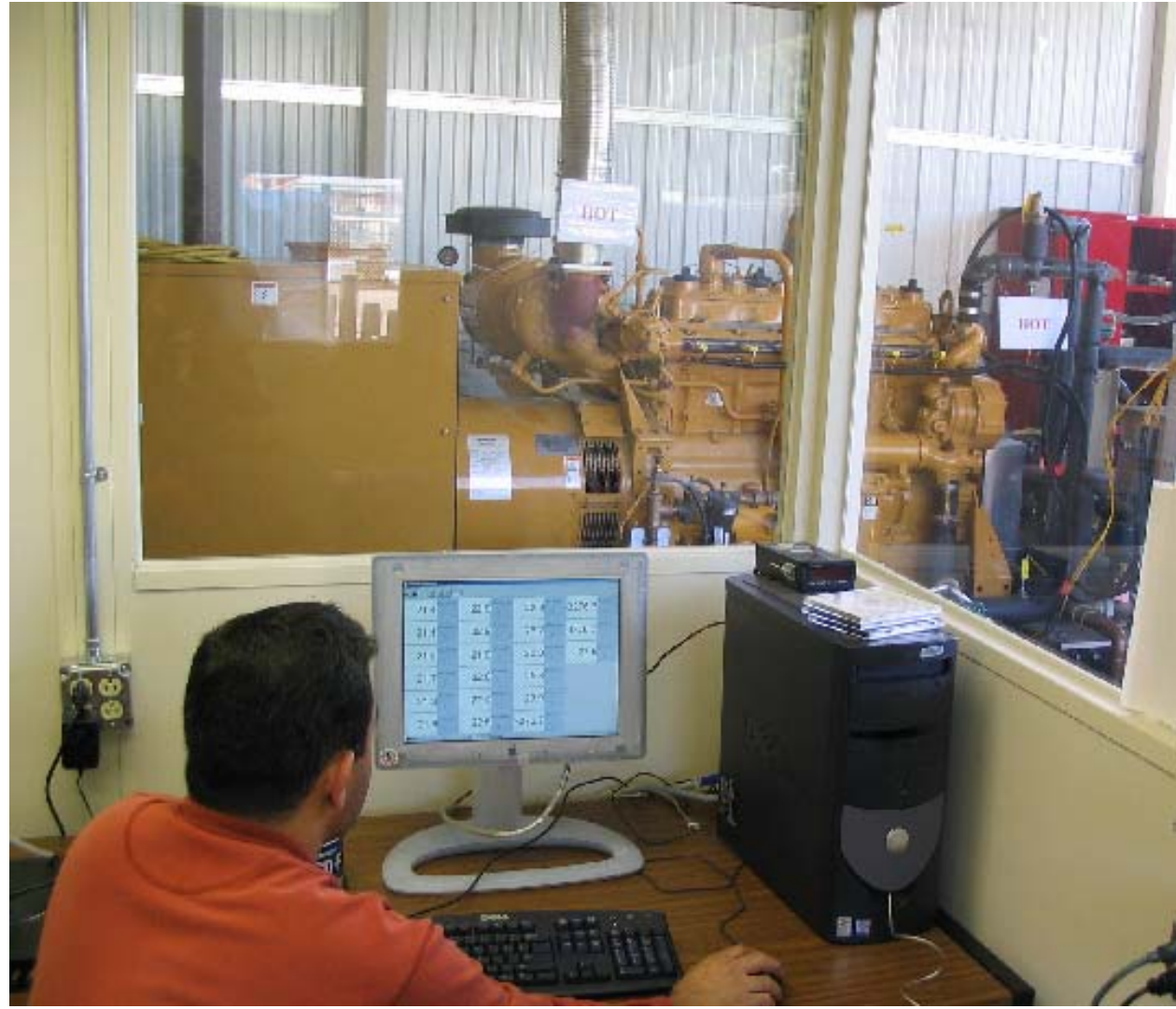

Figure 28: Flexible Data acquisition and control hardware and software system

Photo Credit: Lawrence Livermore National Laboratory

\subsubsection{Engine Testing}

\section{Startup in $\mathrm{HCCl}$ mode}

A safe and reliable strategy for startup in HCCI mode has been developed. This strategy involves first preheating the heat exchanger with the external burner. Once the heat exchanger (EIHX) is sufficiently preheated, startup is achieved using the closed loop engine control system. This system engages the starter and spins the engine. Once the engine reaches startup speed, the fuel solenoid is opened and fuel and air flow to the engine. The fuel and air mixture is drawn through the heat exchanger and preheated fuel and air mixture is inducted into the cylinder. The preheated fuel and air begins to undergo HCCI combustion after a few cycles. Once ignition is achieved the engine control throttle begins to open to bring the engine up to operating speed. Figure 29 shows a startup engine speed trace. Because of the high compression ratio, starting in HCCI mode is a safe means of startup, as opposed to starting in spark-ignition and transitioning to HCCI. To start in SI mode a near-stoichiometric fuel air mixture would 
be required along with late-phased (after TDC) spark timing to prevent knock. The potential exists for preignition: stoichiometric knock at this high compression ratio could cause great damage to the engine. Startup in HCCI mode will avoid this potentially damaging operating regime.

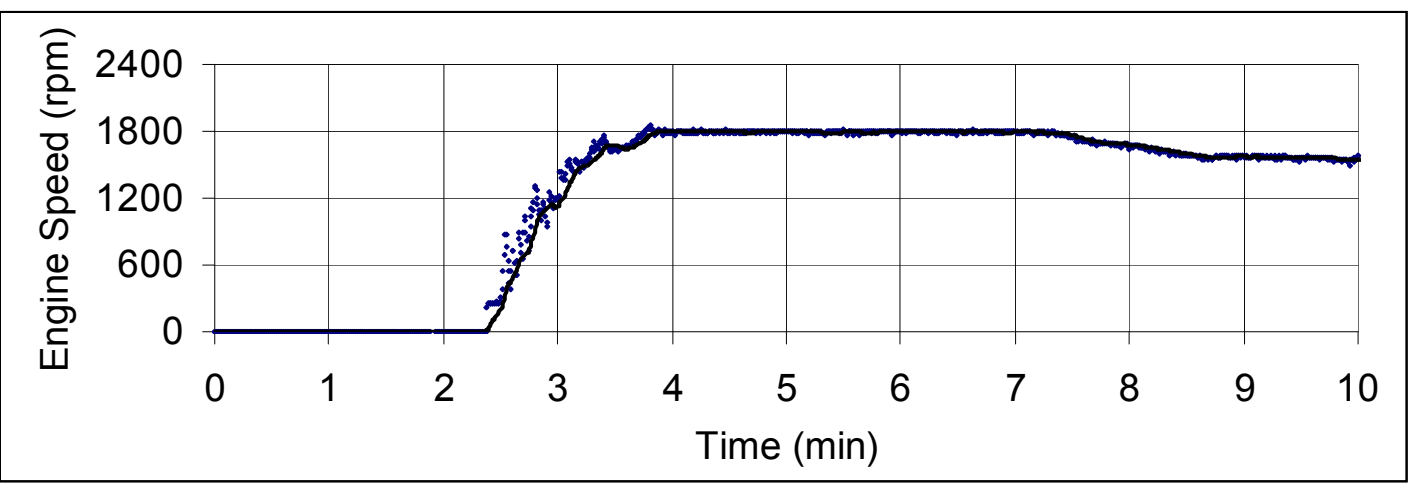

Figure 29:Engine speed versus time for $\mathrm{HCCl}$ mode startup

\section{$\mathrm{HCCl}$ engine operation with thermal control system}

Figure 30 shows cylinder pressure traces for initial firing of the engine with the modified manifold in HCCI mode, operated at 0.35 equivalence ratio and $1800 \mathrm{rpm}$. For these operating conditions, no attempt was made to balance the cylinders, but, even so, relatively good balance in combustion timing is achieved with the manifold at base setting. 


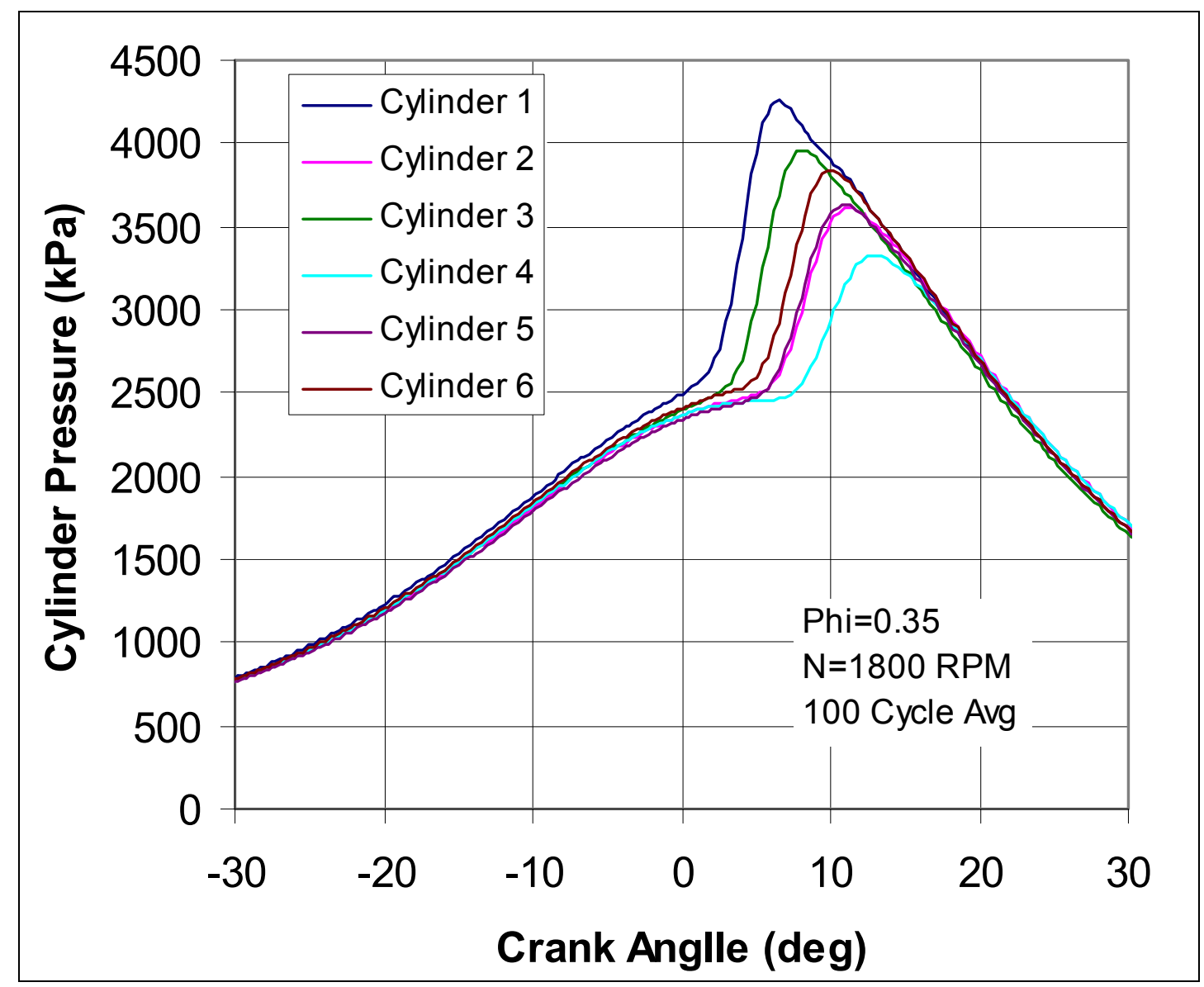

Figure 30: Pressure versus crank angle for each cylinder during initial $\mathrm{HCCl}$ operation with new intake manifold

\section{Balancing Cylinder-by-cylinder combustion timing}

Figure 31 shows the effect of adjusting the intake temperature on the HCCI engine using the temperature control mixing valve. Cylinder 1 combustion timing is much earlier than other cylinders. The mixing valve is adjusted to bring cylinder 1 into line with the other cylinders. 


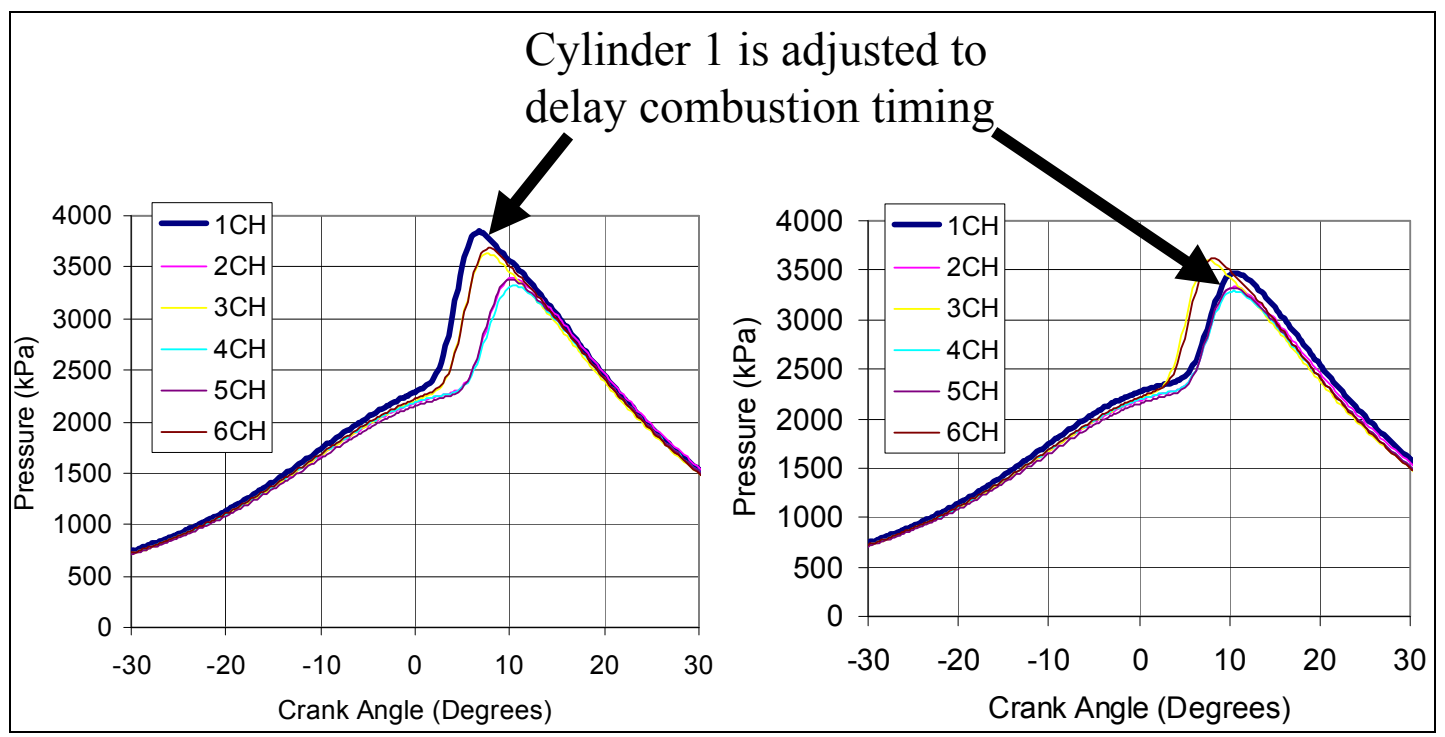

Figure 31: Combustion timing controlled by adjusting the balance of hot and cold flow on an individual cylinder

Figure 32 shows pressure traces for the engine operated with the mixing valves adjusted to achieve balanced operation of the engine, at $1800 \mathrm{rpm}$ and $40 \mathrm{~kW}$ in naturally aspirated operation. This result proves the viability of the chosen thermal management approach for HCCI engine control.

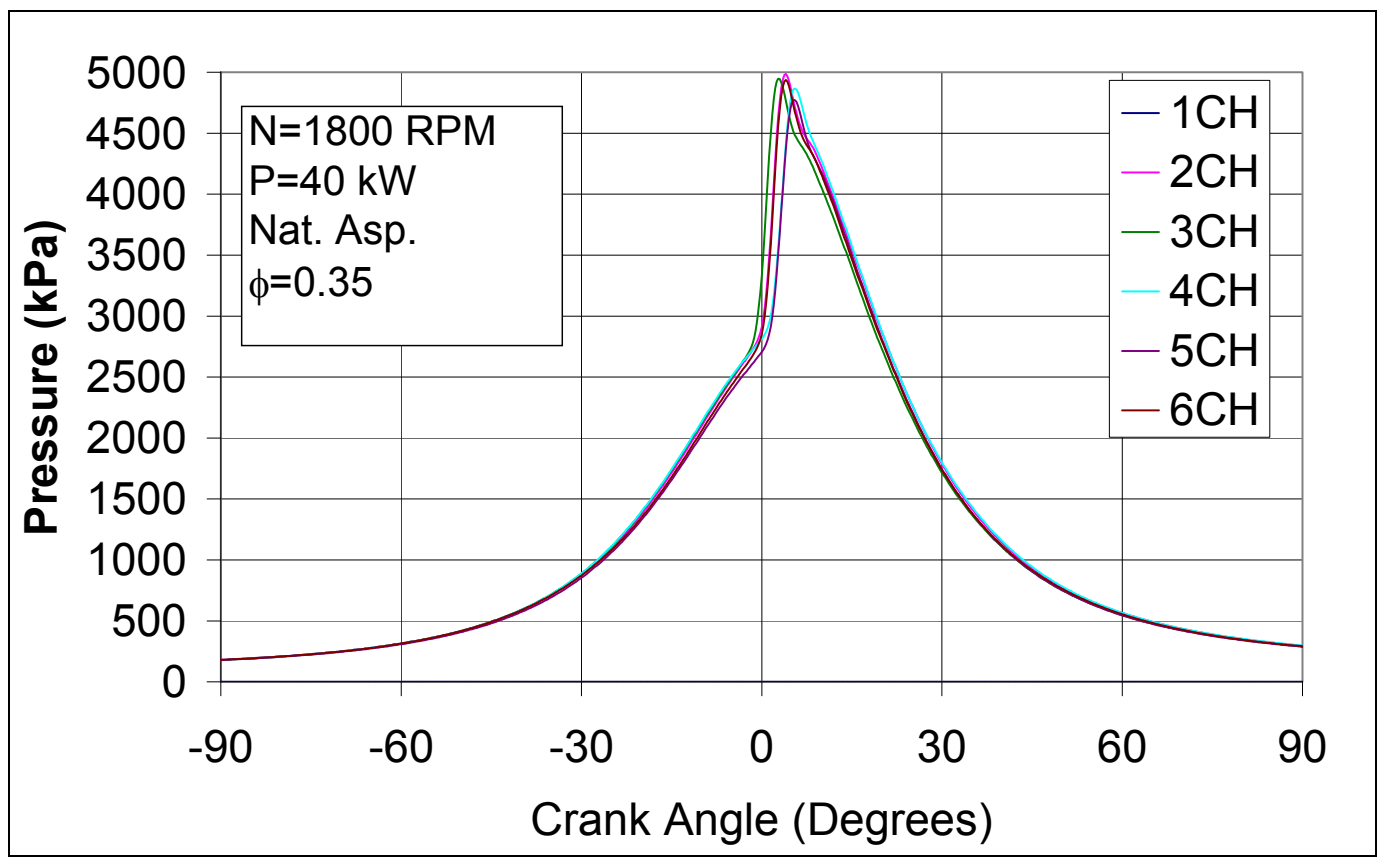

Figure 32: Pressure traces for steady state operation of the generator set at $40 \mathrm{~kW}$ and 1800 RPM naturally aspirated 


\section{Incomplete Activities}

Operation of the engine in HCCI mode at the rated operating point has not been achieved. While significant progress was made towards implementation of the final design, setbacks prevented completing the design to be able to achieve full load operation. The main issue is that the changes to the engine were far more extensive than originally planned for, thus a great deal more time, effort, and materials were required than were available to us. Still, the engine generator set design has made significant progress towards full implementation and is near completion.

\subsection{Hours Operation of $\mathrm{HCCl}$ ARICE Multi-cylinder Engine}

Because the implementation of the final ARICE design and testing of operating in HCCI mode at ARICE rated operating point was not completed, the 1000 hours of operation of the HCCI ARICE Multi-cylinder Engine was not completed.

\subsection{Technology Transfer Activities}

Formal and informal technology transfer activities were conducted throughout this program. Formal activities include the preparation of three technical papers presented at Technical Meetings of the American Society of Mechanical Engineers, based directly on the work for this project. Technical presentations of this work were also made at the $1^{\text {st }}$ and $2^{\text {nd }}$ Annual Advanced Stationary Reciprocating Engines Conference, sponsored jointly by the Energy Commission ARICE Program and the United States Department of Energy (U.S. DOE) Advanced Reciprocating Engine Systems (ARES) Program. Informal activities were also conducted throughout this project. These took the form of interactions with members of all major US Engine Manufacturers during site visits, offline interactions at technical meetings, phone calls, and email interactions. This work has benefited from LLNL U.S. DOE sponsored HCCI combustion R\&D that involves close collaboration with members of the engine manufacturing industry. 


\subsection{Conclusions and Recommendations}

\subsection{Conclusions}

The technical approach was to develop and operate a Caterpillar 3406 natural gas engine converted from a spark ignited engine into an HCCI engine. The goal of achieving the ARICE performance targets, primarily a $200 \mathrm{~kW}$ engine with $45 \%$ brake thermal efficiency and $0.015 \mathrm{~g} / \mathrm{bhp}-\mathrm{hr} \mathrm{NO}_{\mathrm{x}}$, has not yet been realized. However progress towards development of practical HCCI engine system for stationary power generation has been made. All major engine systems had been modified with a view to obtain an HCCI engine system.

- A thermal management system was designed and built based on analysis. The system consists of a preheater and an intercooler connected in parallel. Fresh charge is circulated through either heat exchanger and then blended to obtain appropriate combustion. This system also allows for cylinder by cylinder control of intake temperature.

- The engine is started in HCCI mode by running a natural gas fueled combustor that heats the preheater. The intake gases are then circulated through the hot preheater, reaching a high enough temperature for HCCI ignition to occur. Once combustion starts, it is self-sustaining, and therefore the burner can be turned off quickly after ignition.

- The fueling system was modified by replacing the stock natural gas carburetor by a carburetor designed for liquid petroleum gas. This change adjusts the equivalence ratio to the value desired for HCCI combustion $(\phi \sim 0.4)$, and eliminates the risk of over fueling that may damage the engine.

- Selection of a turbocharger caused problems, as the low temperature exhaust in HCCI engines makes commercially available turbochargers inappropriate for HCCI operation. Instead, a supercharger was selected, at the expense of reduced power output and efficiency.

- A real-time operational control system was implemented and allowed the development of control algorithms for HCCI engine control. The control system activated blending valves between hot and cold intake streams to obtain the appropriate charge temperature for optimum ignition timing in all cylinders.

- The engine was run in HCCI mode. Good and consistent combustion timing was obtained in all cylinders. High power operation had not been possible because only limited testing with the supercharged engine had been conducted. The engine delivered $50 \mathrm{~kW}$ with atmospheric intake. Efficiency and power targets were not met due to the lack of an appropriate turbocharger. 


\subsection{Recommendations}

Progress has been made in this project, but complete development of an HCCI engine for stationary power meeting the ARICE performance targets has not been achieved. The key remaining tasks are:

1. Complete installation of software and actuators for fully automated engine control,

2. Conduct testing of the engine at full load operation, and

3. Transition technology to a manufacturer or assembler through partnership and licensing.

In the future, the engine will be used as a fully instrumented test bed for performance studies of HCCI combustion. This HCCI engine is an ideal test bed for testing control systems for inexpensive and robust combustion control in multi-cylinder engines. Future research could focus further on basic research of HCCI control. Various linear and nonlinear control methodologies could be employed to develop control algorithms capable to provide online optimization of the engine efficiency and emissions. 


\section{References}

Aceves, S. M., Flowers, D. L., Westbrook, C. K., Pitz, W., Smith, J.R., Dibble, R. W. Christensen, M., and Johansson, B., 2000, "A Multi-Zone Model for Prediction of HCCI Combustion and Emissions," SAE paper 2000-01-0327.

Aceves, S.M., Martinez-Frias, J., and Reistad, G.M., 2004, "Analysis of Homogeneous Charge Compression Ignition (HCCI) Engines for Cogeneration Applications," Submitted for publication, Proceedings of the ASME Advanced Energy Systems Division.

Caterpillar Engine Company, 2001a, “Gas Generator Set,” LEHE143-02 (03-02).

Caterpillar Engine Company, 2001b, “G3406 TA: Gas Engine Technical Data,” DM544000 .

Christensen, M., Johansson, B., Amneus, P., and Mauss, F., 1998, "Supercharged Homogeneous Charge Compression Ignition," SAE Paper 980787.

Flynn, P. F., Hunter, G. L., Farrell, L.A., Durrett, R. P., Akinyemi, O. C., Westbrook, C. K. and Pitz, W. J., 2000, "The Inevitability of Engine-Out NOx Emissions from Spark-Ignition and Diesel Engines," Proceedings of the Combustion Institute, Vol 28.

Flynn, P.F., Zur Loye, A.O., Durrett, R.P., Moore, G., Muntean, G.G., Peters, L.L., Pierz, P.M., Wagner, J.A., Wright, J.F., and Yeager, J.M., 1999, Premixed Charge Compression Ignition Engine with Optimal Combustion Control. Cummins Engine Company, Inc.

Frenklach, M.,Wang, H., Goldenberg, M., Smith G. P., Golden, D. M., Bowman, C. T., Hanson, R. K., Gardiner, W. C., and Lissianski, V., 1995, “GRI-Mech - An Optimized Detailed Chemical Reaction Mechanism for Methane Combustion", GRI Topical Report No. GRI-95/0058.

Hashizume, T., Miyamoto, T., Akagawa, H., and Tsujimura, K., 1998, "Combustion and Emission Characteristics of Multiple Stage Diesel Combustion," SAE Paper 980505.

Heywood, J. B., 1988, Internal Combustion Engine Fundamentals, McGraw-Hill, New York, NY.

Hiltner, J., Fiveland, S., Agama, R., and Willi, M., 2002, "System Efficiency Issues for Natural Gas Fueled HCCI Engines in Heavy-Duty Stationary Applications," SAE paper 2002-01-0417.

Ishibashi, Y. and Asai, M., 1996, "Improving the Exhaust Emissions of Two-Stroke Engines by Applying the Activated Radical Concept," SAE Paper 960742.

Kee, R.J., Rupley, F.M., Meeks, E., and Miller, J.A., 1996, “CHEMKIN III: A Fortran Chemical Kinetics Package for the Analysis of Gas-Phase Chemical and Plasma 
Kinetics," Sandia National Laboratories Report SAND96-8216, Livermore, CA, May.

Klein, S. A., and Alvarado, F. L., 2002, “Engineering Equation Solver,” F-Chart Software, Box 44042, Madison, WI 53744.

Law, D., Allen, J., 2002, “Variable Valve Actuated Controlled Auto-Ignition: Speed Load Maps and Strategic Regimes of Operation, SAE Paper 2002-01-0422.

Martinez-Frias, J., Aceves, S. M., Flowers, D., 2005, "Improving Ethanol Life Cycle Energy Efficiency by Direct Combustion of Wet Ethanol in HCCI engines," Proceedings of the ASME Advanced Energy Systems Division.

Miyamoto, T., Hayashi, A.K., Harada, A., Sasaki, S., Hisashi, A., and Tujimura, K., 1999, "A Computational Investigation of Premixed Lean Diesel Combustion," SAE Paper 1999-01-0229.

Mirimoto, S. S., Kawabata, K., Sakurai, T., Amano, T., 2001, “Operating Characteristics of a Natural Gas-Fired Homogeneous Charge Compression Ignition Engine (Performance Improvement Using EGR)," SAE Paper 2001-01-1034.

Onishi, S., Jo, S.H., Shoda, K., Jo, P.D., and Kato, S., 1979, "Active Thermo-Atmosphere Combustion (ATAC) - A New Combustion Process for Internal Combustion Engines," SAE Paper 790501.

Patton, K. J., Nitschke, R. G., and Heywood, J. B., 1989, “Development and Evaluation of a Friction Model for Spark-Ignition Engines," SAE paper 890836.

Pitz, W. J., Westbrook, C. K., and Leppard, W. R., 1991, “Autoignition Chemistry of C4 Olefins Under Motored Engine Conditions: A Comparison of Experimental and Modeling Results," SAE paper 912315.

Suzuki, H., Koike, N., and Odaka, M., 1998, "Combustion Control Method of Homogeneous Charge Diesel Engines," SAE Paper 980509.

Wilson, D. G., 1993, The Design of High-Efficiency Turbomachinery and Gas Turbines, The MIT Press, Cambridge, Massachusetts.

Woschni, G., 1967, “Universally Applicable Equation for the Instantaneous Heat Transfer Coefficient in the Internal Combustion Engine," SAE Paper 670931.

Yanagihara, H., Sato, Y., and Mizuta, J., 1996, "A simultaneous reduction of NOx and Soot in Diesel Engines Under a New Combustion System (Uniform Bulky Combustion System - UNIBUS)," Proceedings of the 17th Vienna Motor Symposium

Yang, J., Culp, T., Kenney, T., 2002, “Development of a Gasoline Engine System Using HCCI Technology - The Concept and the Test Results," SAE Paper 2002-01-2832. 


\subsection{Glossary}

Acronym

ARES

ARICE

ATDC

bkW

BTE

C

$\mathrm{Cl}$

CO

CPR

DC

DI

EGR

EIHX

EPAG

ETV

g/bhp-hr

$\mathrm{HC}$

$\mathrm{HCCl}$

HCS

$\mathrm{Hz}$

$\mathrm{kPa}$

LLNL

$\mathrm{mA}$

$\mathrm{mm}$

ppm

PI

PID

PIER

\section{Definition}

Advanced Reciprocating Engine Systems

Advanced Reciprocating Internal Combustion Engine

After Top Dead Center

Brake-Kilowatt

Brake Thermal Efficiency

Celsius

Compression Ignition

Carbon Monoxide

Critical Project Review

Direct Current

Direct Injection

Exhaust Gas Recirculation

Exhaust-to-Intake-Air Heat Exchanger

Environmentally Preferred Advance Generation

Exhaust Throttle Valve

grams/brake horse power hour

Hydrocarbon

Homogeneous Charge Compression Ignition

Hiltner Combustion Systems, LLC

Hertz

Kilopascal

Lawrence Livermore National Laboratory

Milliamp

Millimeter

Parts per Million

Proportional Plus Integral

Proportional-Integral-Derivative

Public Interest Energy Research 
Acronym

RD\&D

rpm

SCR

SI

SOC

TDC

UCB

U.S. DOE

VAC

VCR

VDC

VVT

CAT3401

CAT3406

\section{Definition}

Research, Development, and Demonstration

Revolutions per Minute

Silicon-Controlled Rectifier

Spark Ignited

Start of Combustion

Top-Dead-Center

University of California, Berkeley

United States Department of Energy

Volts Alternating Current

Variable Compression Ratio

Volts Direct Current

Variable Valve Timing

Caterpillar 1-cylinder engine model 3401

Caterpillar 6-cylinder engine model 3406

\begin{tabular}{|ll}
\hline \multicolumn{2}{l}{ Symbols: } \\
$\mathrm{c}_{\mathrm{p}}$ & specific heat at constant pressure, $\mathrm{J} \mathrm{kg}^{-1} \mathrm{~K}^{-1}$ \\
$\mathrm{C}_{\mathrm{v}}$ & specific heat at constant volume, $\mathrm{J} \mathrm{kg}^{-1} \mathrm{~K}^{-1}$ \\
$\dot{\mathrm{m}}$ & mass flow rate, $\mathrm{kg} \mathrm{s}^{-1}$ \\
$\mathrm{p}$ & pressure, Pa \\
$\mathrm{T}$ & temperature, $\mathrm{K}$ \\
$\varepsilon$ & Heat exchanger effectiveness \\
$\phi$ & equivalence ratio \\
$\gamma$ & Specific heat ratio $\mathrm{c}_{\mathrm{p}} / \mathrm{c}_{\mathrm{v}}$ \\
$\eta_{\mathrm{c}}$ & combustion efficiency \\
$\eta_{\mathrm{p}}$ & polytropic efficiency \\
$\theta$ & crank angle, degrees
\end{tabular}

\section{Subscripts}

i intercooler

min minimum

max maximum

h heater

w water 


\section{Appendix A: WAVE Analysis of CAT 3406 HCCI Engine for ARICE}

Presentation by Ricardo Inc. summarizing the analysis of the ARICE engine breathing design. 
APA-2 


\section{Appendix B: HCCI-ARICE Natural Gas Engine Development for Stationary Power Applications in California}

Presentation by LLNL at 2nd Annual Advanced Stationary Reciprocating Engines Conference: Moving Forward in Low-Emissions and High-Efficiency Technologies. March 16, 2005, Diamond Bar, CA. 
APB-2 


\section{Appendix C: Thermal Management for 6-Cylinder HCCI Engine: Low Cost, High Efficiency, Ultra-Low NOx power Generation}

ASME Paper ICEF2004-930: Presented at the 2004 Fall Technical Conference ASME International Combustion Engine Division October 24-27, 2004, Long Beach, CA, USA. 
APC-2 


\section{Appendix D: Development and Testing of a 6-Cylinder HCCI Engine and for Distributed Generation}

ASME Paper ICEF2005-1342: Presented at the ICEF2005ASME Internal Combustion Engine Division 2005 Fall Technical Conference, September 11-14, 2005, Ottawa, Canada. 
APD-2 


\section{Appendix E: Analysis of Homogeneous Charge Compression Ignition (HCCI) Engines for Cogeneration Applications}

ASME Paper IMECE 2004-62371: Presented at IMECE 2004 ASME International Mechanical Engineering Congress \& Exposition, November 13-19, 2004, Anaheim, CA, USA. 